\title{
A MODIFIED BOOST CONVERTER WITH REDUCED INPUT CURRENT RIPPLE
}

\author{
A Thesis \\ presented to \\ the Faculty of California Polytechnic State University, \\ San Luis Obispo
}

\author{
In Partial Fulfillment \\ of the Requirements for the Degree \\ Master of Science in Electrical Engineering
}

by

Nathan H. Lentz

June 2017 
(C) 2017

Nathan H. Lentz

ALL RIGHTS RESERVED 
TITLE: A Modified Boost Converter with Reduced Input Current Ripple

AUTHOR: Nathan H. Lentz

DATE SUBMITTED: June 2017

COMMITTEE CHAIR: Taufik, Ph.D.

Professor of Electrical Engineering

COMMITTEE MEMBER: David Braun, Ph.D.

Professor of Electrical Engineering

COMMITTEE MEMBER: Xiao-Hua (Helen) Yu, Ph.D.

Professor of Electrical Engineering 


\begin{abstract}
A Modified Boost Converter with Reduced Input Current Ripple

Nathan H. Lentz
\end{abstract}

Battery-powered trends in consumer electronics, transportation, and renewable energy sectors increase demands on DC/DC converter technology. Higher switching frequency and efficiency reduces solution size and cost, while increasing power capabilities. Still, switching noise remains the primary drawback associated with any DC/DC converter. Reducing a converter's input ripple helps prevent switching noise from spreading to other systems on a shared DC power bus. This thesis covers the analysis, simulation, and implementation of a recently-proposed boost converter topology, alongside an equivalent standard boost converter, operating in steady-state, continuous conduction mode. A Matlab-based simulation predicts each converter's input ripple performance using a state-space model. The converters' hardware implementation minimizes component and layout differences to create an equivalent comparison. The simulation and hardware measurements demonstrate a $40 \%$ input current ripple reduction using the modified topology. Replacing standard boost converters with the modified topology minimizes the switching noise conducted through a system's DC power network.

Keywords: dc/dc, boost, converter, input, current, ripple 


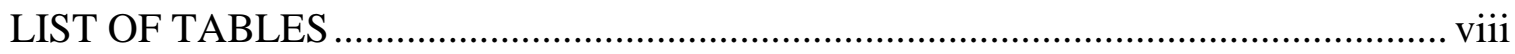

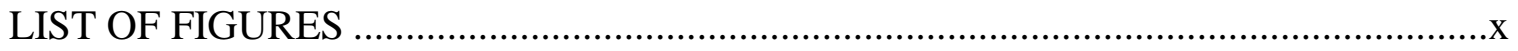
CHAPTER

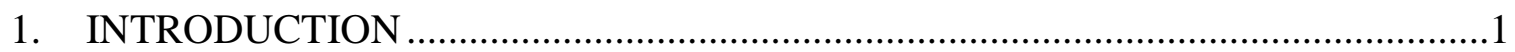

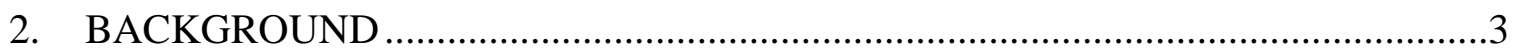

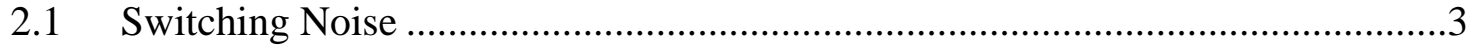

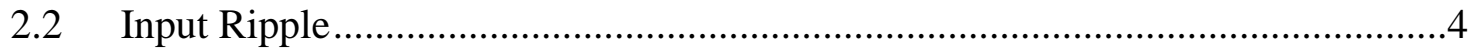

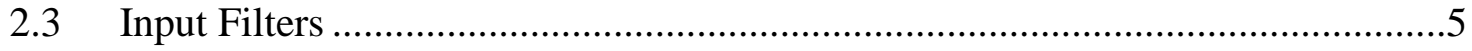

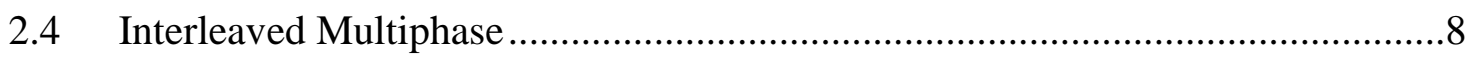

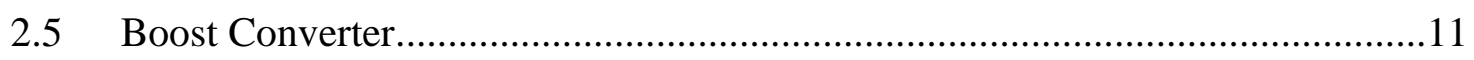

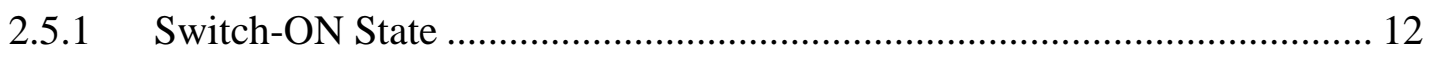

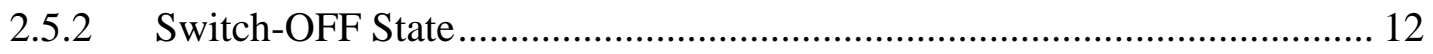

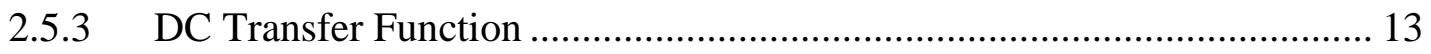

2.5.4 Continuous Conduction Mode Operation …………................................... 14

2.5.5 Component Ratings......................................................................... 15

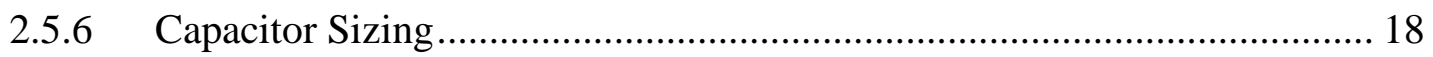

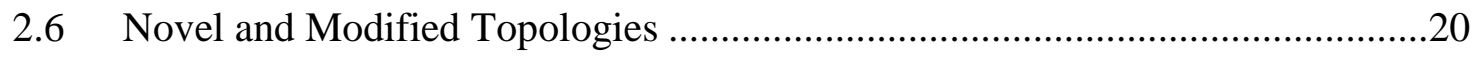

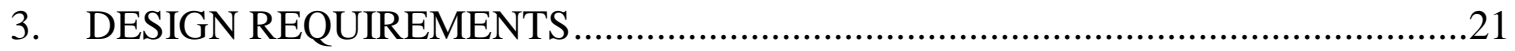

3.1 Current Ripple Performance.......................................................................21

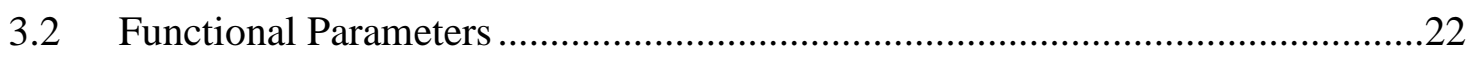

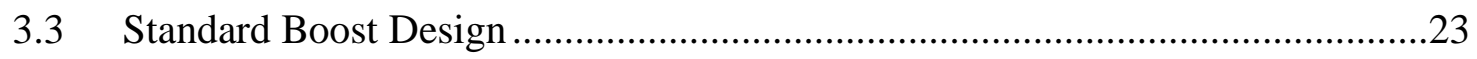

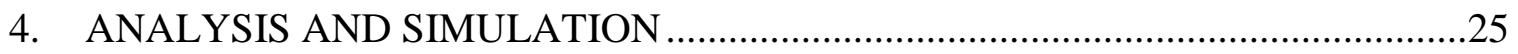

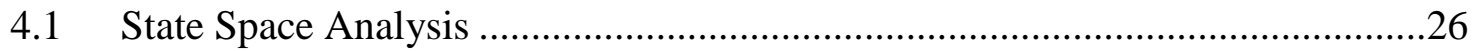

4.1.1 Standard Boost Converter .................................................................. 27

4.1.2 Modified Boost Converter ……………………….................................. 30

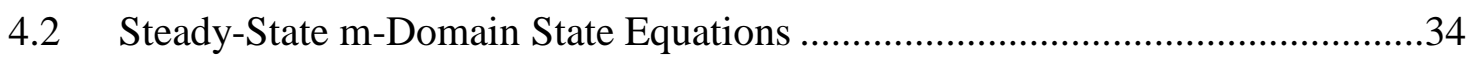

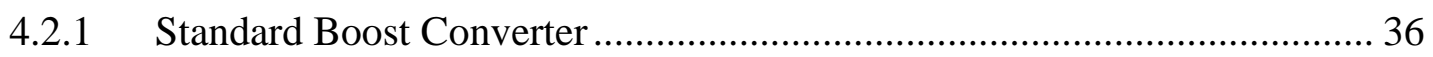

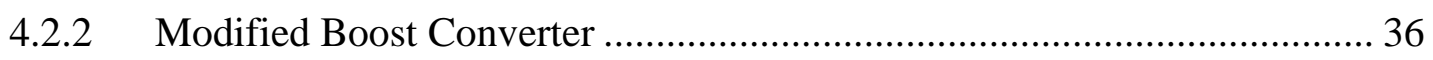

$4.3 \quad$ Numerical m-Domain State Equation Solutions …………………………............37 


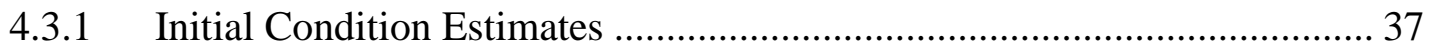

4.3.2 Iterative State Equation Solution ......................................................... 38

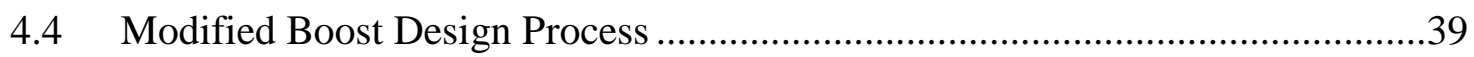

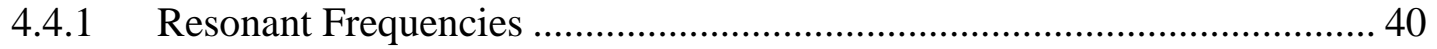

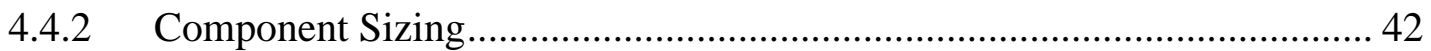

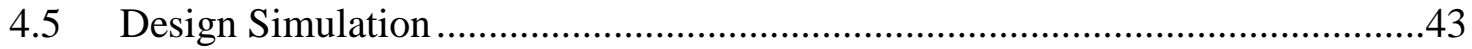

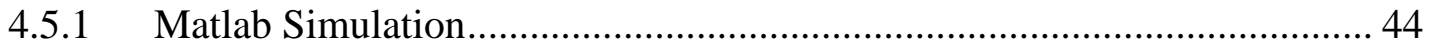

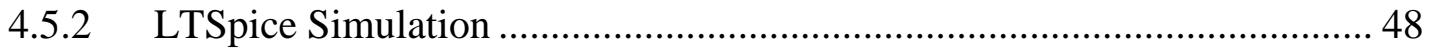

4.5.3 Simulation Comparison ...................................................................... 51

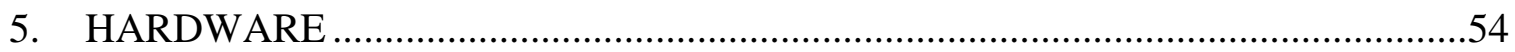

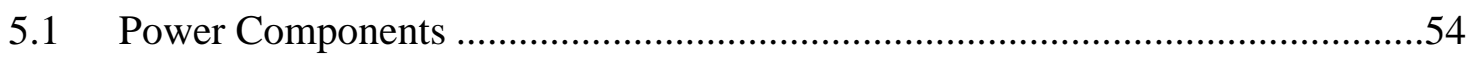

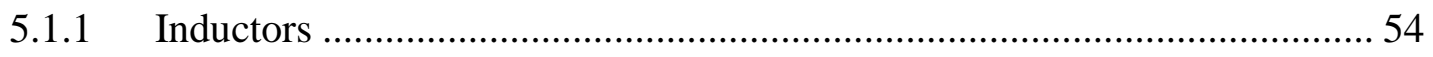

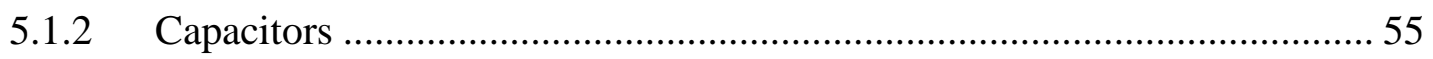

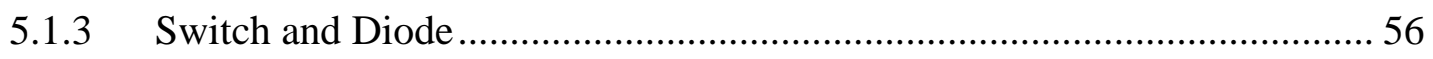

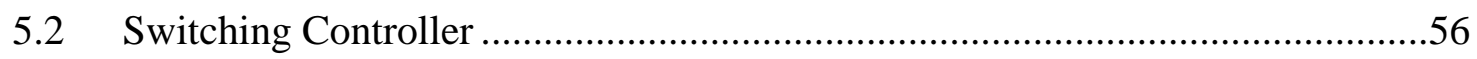

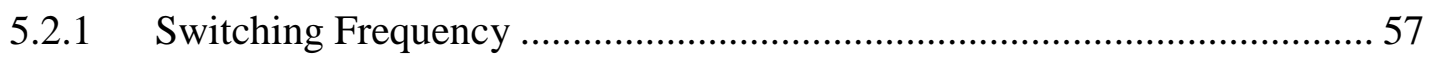

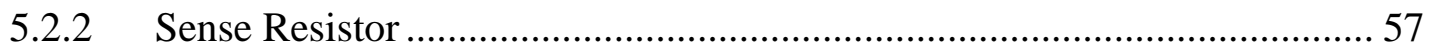

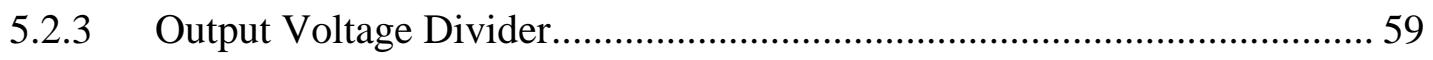

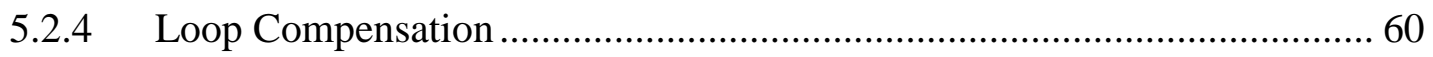

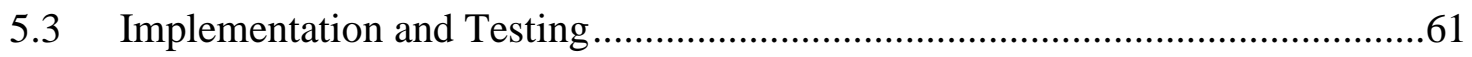

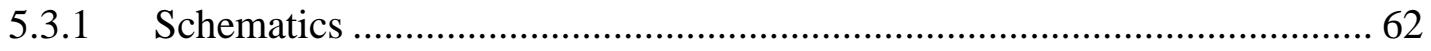

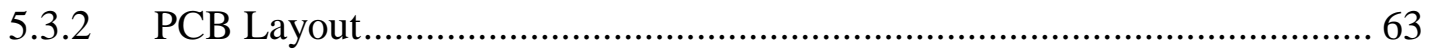

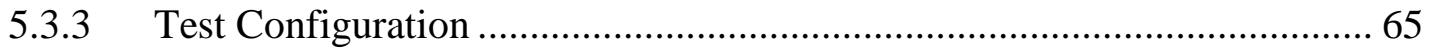

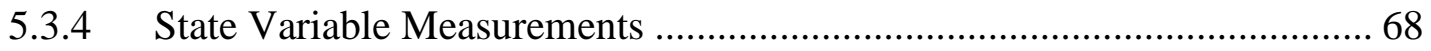

5.3.5 Irregular Conduction Limitations ...................................................... 73

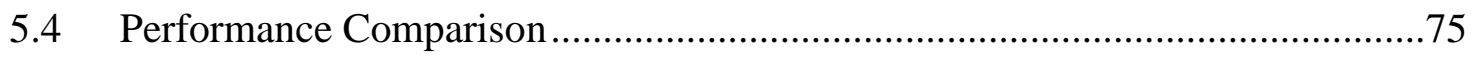

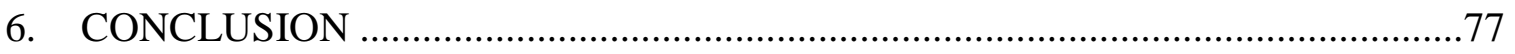

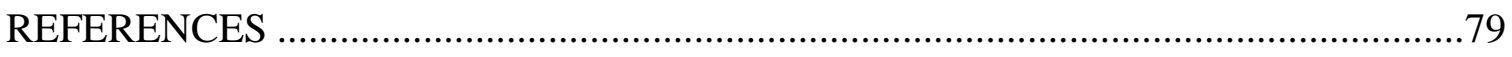

APPENDICES

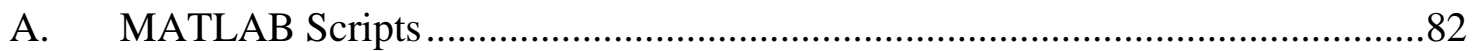

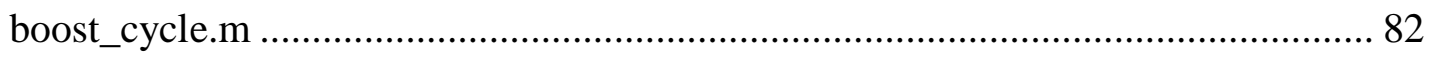

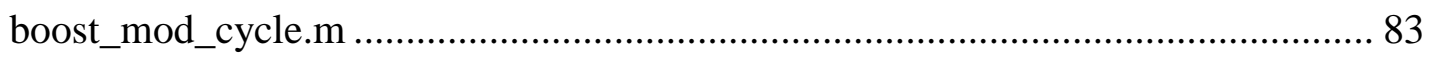

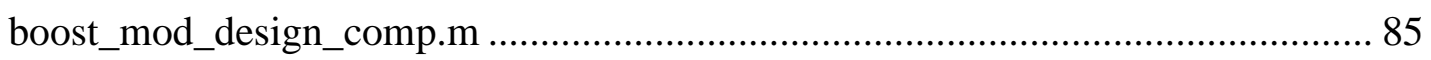




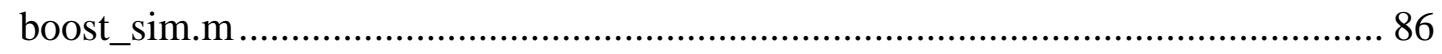

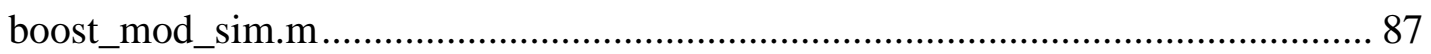

B. Design Simulation Data ............................................................................... 90

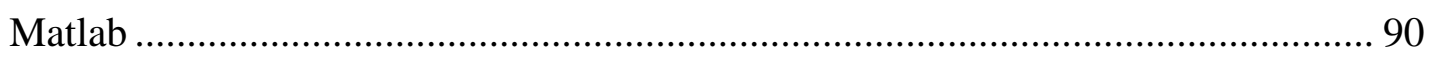

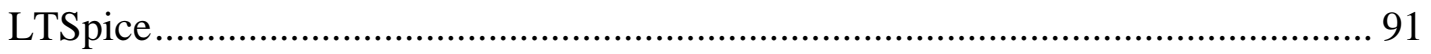

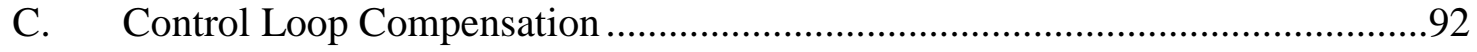

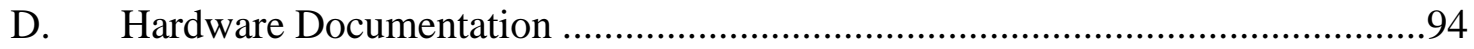

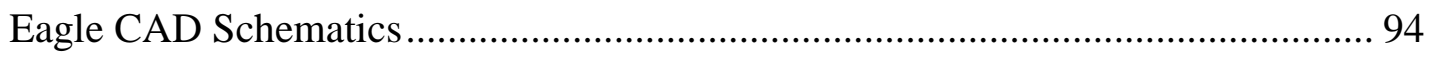

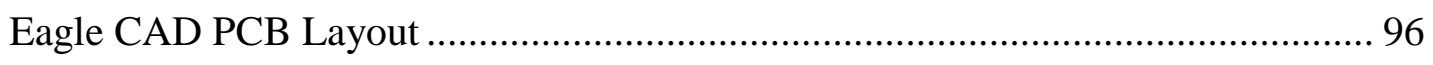

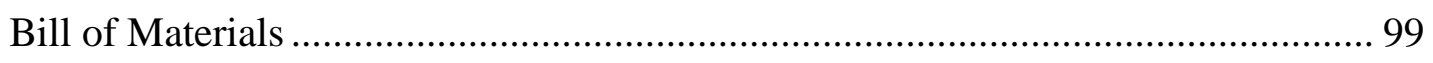




\section{LIST OF TABLES}

Table 2-1. Interleaved Multiphase Converter Properties .....................................................

Table 2-2. Boost Converter Component Ratings [27] ........................................................17

Table 3-1. Functional Converter Parameters ................................................................22

Table 3-2. Converter Design Parameters ...................................................................24

Table 4-1. Standard Boost Converter Component Averages...............................................

Table 4-2. Modified Boost Converter Component Averages ...............................................38

Table 4-3. State Equation Initial Condition Estimates.......................................................38

Table 4-4. Modified Boost Converter Component Values .................................................43

Table 4-5. Converter Design Parameter Summary …………………………………….....44

Table 4-6. Matlab and Theoretical Standard Boost Design Performance ..........................45

Table 4-7. Matlab and Theoretical Modified Boost Design DC Performance ...................47

Table 4-8. Standard Boost Simulation Measurement Comparison......................................51

Table 4-9. Modified Boost Simulation Measurement Comparison ....................................52

Table 4-10. Simulated Boost Converter Input Current Ripple Reduction...........................53

Table 5-1. WE-FAMI Series Inductor Properties .............................................................54

Table 5-2. Power-Path Capacitor Current and MLCC Configuration ................................55

Table 5-3. Power-Path MLCC Properties ...................................................................5

Table 5-4. Switching Component Rating Margins ………………………………….......56

Table 5-5. LM3487 Pin Descriptions [37] ................................................................57

Table 5-6. LM3478 Current Sense Feedback Parameters [37] .........................................59

Table 5-7. Converter Output Voltage Difference at Full Load..........................................66

Table 5-8. Converter Full Load DC Characteristics Comparison.......................................67

Table 5-9. State Variable Oscilloscope Measurement Methods .........................................69

Table 5-10. Standard Boost Converter Hardware Test Results ..........................................70

Table 5-11. Modified Boost Converter Hardware Test Results ..........................................73

Table 5-12. Hardware Input Current Ripple Comparison …………..................................76

Table B-1. Matlab-simulated Standard Boost Design Measurements ...............................90

Table B-2. Matlab-Simulated Modified Boost Design Measurements ...............................90 
Table B-3. LTSpice Standard Boost Design Measurements ........................................91

Table B-4. LTSpice Modified Boost Design Measurements .........................................91

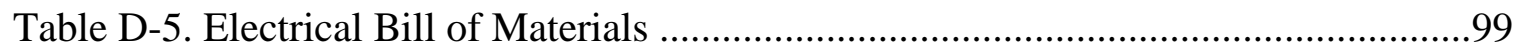




\section{LIST OF FIGURES}

Page

Figure 2-1. Typical Triangular and Trapezoidal Switching Waveforms .............................3

Figure 2-2. DC/DC Converter with Input Filter Network ....................................................6

Figure 2-3. Middlebrook Criteria with Generic Impedance Curves ....................................6

Figure 2-4. Shunt (Left) and Parallel (Right) Damped LC Filters ........................................

Figure 2-5. Three-Phase Interleaved Switching ..........................................................

Figure 2-6. Two-Phase Buck Converter Current Ripple Cancellation [20].........................

Figure 2-7. Two-Phase Boost Converter ....................................................................... 10

Figure 2-8. Standard Boost Converter Topology …………………………………......11

Figure 2-9. Boost Converter Switch-ON State ……………...............................................12

Figure 2-10. Boost Converter Switch-OFF State ...........................................................13

Figure 2-11. Boost Converter Steady-State Inductor Current ..........................................14

Figure 2-12. Boost Converter BCM Inductor Current.....................................................15

Figure 2-13. Boost Converter Current and Voltage Polarities...........................................16

Figure 2-14. Boost Converter Current Waveforms.........................................................16

Figure 2-15. Boost Converter Voltage Waveforms …………….......................................17

Figure 2-16. Boost Converter Output Capacitor Charge Storage .....................................18

Figure 2-17. Boost Converter Input Capacitor Charge Storage........................................19

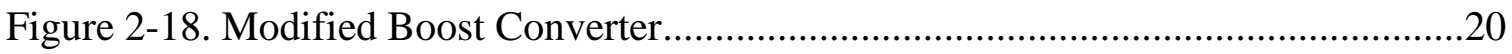

Figure 4-1. Modified Boost Converter DC Voltages.......................................................25

Figure 4-2. Standard Boost Converter State Variables .....................................................27

Figure 4-3. Standard Boost Converter Switch-On State Variables.....................................27

Figure 4-4. Standard Boost Converter Switch-Off State Variables ...................................28

Figure 4-5. Modified Boost Converter State Variables ......................................................30

Figure 4-6. Modified Boost Converter Switch-On State Variables ......................................30

Figure 4-7. Modified Boost Converter Switch-Off State Variables ...................................31

Figure 4-8. Time-domain and m-domain Switching Transitions.........................................35

Figure 4-9. Iterative Numerical State Equation Solution...................................................39

Figure 4-10. LTSpice Modified Boost Converter Resonance Simulation ...........................41 
Figure 4-11. LTSpice Modified Boost Converter Simulated Input Impedance .41

Figure 4-12. Max. Modified Boost Resonant Frequency versus $C_{1}$ Value......................42

Figure 4-13. Modified Boost Converter Component Sizing Chart .................................42

Figure 4-14. Matlab State Variable Waveforms for Standard Boost..............................44

Figure 4-15. Matlab Modified Boost Inductor Current Waveforms ................................46

Figure 4-16. Matlab Modified Boost Capacitor Voltage Waveforms .............................46

Figure 4-17. Matlab Modified Boost Capacitor Current Waveforms ..............................47

Figure 4-18. LTSpice Standard Boost Transient Simulation........................................48

Figure 4-19. LTSpice State Variable Waveforms for Standard Boost ...........................49

Figure 4-20. LTSpice Modified Boost Transient Simulation ......................................49

Figure 4-21. LTSpice Modified Boost Inductor Current Waveforms .............................50

Figure 4-22. LTSpice Modified Boost Capacitor Voltage Waveforms ...........................50

Figure 4-23. LTSpice Modified Boost Capacitor Current Waveforms ...........................51

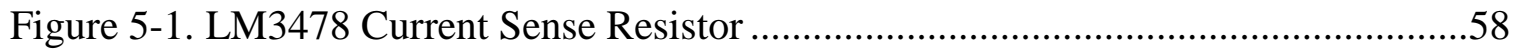

Figure 5-2. Output Voltage Feedback Divider ......................................................60

Figure 5-3. LM3478 Type-I Loop Compensator ...................................................61

Figure 5-4. Simplified Standard Boost Design Schematic ............................................62

Figure 5-5. Simplified Modified Boost Design Schematic..........................................63

Figure 5-6. Top and Bottom PCB Layers Annotated ..............................................64

Figure 5-7. Assembled PCB (Top View) .............................................................64

Figure 5-8. Standard Boost Converter Hardware Test Connections...............................65

Figure 5-9. Modified Boost Converter Hardware Test Connections ..............................66

Figure 5-10. Final Converter Assembly Test Points...................................................67

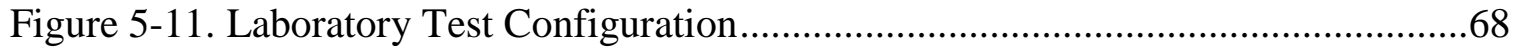

Figure 5-12. Standard Boost Hardware Inductor Current ..........................................69

Figure 5-13. Standard Boost Hardware Output Voltage (AC Coupling)..........................70

Figure 5-14. Modified Boost Hardware L ${ }_{1}$ Current .......................................................

Figure 5-15. Modified Boost Hardware $\mathrm{L}_{2}$ Current ................................................. 71

Figure 5-16. Modified Boost Hardware $C_{1}$ Voltage (AC Coupling) ..............................72

Figure 5-17. Modified Boost Hardware Output Voltage (AC Coupling) .........................72

Figure 5-18. Standard Boost Subharmonic Oscillation at $800 \mathrm{~mA}$ Load ........................74 
Figure 5-19. Modified Boost Subharmonic Oscillation at 1.1 A Load............................74

Figure 5-20. Input Current Ripple Performance in Simulation and Hardware ..................76

Figure D-1. Standard Boost Converter Eagle CAD Schematic ......................................94

Figure D-2. Modified Boost Converter Eagle CAD Schematic ....................................95

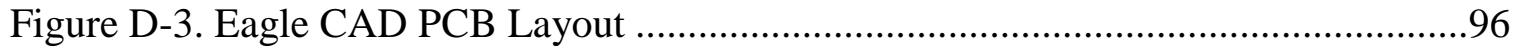

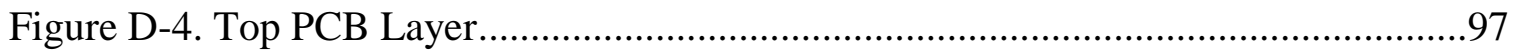

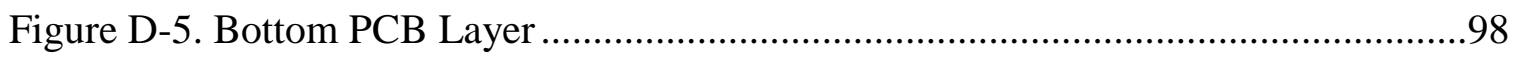




\section{INTRODUCTION}

Globally, electricity continues growing faster than any form of end-use energy consumption [1]. Many primary energy sources, including fossil fuels, nuclear, hydro, solar, and wind, fuel the electric power generation serving numerous end-uses. Between generation and end-use, power electronics control the electrical energy flow to countless systems. Electrical systems increasingly rely on power electronics as growing electricity demand strains global energy supplies.

Power electronics achieve high-efficiency energy transfer using switches. While on, an ideal switch conducts current without a voltage drop across the device.

Conversely, the ideal switch does not conduct current while off, regardless of voltage imposed across the device. The product of voltage across the device and current through the device always remains zero, preventing the ideal switch from dissipating power. Transistors, diodes, and other semiconductor devices provide the electronic switching capability to realize power converters. General Electric introduced the first power semiconductor device, a thyristor, in 1958 [2]. Later technologies including power bipolar and field-effect transistors increased energy capacity and switching frequency. A power converter's switches alternately direct energy from the source into reactive storage elements, typically inductors and capacitors, and from storage elements to the load. This switch-mode behavior resembles a metro station, where trains periodically transfer passenger groups to their destination [3].

Power converters adapt energy flow between alternating current (AC) and direct current (DC) forms at varying voltage levels. These circuits commonly perform a combination of rectification (AC/DC conversion), inversion (DC/AC conversion), and 
step-up or step-down DC/DC conversion. Traditional electronic power supplies stepdown $\mathrm{AC}$ line voltage through a large $60-\mathrm{Hz}$ transformer, rectify the low-voltage $\mathrm{AC}$, and distribute power to different subsystems using linear voltage regulators. DC/DC converters eliminate the need for bulky transformers and inefficient linear regulators by increasing (step-up) or decreasing (step-down) DC voltages. High-efficiency and highfrequency operation minimize heat dissipation and magnetic component size, reducing overall power supply size. These characteristics enable the miniaturization of modern electronic devices.

Today, DC power source trends increase systems' DC/DC converter performance demands. Portable electronics need high efficiency to reduce size and extend battery life. Battery electric vehicles operate at high DC voltages to manage increasing power requirements. Microinverters for solar photovoltaic (PV) modules often include intermediate DC/DC conversion to reach appropriate AC output voltage levels. These trends point toward increased DC/DC converter deployment and a need to continue improving converter performance. 


\section{BACKGROUND}

\subsection{Switching Noise}

The primary drawback associated with DC/DC converters, switching noise, presents a significant challenge for system engineers. Switch-mode operation adds AC ripple to a converter's DC input and output signals. Poorly designed DC/DC converters allow this switching noise to spread to nearby circuits, causing electromagnetic interference (EMI). EMI refers to undesired conducted or radiated electromagnetic signals that degrade or impair the performance of electrical systems. Minimizing switching noise and preventing its transmission helps improve system reliability.

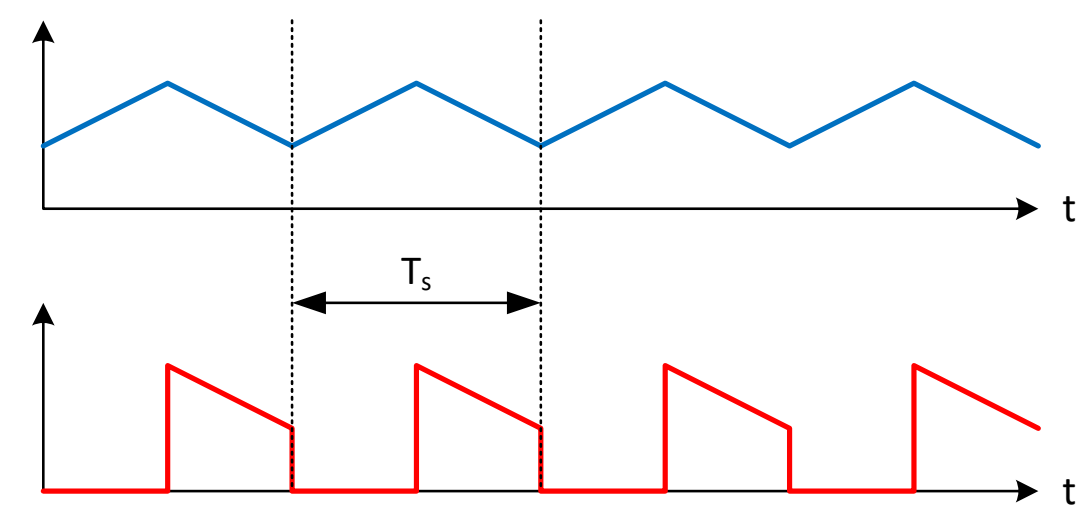

Figure 2-1. Typical Triangular and Trapezoidal Switching Waveforms

Switching noise spreads through both electromagnetic conduction and radiation.

DC/DC converters typically produce triangular and trapezoidal waveforms such as those shown in Figure 2-1. These waveforms carry significant energy at the switching frequency (2-1) and its harmonics which typically sit between $100 \mathrm{kHz}$ and several MHz. The sharp transitions particularly associated with trapezoidal waveforms contain energy at much higher frequencies in the GHz range. Conduction dominates EMI transmission at 
lower frequencies, before parasitic effects dominate electrical circuits, and radiation increases at higher frequencies, when wavelength approaches physical conductor length.

$$
f=\frac{1}{T}
$$

EMI regulations reflect the characteristics of switching noise among other sources. Typical tests limit conducted emissions between $150 \mathrm{kHz}$ to $30 \mathrm{MHz}$ and radiated emissions from $30 \mathrm{MHz}$ to $2 \mathrm{GHz}$. Government regulators impose EMI limits to ensure electrical interoperability, particularly among wireless electronics and power supplies connected to the AC grid. Mitigating switching noise helps achieve EMI compliance in many applications. At a system level, specific grounding and shielding techniques reduce conducted and radiated EMI introduced by switching noise sources [4]. Switching noise also propagates within systems from power converters to nearby signal conductors [5]. Printed circuit board (PCB) layout and grounding techniques help minimize EMI radiation along high-frequency current paths [6] [7]. These approaches primarily focus on containing radiated switching noise emission. Preventing switching noise conduction relies on reducing or containing ripple at the power converter's input and output terminals.

\section{$2.2 \quad$ Input Ripple}

The discontinuous currents caused by switch-mode operation add an AC ripple component to any $\mathrm{DC} / \mathrm{DC}$ converter's input current. When input current ripple conducts through a voltage source, switching noise spreads to other circuits connected to the same source. This conducted EMI significantly impacts systems that draw power from rectified AC-line voltage or a battery. Current ripple also adversely impacts maximum power 
point tracking (MPPT) and the transfer efficiency of solar photovoltaic modules [8] [9]. Reducing the current ripple seen by a converter's input source beneficially impacts many systems.

Designers may choose a DC/DC converter topology based on the relative amount of current ripple introduced. Inductor-fed topologies (boost, Cuk, and SEPIC) produce significantly less input current ripple than switch-fed topologies (buck and buck-boost). At a minimum, most designs employ an input capacitor for input ripple reduction. This simple solution provides adequate filtering performance for some applications. Highperformance converters must incorporate additional input ripple reduction methods, including more complex filters, multiphase interleaving, and specialized topologies.

\subsection{Input Filters}

Adding a filter between the input source and power converter provides bidirectional noise isolation. Figure 2-2 displays the general input filter configuration, using a low-pass response to attenuate high-frequency AC ripple. The filter attenuates both voltage ripple introduced by the source and current ripple introduced by the converter. This behavior prevents noise from spreading between systems connected to the same voltage source, such as a battery or rectified line voltage feeding multiple DC/DC converters. Input filters help system designers contain EMI without changing the DC/DC converter topology. 


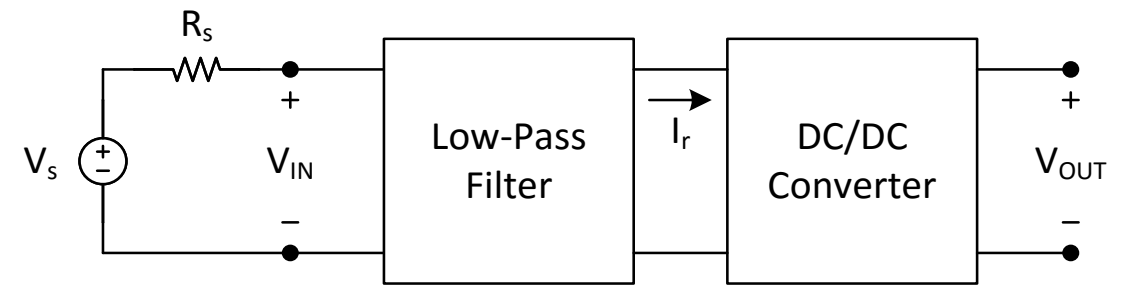

Figure 2-2. DC/DC Converter with Input Filter Network

Though adding the filter improves ripple suppression, the interaction between filter and converter may destabilize the system. Yu and Biess first described these conditions in 1971 [10]. Later analysis performed by R. D. Middlebrook, provided graphical criteria that predict instability when the filter's output impedance exceeds the converter's input impedance at any frequency [11] [12]. Middlebrook developed a canonical DC/DC converter model capable of predicting a converter's input impedance based on design parameters [11] [12]. Figure 2-3 presents the canonical converter input impedance determined by the converter's inductance, output capacitance, and load resistance. Jang and Erickson later adapted the Middlebrook criteria to predict instability in current-mode controlled converters [13]. These tools provide the means to design an input filter in conjunction with a converter or as a modification to an existing converter.

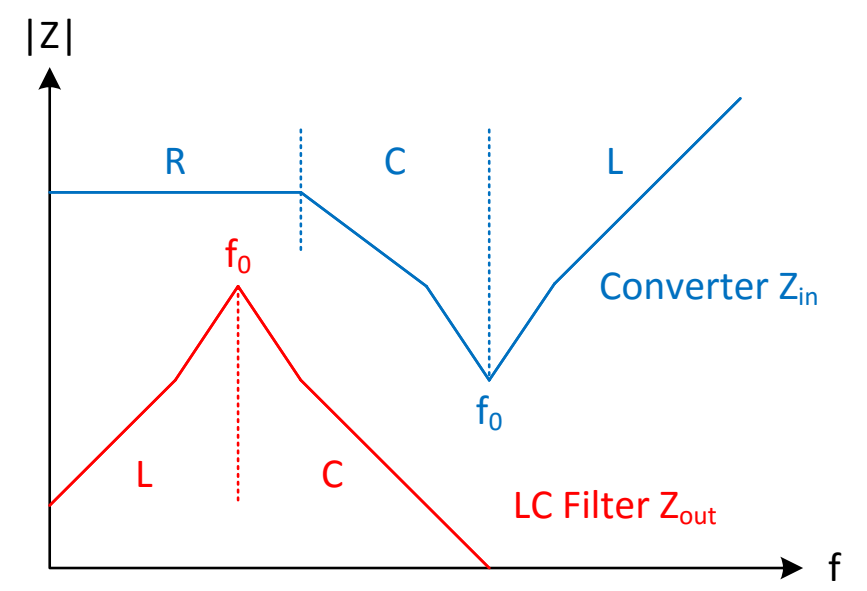

Figure 2-3. Middlebrook Criteria with Generic Impedance Curves 
Higher-order input filters present instability risk due to resonant behavior. A generic LC filter exhibits output impedance characteristics of the form shown in Figure 2-3. Resonant frequency location and damping factor determine whether the filter violates the Middlebrook criteria. Lowering the filter's resonant frequency eases damping requirements but increases the filter component sizes. Figure 2-4 presents two damped LC filter circuits; Erickson demonstrates optimal damping for both filters [14]. Yu and Salato offer a damping technique that uses the LC filter's parasitic series resistances to minimize the number of filter components [15]. Most input filter design approaches either seek to minimize the filter's impact on converter performance or the filter's cost (number of components, size, etc.) [16] [17] [18] [19].
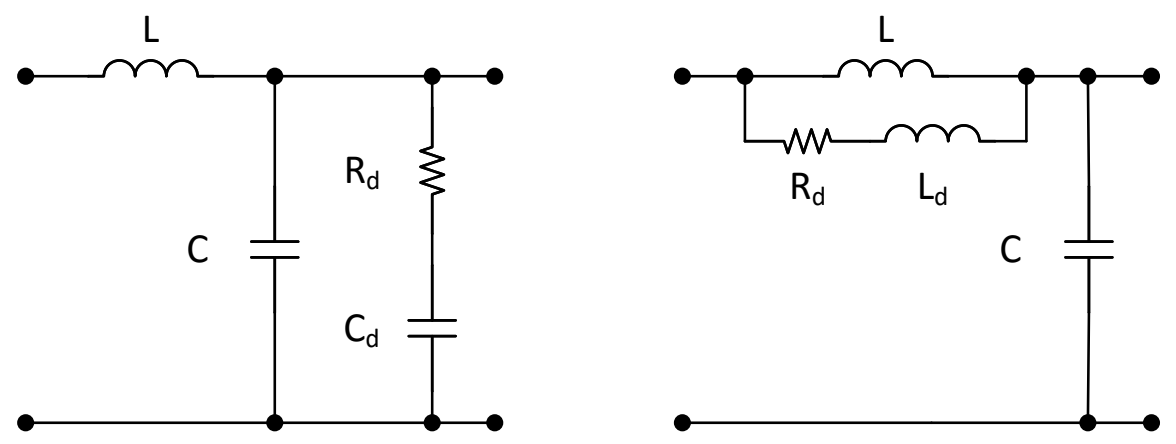

Figure 2-4. Shunt (Left) and Parallel (Right) Damped LC Filters

Input filter designers minimize conducted EMI in new or existing systems. Input filters help compensate for noisy converter topologies. The filter must be designed to prevent impacting the DC/DC converter's stability by employing one of many available damping techniques. An optimally designed input filter reduces switching noise conduction, without impacting transient response, at minimal additional cost and physical size. 


\subsection{Interleaved Multiphase}

High-power applications often require multiphase power converters, which operate several implementations of the same converter topology in parallel. In these designs, each phase only provides a fraction of the total load, reducing the converter's total power dissipation [20]. Low-voltage, high-power computer processor applications influence many designs based around the multiphase buck topology [21] [22] [23].

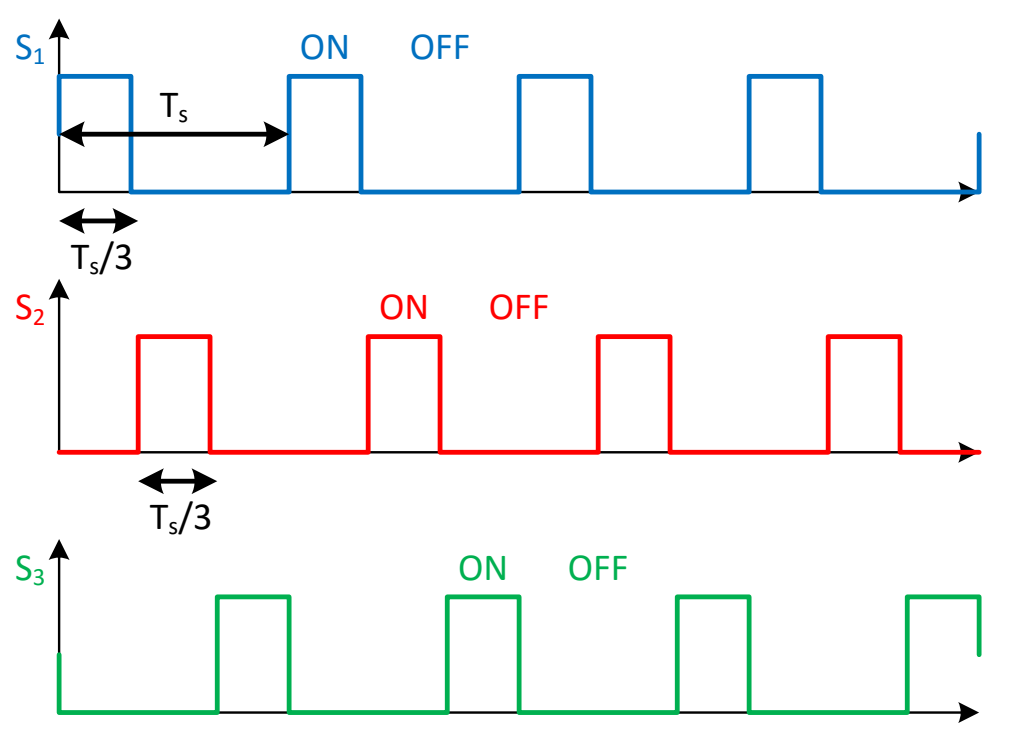

Figure 2-5. Three-Phase Interleaved Switching

Interleaving the multiphase converter's switching signals reduces the ripple introduced and scales the ripple frequency proportional to the number of phases. Interleaved switching signals turn on each phase alternately rather than in unison. Figure 2-5 demonstrates three-phase interleaved switching. The switching controller implements interleaving by introducing a proportional delay between each converter phase. The delayed current waveforms sum at the input and output terminals, and the resulting ripple appears at a multiple of the switching frequency. Table 2-1 summarizes the relationship between the number of converter phases, switching delay, and overall ripple frequency. 
Table 2-1. Interleaved Multiphase Converter Properties

\begin{tabular}{|c|c|c|}
\hline Number of Phases & Switching Delay & Ripple Frequency \\
\hline 2 & $\frac{1}{2} T$ & $2 f$ \\
\hline 3 & $\frac{1}{3} T$ & $3 f$ \\
\hline 4 & $\frac{1}{4} T$ & $4 f$ \\
\hline
\end{tabular}

Interleaving creates ripple reduction because of the delay between each phase.

The duty cycle, shared across all phases, determines the ripple cancellation. Figure 2-6 demonstrates current ripple cancellation at the output terminal of a two-phase buck converter. The inductor current ripple flowing through the output capacitor cancels, when the converter operates at a 50\% duty cycle. Similarly, a three-phase converter would achieve complete ripple cancellation at $33 \%$ and $67 \%$ duty cycles, and a four-phase converter would achieve complete cancellation at $25 \%, 50 \%$, and $75 \%$.

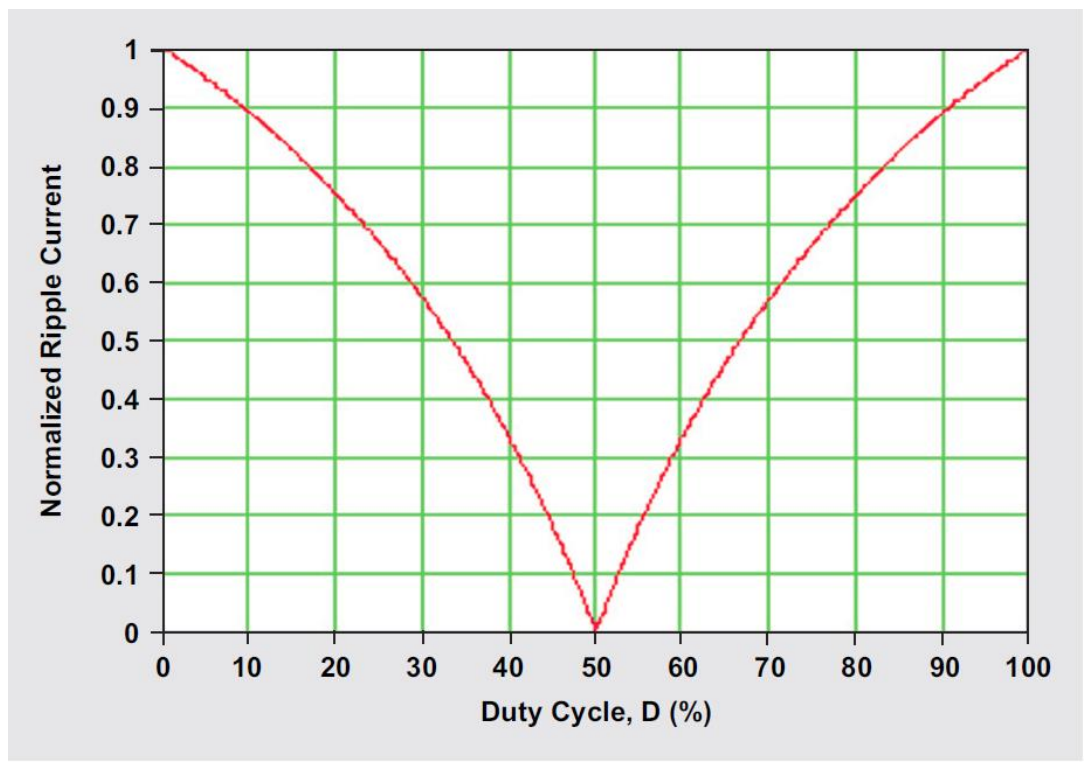

Figure 2-6. Two-Phase Buck Converter Current Ripple Cancellation [20] 
The combined ripple cancellation and frequency scaling eases filtering requirements. A multiphase converter requires a much smaller filter than a single-phase converter to achieve equivalent ripple performance. Ripple cancellation also reduces the inductance per phase required to match single-phase performance. These characteristics decrease the solution size for high-power applications. However, the relationship between duty cycle and ripple cancellation restricts design choices. A two-phase converter only achieves significant ripple reduction at duty cycle around 50\%. Increasing the number of phases provides more options, but significantly increases design complexity.

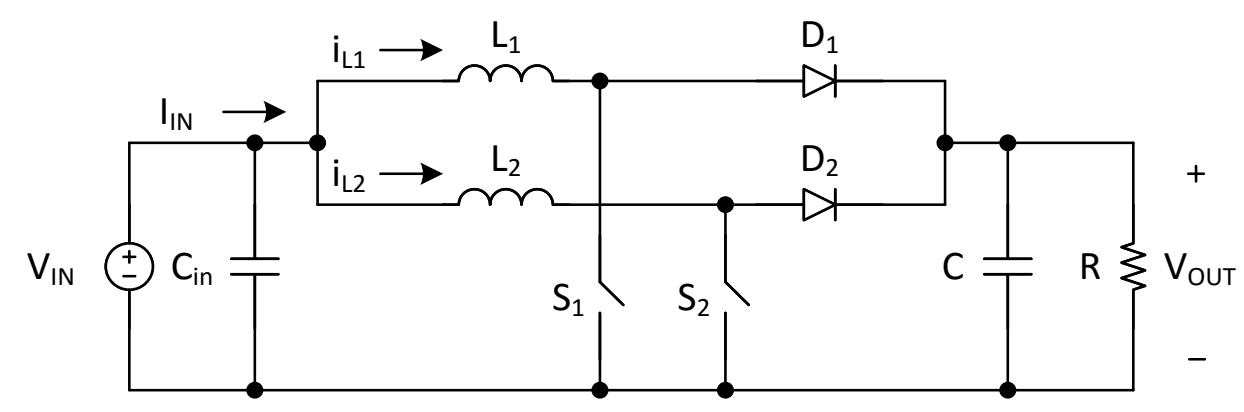

Figure 2-7. Two-Phase Boost Converter

Parallel converters in a multiphase solution reduce the conduction losses associated with a large input current, and interleaved switching provides some ripple cancellation. A multiphase boost converter, shown in Figure 2-7, also exhibits inductor ripple cancellation properties at the input terminal [24]. High-power solar PV inverters benefit from using multiphase boost converters because of current sharing and ripple cancellation [25] [26]. These converters undoubtedly improve efficiency, but restrict duty cycle selection when operated for maximum ripple reduction. 


\subsection{Boost Converter}

Figure 2-8 depicts the boost topology, a standard DC/DC step-up converter, which contains a single switch and operates alternately between two states: switch-on and switch-off.

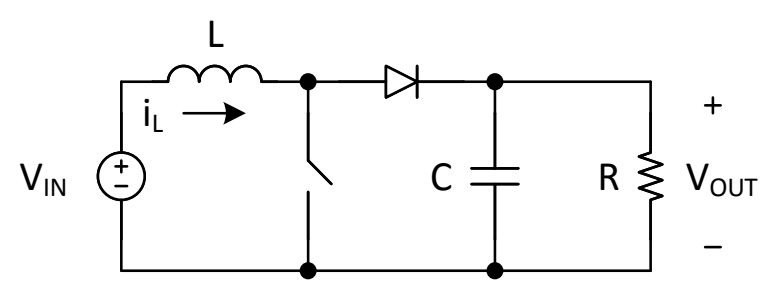

Figure 2-8. Standard Boost Converter Topology

Duty cycle, referred to as a percentage or a ratio less than unity, relates the switching period to the time spent in the switch-on (2-2) and switch-off (2-3) states.

$$
\begin{gathered}
t_{O N}=D \cdot T \\
t_{O F F}=(1-D) \cdot T
\end{gathered}
$$

Circuit operation depends on the relationship between inductor current and voltage (2-4).

$$
V_{L}=L \cdot \frac{d i_{L}}{d t}
$$

Turning the switch on and off changes the voltage applied across the inductor, alternately increasing and decreasing inductor current. This action, stores energy from the input source in the inductor's magnetic field, and then releases energy to the load. Because the converter always applies voltage across the inductor, the converter's input current never settles to a flat DC level. Inductor current ripple manifests as input current ripple in a boost converter. 


\subsubsection{Switch-ON State}

In the switch-on state, the inductor stores energy from the input, while the capacitor releases energy to drive the load. Turning the switch on, reverse biases the diode, separating the circuit's two halves as in Figure 2-9.

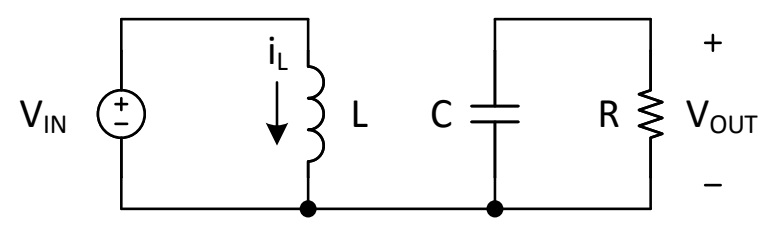

Figure 2-9. Boost Converter Switch-ON State

The inductor current ramps up with slope (2-5) defined by equation (2-4).

Constant input voltage guarantees a fixed linear slope (2-6), equivalent to the change in current relative to the time spent in the switch-on state (2-2). This equivalence leads to a description of the peak-to-peak current ripple (2-7).

$$
\begin{gathered}
\frac{d i_{L}}{d t}=\frac{V_{I N}}{L} \\
\frac{\Delta i_{L(O N)}}{\Delta t_{O N}}=\frac{V_{I N}}{L} \\
\Delta i_{L(O N)}=\frac{V_{I N} \cdot D T}{L}
\end{gathered}
$$

\subsubsection{Switch-OFF State}

In the switch-off state, energy from input source and energy stored in the inductor flow to the capacitor and load. With the switch off, the diode becomes forward biased and connects the inductor to the output node as in Figure 2-10. 


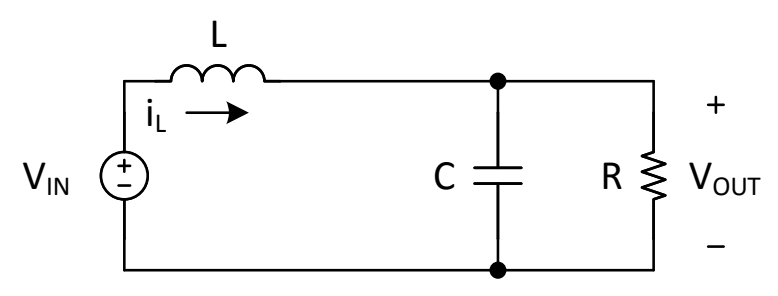

Figure 2-10. Boost Converter Switch-OFF State

The difference between input and output voltage determines inductor current slope (2-8) while the switch remains 'OFF'. Assuming constant DC input and output voltage, the switch-off state also exhibits linear inductor current slope (2-9). Equation (210) presents the peak-to-peak inductor current ripple during the switch-off state.

$$
\begin{gathered}
\frac{d i_{L}}{d t}=\frac{V_{I N}-V_{O U T}}{L} \\
\frac{\Delta i_{L(O F F)}}{\Delta t_{O F F}}=\frac{V_{I N}-V_{O U T}}{L} \\
\Delta i_{L(O F F)}=\frac{\left(V_{I N}-V_{O U T}\right) \cdot(1-D) T}{L}
\end{gathered}
$$

\subsubsection{Transfer Function}

Under steady-state operating conditions, inductor current reaches a fixed DC value. Figure 2-11 depicts these conditions, where net inductor current change reaches zero. 


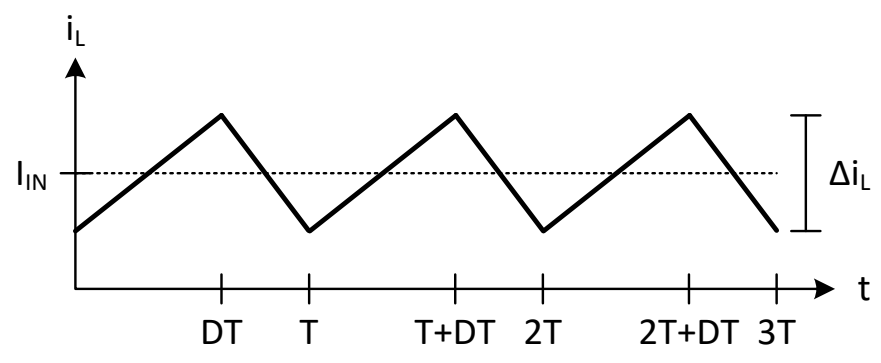

Figure 2-11. Boost Converter Steady-State Inductor Current

Equation (2-11) describes the steady-state operating condition mathematically.

$$
\Delta i_{L(O N)}=\Delta i_{L(O F F)}
$$

Substituting the inductor current ripple expressions in the switch-on (2-7) and switch-off (2-10) state leads to the boost converter's DC voltage transfer function (2-13).

$$
\begin{gathered}
\frac{V_{I N} \cdot D T}{L}=\frac{\left(V_{I N}-V_{\text {OUT }}\right) \cdot(1-D) T}{L} \\
V_{\text {OUT }}=\frac{V_{I N}}{(1-D)}
\end{gathered}
$$

The ideal power relationship (2-14), in a lossless converter, extends the DC voltage transfer function to the DC current transfer function (2-15).

$$
\begin{gathered}
P_{\text {OUT }}=V_{\text {OUT }} I_{\text {OUT }}=P_{I N}=V_{I N} I_{I N} \\
I_{I N}=\frac{I_{\text {OUT }}}{(1-D)}
\end{gathered}
$$

\subsubsection{Continuous Conduction Mode Operation}

A DC/DC converter's inductor current describes the operating mode. Continuous conduction mode (CCM) implies inductor current flow throughout the switching cycle. Discontinuous conduction mode (DCM) occurs when the inductor current drops to zero during the switch-off state. In this scenario, the diode prevents negative current flow and 
the inductor current remains at zero until the next switch-on cycle. DCM naturally occurs, when a converter operates under light loads well below specified maximums. The general converter design process assumes CCM operation at maximum rated load.

A special CCM case called boundary conduction mode (BCM), illustrated by Figure 2-12, delineates the barrier between CCM and DCM. BCM represents the minimum conditions for CCM operation.

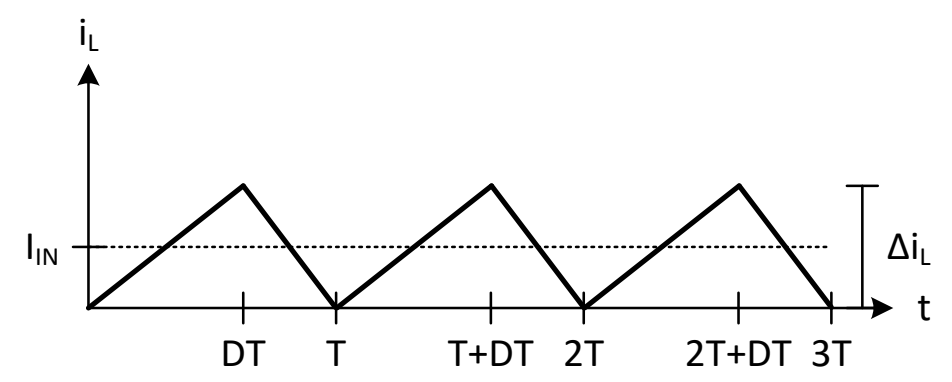

Figure 2-12. Boost Converter BCM Inductor Current

Maintaining CCM operation constrains inductor current ripple given the desired average inductor current level. The BCM constraint (2-16) describes a minimum inductance, known as the critical inductance (2-17) required to maintain continuous conduction.

$$
\begin{gathered}
\frac{\Delta i_{L}}{2} \leq I_{L} \\
L_{c} \geq \frac{V_{I N} \cdot D T}{2 I_{I N}}
\end{gathered}
$$

\subsubsection{Component Ratings}

Voltage and current waveforms help determine each component's basic ratings. Manufacturers specify voltage ratings as peak values and current ratings as average or 
RMS values. Figure 2-13 defines component current and voltage polarities in the boost converter.
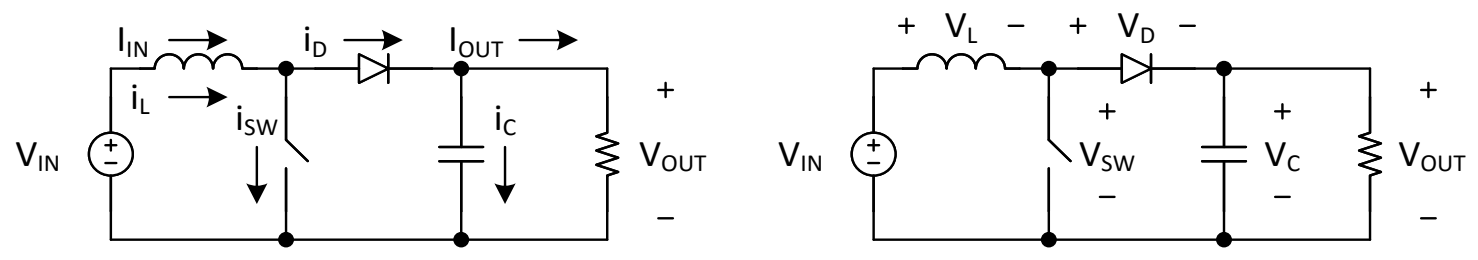

Figure 2-13. Boost Converter Current and Voltage Polarities

Inductor current splits between the switch and diode. These components conduct alternately; the switch carries the inductor current during the 'ON' state and the diode carries the inductor current during the 'OFF' state. Diode current splits between the output capacitor and the load. The load conducts the DC output current and the output capacitor conducts the AC component of the diode current. Figure 2-14 depicts the current waveforms for each component.
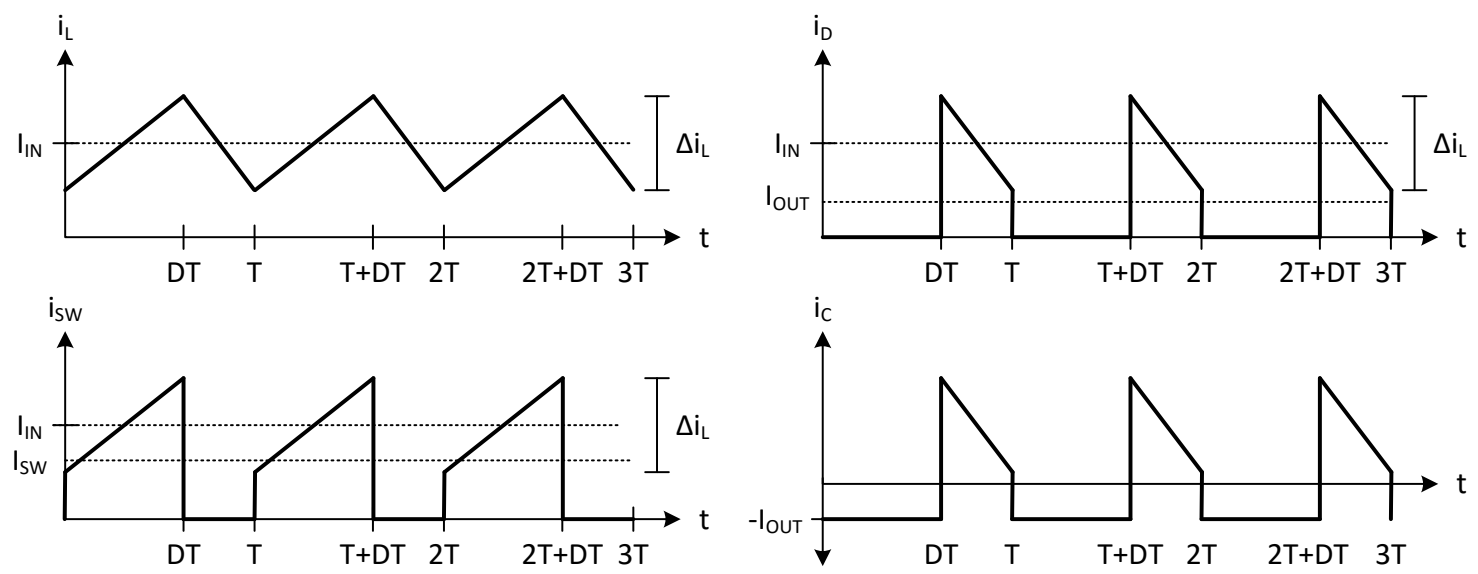

Figure 2-14. Boost Converter Current Waveforms

During the switch-on state, the inductor see the input voltage and the reversebiased diode sees the output voltage. During the switch-off state, the inductor sees a 
negative voltage, equal to the difference between input and output voltages, while the switch sees the output voltage across its terminals. Capacitor voltage always equals the output voltage, including the additional ripple caused by integrating the capacitor current.

Figure 2-15 illustrates each component's voltage waveform.
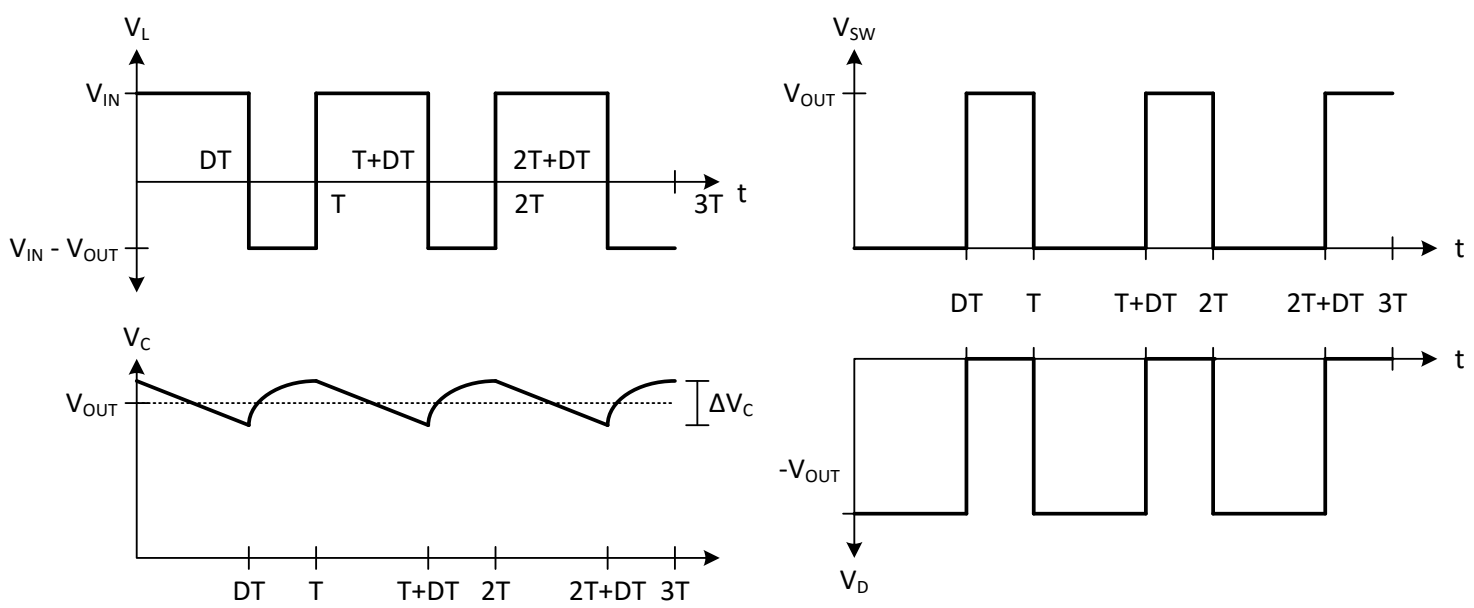

Figure 2-15. Boost Converter Voltage Waveforms

Table 2-2 summarizes the boost converter's relevant component ratings determined based on voltage and current waveforms.

Table 2-2. Boost Converter Component Ratings [27]

\begin{tabular}{|c|c|c|}
\hline Component & Rating & Value \\
\hline \multirow{2}{*}{ Switch } & Drain Current & $I_{d}>I_{I N} \cdot D$ \\
\hline & Drain-Source Voltage & $V_{d s}>V_{O U T}$ \\
\hline \multirow{2}{*}{ Diode } & Forward Current & $I_{F}>I_{O U T}$ \\
\hline & Max. Repetitive Reverse Voltage & $V_{r r m}>V_{\text {OUT }}$ \\
\hline Capacitor & DC Voltage & $V_{C(\max )}>V_{O U T}+\frac{\Delta V_{O U T}}{2}$ \\
\hline \multirow[b]{2}{*}{ Inductor } & Saturation Current & $I_{s a t}>I_{I N}+\frac{\Delta i_{L}}{2}$ \\
\hline & RMS Current & $I_{r m s}>\sqrt{I_{I N}{ }^{2}+\frac{\Delta i_{L}^{2}}{12}}$ \\
\hline
\end{tabular}




\subsubsection{Capacitor Sizing}

Capacitors handle the $\mathrm{AC}$ current ripple at a DC/DC converter's input and output terminals. During steady-state operation, the net charge stored and released by a capacitor must approach zero over the switching cycle. Charging and discharging the capacitor introduces voltage ripple across the capacitor (2-18), the primary design parameter associated with input and output capacitors.

$$
\Delta V=\frac{Q}{C}
$$

Integrating the positive or negative portion of the ripple current over a half switching cycle specifies the maximum charge stored or released by the capacitor. Figure 2-16 applies this technique to a boost converter's output capacitor.

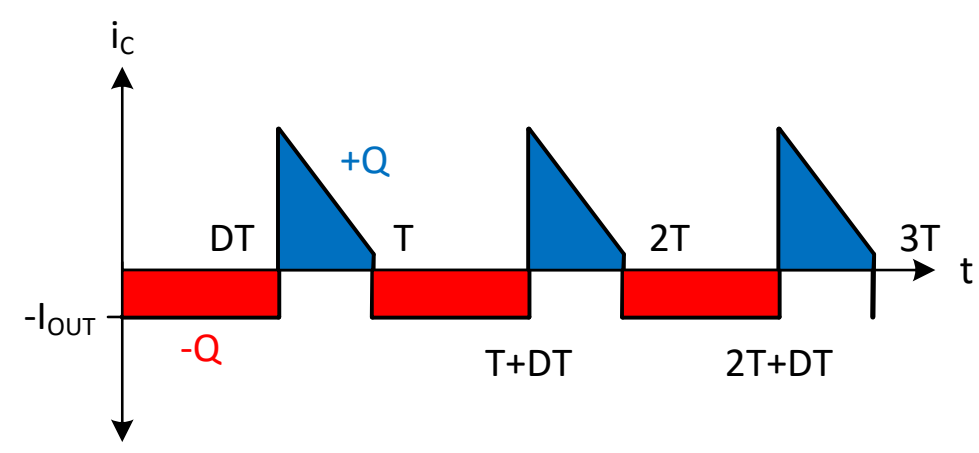

Figure 2-16. Boost Converter Output Capacitor Charge Storage

The DC output current and switching cycle parameters determine the output capacitor charge (2-19). Combining equations (2-18), (2-19), and (2-20) expresses the required output capacitance to achieve a specified voltage ripple ratio (2-21).

$$
\begin{gathered}
Q_{C_{\text {out }}}=I_{\text {OUT }} \cdot D \cdot T \\
I_{\text {OUT }}=\frac{V_{\text {OUT }}}{R}
\end{gathered}
$$




$$
C_{\text {out }}=\frac{D \cdot T}{R \cdot \frac{\Delta V_{\text {out }}}{V_{\text {ouT }}}}
$$

Though often omitted from schematics during theoretical analysis, practical DC/DC converter implementations require an input capacitor. This provides a lowimpedance source for high-frequency current ripple drawn by the converter. Inductor current ripple determines the charge stored on a boost converter's input capacitor, as Figure 2-17 depicts.

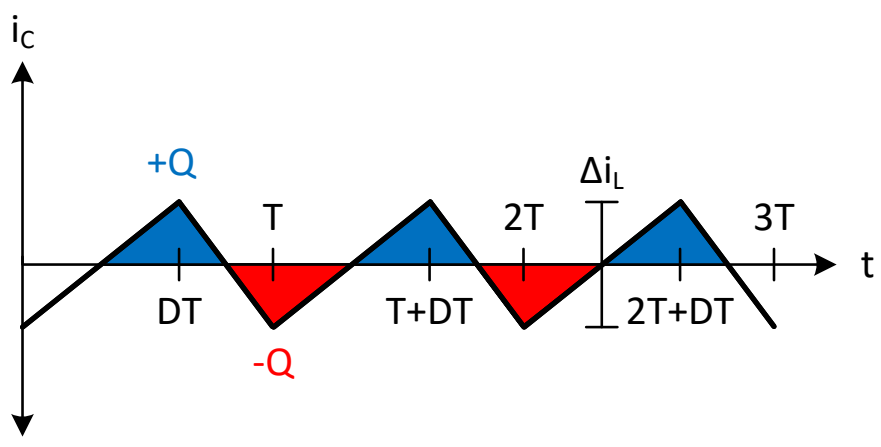

Figure 2-17. Boost Converter Input Capacitor Charge Storage

Like the output, input voltage ripple requirements determine input capacitance. Applying inductor current ripple (2-7) and input capacitor charge (2-22) expressions to the capacitor's charge-voltage relationship (2-18) specifies input capacitance in terms of converter parameters and input voltage ripple specifications (2-23).

$$
\begin{gathered}
Q_{C_{\text {in }}}=\frac{\Delta i_{L} \cdot T}{8} \\
C_{\text {in }}=\frac{D \cdot T^{2}}{8 L \cdot \frac{\Delta V_{I N}}{V_{I N}}}
\end{gathered}
$$




\subsection{Novel and Modified Topologies}

Many step-up converter applications require performance beyond the standard boost converter's capabilities. Such needs produce novel step-up topologies designed to optimize different performance criteria; including efficiency, ripple performance, step-up conversion ratio, size, and cost [28] [29] [30] [31].

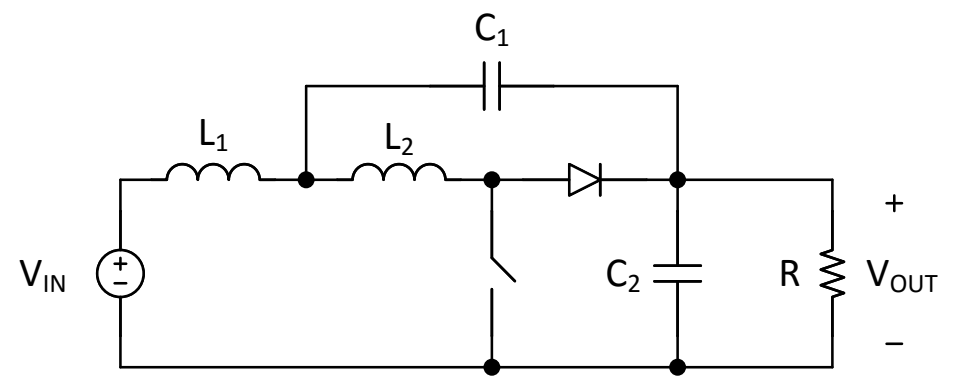

Figure 2-18. Modified Boost Converter

New and modified topologies trade additional complexity for performance enhancement. Figure 2-18 shows a relatively simple modification proposed by Karanam as part of a step-up inverter application [32]. Karanam implemented the modified boost converter, focusing on performance of the inverter rather than the boost converter itself. Using analysis, simulation, and hardware implementation techniques, this work intends to prove the following thesis statement. During steady-state, CCM operation, Karanam's modified boost converter provides a $40 \%$ input current ripple reduction compared against an equivalent standard boost converter. 


\section{DESIGN REQUIREMENTS}

Comparing two related converter topologies requires common performance criteria and design constraints. Equivalent operating conditions and performance measurements ensure proper evaluation of topological converter modifications. This performance comparison primarily concerns the converter's input current ripple, measured through the input inductor. Physical size and cost constitute secondary comparative concerns as some applications value performance over size and cost. A valid performance comparison requires uniform design constraints on input voltage, output voltage, output power, switching frequency, inductance, input capacitance, and output capacitance. Selecting these parameters per standard boost converter characteristics establishes the comparative baseline.

\subsection{Current Ripple Performance}

Input current ripple relates to the converter's inductor current ripple, especially in boost topologies which place the inductor at the input terminal. Current ripple measurements typically concern the peak-to-peak value. But specifications typically remain relative to the established DC current level, as a percentage much like voltage ripple. The boost topology's input current ripple percentage (3-1) relates directly to peakto-peak inductor current ripple (2-7) and DC input current (2-14).

$$
\begin{gathered}
\% \Delta i_{I N}=\frac{\Delta i_{L}}{I_{I N}} \\
\% \Delta i_{I N}=\frac{V_{I N}^{2} \cdot D}{L \cdot f \cdot P_{O U T}}
\end{gathered}
$$


Specific applications dictate the tolerable inductor current ripple percentage. Generally, most design guidelines suggest ripple below $40 \%$. Choosing a relatively large ripple percentage differentiates a topological modification that reduces ripple. Targeting $40 \%$ current ripple in a standard boost design provides adequate opportunity to improve performance without exceeding practical limits.

\subsection{Functional Parameters}

A DC/DC converter's functional parameters determine the component values that complete the converter's design requirements. Table 3-1 summarizes the chosen functional parameters for both boost converters. Three factors influence power and voltage level selection: DC input current, DC voltage gain, and laboratory power supply capabilities. DC/DC converters with large DC input current require larger inductors to achieve low current ripple. A topological modification designed to reduce input current ripple provides greater benefit among converter with large DC input current. Because DC voltage gain correlates with DC input current, high-gain converters also benefit from input ripple current reduction. The available DC power supplies also informed power and voltage parameters. The voltage ripple values reflect compensation for non-ideal capacitors, which produce more ripple due to equivalent series resistance (ESR).

Table 3-1. Functional Converter Parameters

\begin{tabular}{|c|c|}
\hline Parameter & Value \\
\hline Output Power & $30 \mathrm{~W}$ \\
\hline Output Voltage & $20 \mathrm{~V}$ \\
\hline Input Voltage & $6 \mathrm{~V}$ \\
\hline Output Voltage Ripple & $0.5 \%$ \\
\hline Input Voltage Ripple & $0.5 \%$ \\
\hline Inductor Current Ripple & $40 \%$ \\
\hline
\end{tabular}




\subsection{Standard Boost Design}

The functional parameters listed in Table 3-1 determine converter component values and operating conditions. Two key operating conditions, duty cycle (3-3) and load resistance (3-4), directly relate to functional power and voltage levels.

$$
\begin{gathered}
D=1-\frac{V_{I N}}{V_{\text {OUT }}} \\
R=\frac{V_{\text {OUT }}{ }^{2}}{P_{\text {OUT }}}
\end{gathered}
$$

The chose power and voltage levels specify a $70 \%$ duty cycle and $13.333 \Omega$ load resistance.

$$
\begin{gathered}
D=1-\frac{6 \mathrm{~V}}{20 \mathrm{~V}}=0.7 \\
R=\frac{(20 \mathrm{~V})^{2}}{30 \mathrm{~W}}=13.333 \Omega
\end{gathered}
$$

A third operating condition, switching frequency, provides a degree of freedom to adjust component values. Increased switching frequency reduces the inductor (3-5), output capacitor (2-21) and input capacitor (2-23) component values. Because the performance comparison regards inductor current ripple, switching frequency's impact on inductor value outweighs the impact on capacitor values.

$$
L=\frac{V_{I N}{ }^{2} \cdot D}{\% \Delta i_{I N} \cdot f \cdot P_{\text {OUT }}}
$$

Switching frequency also constrains switching controller selection. Some controllers offer adjustable switching frequency, while others operate at a fixed frequency. Generally, most controllers operate between $100 \mathrm{kHz}$ and $2 \mathrm{MHz}$. Selecting a 
$200 \mathrm{kHz}$ switching frequency keeps all three component values within reasonable ranges and preserves a wide selection of switching controllers.

$$
\begin{gathered}
L=\frac{(6 \mathrm{~V})^{2} \cdot 0.7}{0.4 \cdot(200 \mathrm{kHz}) \cdot(30 \mathrm{~W})}=10.5 \mu \mathrm{H} \\
C_{\text {out }}=\frac{D \cdot T_{s}}{R \cdot \frac{\Delta V_{\text {out }}}{V_{\text {ouT }}}}=\frac{0.7 \cdot(5 \mu \mathrm{s})}{(13.333 \Omega) \cdot(0.005)}=52.5 \mu \mathrm{F} \\
C_{\text {in }}=\frac{D \cdot T_{s}^{2}}{8 L \cdot \frac{\Delta V_{I N}}{V_{\text {IN }}}}=\frac{0.7 \cdot(5 \mu \mathrm{s})^{2}}{8 \cdot(10 \mu \mathrm{H}) \cdot(0.005)}=43.75 \mu \mathrm{F}
\end{gathered}
$$

Table 3-2 presents the complete design requirements, derived from the functional parameters and stated design goals, using standard boost converter relationships. These constraints establish the baseline performance of the standard boost converter and limit the modified design to validate the performance comparison.

Table 3-2. Converter Design Parameters

\begin{tabular}{|c|c|}
\hline Parameter & Value \\
\hline Output Power & $30 \mathrm{~W}$ \\
\hline Output Voltage & $20 \mathrm{~V}$ \\
\hline Output Current & $1.5 \mathrm{~A}$ \\
\hline Input Voltage & $6 \mathrm{~V}$ \\
\hline Input Current & $5 \mathrm{~A}$ \\
\hline Load Resistance & $13.333 \Omega$ \\
\hline Switching Frequency & $200 \mathrm{kHz}$ \\
\hline Switch Duty Cycle & $70 \%$ \\
\hline Inductance & $10 \mu \mathrm{H}$ \\
\hline Output Capacitance & $50 \mu \mathrm{F}$ \\
\hline Input Capacitance & $44 \mu \mathrm{F}$ \\
\hline
\end{tabular}




\section{ANALYSIS AND SIMULATION}

Basic converter analysis techniques describe converter performance by exploiting inductor current slope assumptions. These assumptions eliminate the need to solve the underlying differential equations that describe inductor current and capacitor voltage. Section 2.5 presents a typical boost converter analysis assuming a linear inductor current slope during both switching states. Linear inductor current slope implies pure DC voltage across the inductor and a converter switching frequency higher than the converter's LC resonant frequency. These assumptions remain valid for properly-designed boost converters, and the simple analysis accurately predicts inductor current ripple.

The modified boost converter topology challenges the assumptions that facilitate simplified analysis. Assuming the converter's switching frequency exceeds the circuit's resonant frequencies, linear current slope analysis predicts large $\mathrm{L}_{2}$ current ripple, proportional to $\mathrm{V}_{\mathrm{IN}}$, and zero $\mathrm{L}_{1}$ current ripple, based on the DC voltages Figure 4-1 depicts across each inductor.

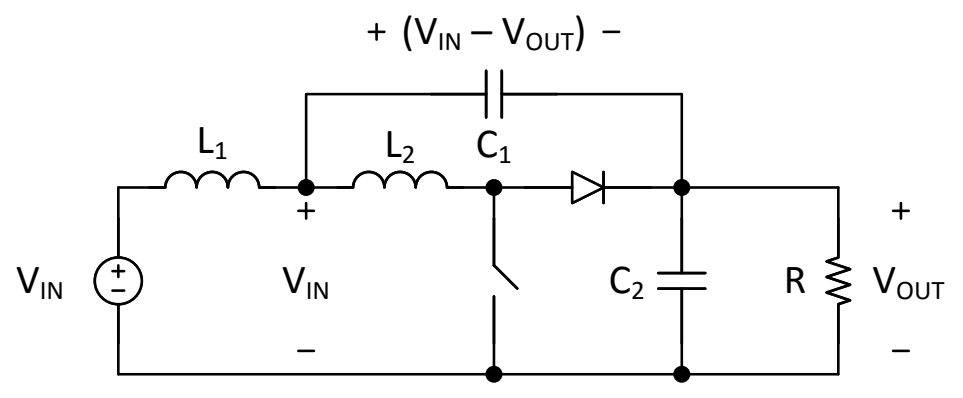

Figure 4-1. Modified Boost Converter DC Voltages

This simple analysis ignores the small voltage ripple on both capacitors, which induces a small current ripple in both inductors. The linear current slope analysis remains accurate when large current ripple introduced by DC voltage across the inductor masks 
the small addition. In the modified boost converter, simple analysis accurately predicts $\mathrm{L}_{2}$ current ripple, but not $\mathrm{L}_{1}$ current ripple, which depends entirely on small AC voltage ripple applied across the inductor. Therefore, input current ripple prediction requires more complex analysis of the modified boost converter.

State space analysis describes a DC/DC converter using a set of time differential equations. Averaging the state space representations during switch-on and switch-off operation provides the converter's DC transfer function, verifying boost-type behavior. Transformation to the $m$-domain, normalizes the time-domain state equation over the converter's switching period. Solving the $m$-domain state equation describes steady-state converter behavior. Unlike sinusoidal waveforms, analytical switching waveform expressions provide little intuition towards performance measurements such as peak-topeak, RMS, and average values [33]. Computer-aided, numerical solutions provide relevant boost converter performance measurements, particularly peak-to-peak and percent input current ripple, facilitating converter design choices. Analyzing the known standard topology alongside the modified topology validates the steady-state model.

\subsection{State Space Analysis}

The state space analysis method describes a system's dynamic elements, state variables, as a set of first-order differential equations known as the state equation. DC/DC converters require a state equation, for each switching state. Control loop and DC transfer function analysis rely on the averaged state equation over all the converter's switching states. Combining the individual state equations sequentially describes the converter's dynamic behavior across the complete switching cycle. 
Energy storage elements, capacitors and inductors, determine a DC/DC converter's dynamic behavior. Simple differential relationships make inductor currents and capacitor voltages the best state variable choices. Circuit analysis completes the associated first order differential equations. Kirchhoff's voltage law (KVL) replaces inductor voltage with capacitor voltage state variables and Kirchhoff's current law (KCL) replaces capacitor current with inductor current state variables. The complete state equation describes each state variable's derivative using the system's state variables and inputs.

\subsubsection{Standard Boost Converter}

The standard boost converter's state model requires two state variables, inductor current, $\mathrm{i}_{\mathrm{L}}$, and output voltage, $\mathrm{v}_{\mathrm{o}}$, shown in Figure 4-2.

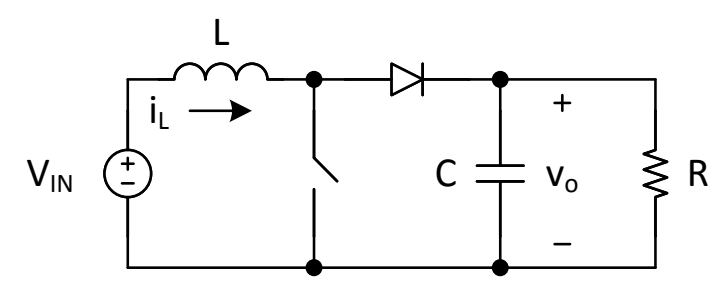

Figure 4-2. Standard Boost Converter State Variables

Figure 4-3 displays the standard boost state variables during the switch-on state.

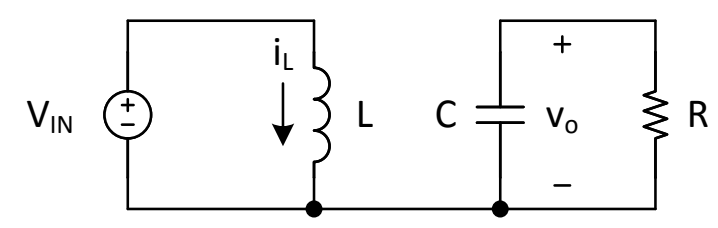

Figure 4-3. Standard Boost Converter Switch-On State Variables

KVL determines the inductor current differential equation (4-1) and KCL provides the output voltage differential equation (4-2). 


$$
\begin{gathered}
\frac{d i_{L}}{d t}=\frac{1}{L} V_{I N} \\
\frac{d v_{o}}{d t}=-\frac{1}{C R} v_{o}
\end{gathered}
$$

The switch-on state equation (4-3) summarizes the state variable differential equations in matrix form.

$$
\left[\begin{array}{c}
\frac{d i_{L}}{d t} \\
\frac{d v_{o}}{d t}
\end{array}\right]=\left[\begin{array}{cc}
0 & 0 \\
0 & -\frac{1}{C R}
\end{array}\right]\left[\begin{array}{l}
i_{L} \\
v_{o}
\end{array}\right]+\left[\begin{array}{c}
\frac{1}{L} \\
0
\end{array}\right] V_{I N}
$$

Figure 4-4 depicts the standard boost state variables in the switch-off state.

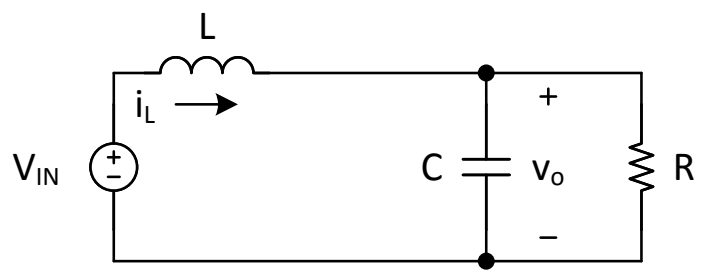

Figure 4-4. Standard Boost Converter Switch-Off State Variables

KVL around the circuit and KCL at the output node determine the inductor current (4-4) and output voltage (4-5) differential equations.

$$
\begin{aligned}
& \frac{d i_{L}}{d t}=\frac{1}{L} V_{I N}-\frac{1}{L} v_{o} \\
& \frac{d v_{o}}{d t}=\frac{1}{C} i_{L}-\frac{1}{C R} v_{O}
\end{aligned}
$$

The switch-off state equation (4-6) summarizes both state-variable differential equations in matrix form.

$$
\left[\begin{array}{c}
\frac{d i_{L}}{d t} \\
\frac{d v_{o}}{d t}
\end{array}\right]=\left[\begin{array}{cc}
0 & -\frac{1}{L} \\
\frac{1}{C} & -\frac{1}{C R}
\end{array}\right]\left[\begin{array}{l}
i_{L} \\
v_{o}
\end{array}\right]+\left[\begin{array}{l}
\frac{1}{L} \\
0
\end{array}\right] V_{I N}
$$


Summing the switch-on and switch-off state equations, weighted by duty cycle and inverse duty cycle, provides the average state equation across the switching period (4-7).

$$
\left[\begin{array}{c}
\frac{d i_{L}}{d t} \\
\frac{d v_{o}}{d t}
\end{array}\right]=D\left[\begin{array}{cc}
0 & 0 \\
0 & -\frac{1}{C R}
\end{array}\right]\left[\begin{array}{l}
i_{L} \\
v_{o}
\end{array}\right]+(1-D)\left[\begin{array}{cc}
0 & -\frac{1}{L} \\
\frac{1}{C} & -\frac{1}{C R}
\end{array}\right]\left[\begin{array}{c}
i_{L} \\
v_{o}
\end{array}\right]+\left[\begin{array}{c}
\frac{1}{L} \\
0
\end{array}\right] V_{I N} \quad(4-7)
$$

The DC transfer functions describe the circuit's behavior as the state variables reach pure DC values. Under these conditions both differentials approach zero.

$$
\left[\begin{array}{l}
\frac{d i_{L}}{d t} \\
\frac{d v_{o}}{d t}
\end{array}\right]=\left[\begin{array}{l}
0 \\
0
\end{array}\right]
$$

Solving the resulting inductor current equation (4-8) yields the DC voltage transfer function (4-9).

$$
\begin{gathered}
0=(1-D)\left(-\frac{1}{L}\right) V_{\text {OUT }}+\frac{1}{L} V_{I N} \\
V_{\text {OUT }}=\frac{V_{I N}}{(1-D)}
\end{gathered}
$$

Solving the output voltage equation (4-10) yields the DC current transfer function (4-12).

$$
\begin{array}{cc}
0=D\left(-\frac{1}{C R}\right) V_{\text {OUT }}+(1-D)\left(\frac{1}{C}\right) I_{I N}+(1-D)\left(-\frac{1}{C R}\right) V_{\text {OUT }} & (4-10) \\
I_{\text {OUT }}=\frac{V_{\text {OUT }}}{R} & (4-11) \\
I_{I N}=\frac{I_{\text {OUT }}}{(1-D)} & (4-12)
\end{array}
$$

State space averaging produces the same DC transfer functions presented in Section 2.5.3 using steady-state current ripple constraints. 


\subsubsection{Modified Boost Converter}

The modified boost converter's state space model requires two additional state variables. Figure 4-5 shows the two inductor currents, $i_{\mathrm{L} 1}$ and $\mathrm{i}_{\mathrm{L} 2}$, and two capacitor voltages, $\mathrm{v}_{\mathrm{C} 1}$ and $\mathrm{v}_{\mathrm{o}}$, describing the modified boost converter's dynamics.

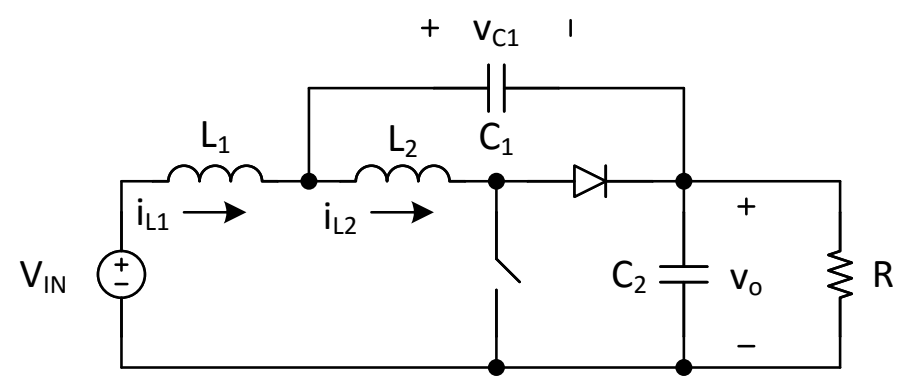

Figure 4-5. Modified Boost Converter State Variables

Figure 4-6 depicts the modified boost state variables during the switch-on state.

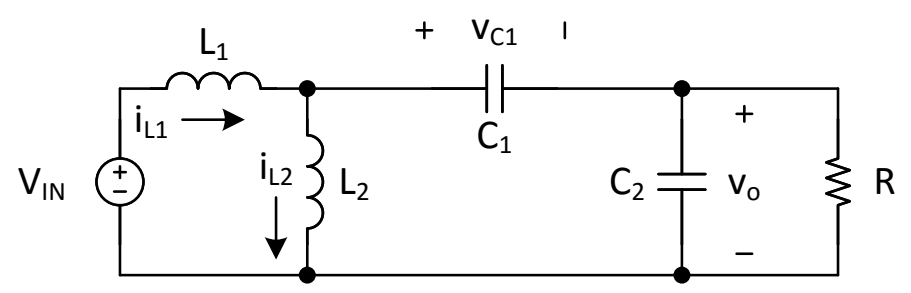

Figure 4-6. Modified Boost Converter Switch-On State Variables

KVL around the outer loop provides the $\mathrm{L}_{1}$ current differential equation (4-13)

and KVL around the inner loop provides the $\mathrm{L}_{2}$ current differential equation (4-14).

$$
\begin{gathered}
\frac{d i_{L 1}}{d t}=-\frac{1}{L_{1}} v_{C 1}-\frac{1}{L_{1}} v_{o}+\frac{1}{L_{1}} V_{I N} \\
\frac{d i_{L 2}}{d t}=\frac{1}{L_{2}} v_{C 1}+\frac{1}{L_{2}} v_{o}
\end{gathered}
$$

KCL at the circuit's two nodes provide the capacitor voltage differential equations for $v_{C 1}$ (4-15) and $v_{o}(4-16)$. 


$$
\begin{gathered}
\frac{d v_{C 1}}{d t}=\frac{1}{C_{1}} i_{L 1}-\frac{1}{C_{1}} i_{L 2} \\
\frac{d v_{o}}{d t}=\frac{1}{C_{2}} i_{L 1}-\frac{1}{C_{2}} i_{L 2}-\frac{1}{C_{2} R} v_{o}
\end{gathered}
$$

The modified boost converter's switch-on state equation (4-17) contains the statevariable differential equations in matrix form.

$$
\left[\begin{array}{c}
\frac{d i_{L 1}}{d t} \\
\frac{d i_{L 2}}{d t} \\
\frac{d v_{C 1}}{d t} \\
\frac{d v_{o}}{d t}
\end{array}\right]=\left[\begin{array}{cccc}
0 & 0 & -\frac{1}{L_{1}} & -\frac{1}{L_{1}} \\
0 & 0 & \frac{1}{L_{2}} & \frac{1}{L_{2}} \\
\frac{1}{C_{1}} & -\frac{1}{C_{1}} & 0 & 0 \\
\frac{1}{C_{2}} & -\frac{1}{C_{2}} & 0 & -\frac{1}{C_{2} R}
\end{array}\right]\left[\begin{array}{c}
i_{L 1} \\
i_{L 2} \\
v_{C 1} \\
v_{o}
\end{array}\right]+\left[\begin{array}{c}
\frac{1}{L_{1}} \\
0 \\
0 \\
0
\end{array}\right] V_{I N}
$$

Figure 4-7 shows the modified boost converter state variables in the switch-off state.

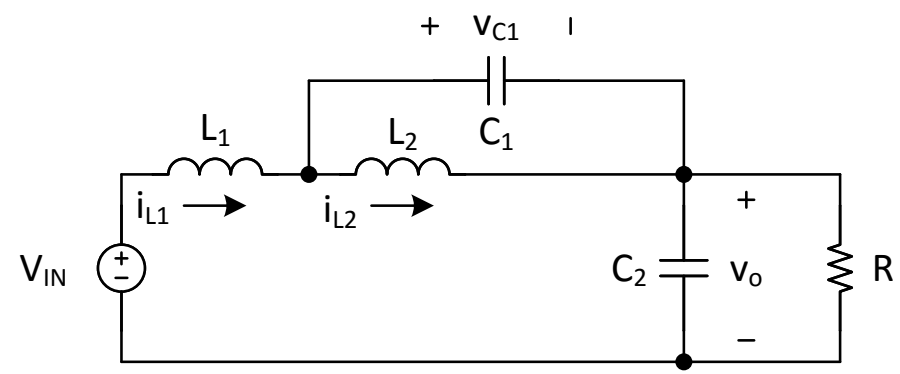

Figure 4-7. Modified Boost Converter Switch-Off State Variables

KVL around the circuit's outer loop determines the $\mathrm{L}_{1}$ current differential equation (4-18). KVL in the $\mathrm{C}_{1}$ loop determines the $\mathrm{L}_{2}$ current differential equation (419).

$$
\frac{d i_{L 1}}{d t}=-\frac{1}{L_{1}} v_{C 1}-\frac{1}{L_{1}} v_{o}+\frac{1}{L_{1}} V_{I N}
$$




$$
\frac{d i_{L 2}}{d t}=\frac{1}{L_{2}} v_{C 1}
$$

$\mathrm{KCL}$ at the circuit's nodes determines the $\mathrm{C}_{1}$ voltage differential equation (4-20) and $\mathrm{C}_{2}$ voltage differential equation (4-21).

$$
\begin{aligned}
& \frac{d v_{C 1}}{d t}=\frac{1}{C_{1}} i_{L 1}-\frac{1}{C_{1}} i_{L 2} \\
& \frac{d v_{o}}{d t}=\frac{1}{C_{2}} i_{L 1}-\frac{1}{C_{2} R} v_{o}
\end{aligned}
$$

The modified boost converter's switch-off state equation (4-22) contains the four state-variable differential equations in matrix form.

$$
\left[\begin{array}{c}
\frac{d i_{L 1}}{d t} \\
\frac{d i_{L 2}}{d t} \\
\frac{d v_{C 1}}{d t} \\
\frac{d v_{o}}{d t}
\end{array}\right]=\left[\begin{array}{cccc}
0 & 0 & -\frac{1}{L_{1}} & -\frac{1}{L_{1}} \\
0 & 0 & \frac{1}{L_{2}} & 0 \\
\frac{1}{C_{1}} & -\frac{1}{C_{1}} & 0 & 0 \\
\frac{1}{C_{2}} & 0 & 0 & -\frac{1}{C_{2} R}
\end{array}\right]\left[\begin{array}{c}
i_{L 1} \\
i_{L 2} \\
v_{C 1} \\
v_{o}
\end{array}\right]+\left[\begin{array}{c}
\frac{1}{L_{1}} \\
0 \\
0 \\
0
\end{array}\right] V_{I N}
$$

Summing the modified boost converter's state equations, weighted by their switching period fraction, produces the average state equation (4-23).

$$
\left[\begin{array}{l}
\frac{d i_{L 1}}{d t} \\
\frac{d i_{L 2}}{d t} \\
\frac{d v_{C 1}}{d t} \\
\frac{d v_{o}}{d t}
\end{array}\right]=D \cdot A_{\text {switch-on }}\left[\begin{array}{c}
i_{L 1} \\
i_{L 2} \\
v_{C 1} \\
v_{o}
\end{array}\right]+(1-D) \cdot A_{\text {switch-off }}\left[\begin{array}{c}
i_{L 1} \\
i_{L 2} \\
v_{C 1} \\
v_{o}
\end{array}\right]+\left[\begin{array}{c}
\frac{1}{L_{1}} \\
0 \\
0 \\
0
\end{array}\right] V_{I N}(4-23)
$$




$$
\begin{aligned}
A_{\text {switch-on }} & =\left[\begin{array}{cccc}
0 & 0 & -\frac{1}{L_{1}} & -\frac{1}{L_{1}} \\
0 & 0 & \frac{1}{L_{2}} & \frac{1}{L_{2}} \\
\frac{1}{C_{1}} & -\frac{1}{C_{1}} & 0 & 0 \\
\frac{1}{C_{2}} & -\frac{1}{C_{2}} & 0 & -\frac{1}{C_{2} R}
\end{array}\right] \\
A_{\text {switch-off }} & =\left[\begin{array}{cccc}
0 & 0 & -\frac{1}{L_{1}} & -\frac{1}{L_{1}} \\
0 & 0 & \frac{1}{L_{2}} & 0 \\
\frac{1}{C_{1}} & -\frac{1}{C_{1}} & 0 & 0 \\
\frac{1}{C_{2}} & 0 & 0 & -\frac{1}{C_{2} R}
\end{array}\right]
\end{aligned}
$$

The differentials approach zero as the state variables reach their DC value.

$$
\left[\begin{array}{l}
\frac{d i_{L 1}}{d t} \\
\frac{d i_{L 2}}{d t} \\
\frac{d v_{C 1}}{d t} \\
\frac{d v_{o}}{d t}
\end{array}\right]=\left[\begin{array}{l}
0 \\
0 \\
0 \\
0
\end{array}\right]
$$

Solving the averaged $\mathrm{L}_{1}$ current equation (4-24) and the averaged $\mathrm{L}_{2}$ current equation (4-25) determine the relationships between the circuit's average voltages (4-25 and 4-27).

$$
\begin{array}{cc}
-\frac{D}{L_{1}}\left(V_{C 1}+V_{\text {OUT }}\right)-\frac{(1-D)}{L_{1}}\left(V_{C 1}+V_{\text {OUT }}\right)+\frac{1}{L_{1}} V_{I N}=0 & (4-24) \\
V_{I N}=V_{C 1}+V_{\text {OUT }} & (4-25) \\
\frac{D}{L_{2}}\left(V_{C 1}+V_{\text {OUT }}\right)+\frac{(1-D)}{L_{2}} V_{C 1}=0 \\
V_{C 1}=-D V_{\text {OUT }}
\end{array}
$$


Consolidating both relationships produces the modified boost converter's DC transfer function (4-28).

$$
V_{\text {OUT }}=\frac{V_{I N}}{(1-D)}
$$

Solving the average C1 voltage equation (4-29) demonstrates the equality between the average inductor currents (4-30).

$$
\begin{array}{cc}
\frac{D}{C_{1}}\left(I_{I N}-I_{L 2}\right)+\frac{(1-D)}{C_{1}}\left(I_{I N}-I_{L 2}\right)=0 & (4-29) \\
I_{I N}=I_{L 2} & (4-30)
\end{array}
$$

Considering the equality of the average inductor currents while solving the average $\mathrm{C}_{2}$ voltage equation (4-31) yields the DC current transfer function (4-32).

$$
\begin{gathered}
\frac{D}{C_{2}}\left(I_{I N}-I_{L 2}-\frac{V_{O U T}}{R}\right)+\frac{(1-D)}{C_{2}}\left(I_{I N}-\frac{V_{O U T}}{R}\right)=0 \\
I_{I N}=\frac{I_{O U T}}{(1-D)}
\end{gathered}
$$

The modified boost converter's DC transfer functions match the standard boost topology, demonstrating functional equality. On average, both converters share the same relationships between switch duty cycle and input and output quantities.

\subsection{Steady-State m-Domain State Equations}

During steady-state operation, a DC/DC converter returns to the same state at the beginning of each switching cycle. The switch-on and switch-off state equations each govern a portion of the cycle. Modeling the switching transition creates a unified, periodic state equation. An $m$-domain state equation describes the converter's behavior over a generalized switching cycle. 
Independent variable transformation (4-33) partitions the time domain into a set of discrete switching cycles in the $m$-domain [33].

$$
\begin{gathered}
t=(n+m) T \\
n=0,1,2,3, \ldots \\
0 \leq m<1
\end{gathered}
$$

Applying the transformation reduces a periodic, time-domain differential equation (4-34) into an $m$-domain differential equation (4-35) describing the $n^{\text {th }}$ time-domain cycle.

$$
\begin{gathered}
\frac{d x(t)}{d t}=x(t) \\
\frac{d x_{n}(m)}{d m}=x_{n}(m) \cdot T
\end{gathered}
$$

The transformation also simplifies the converter's switching transition model. Transitions in the time domain occur relative to the switching period and duty cycle. However, $m$-domain switching transitions depend only on duty cycle, allowing a simple piecewise function to model the transition. Figure 4-8 illustrates this difference.

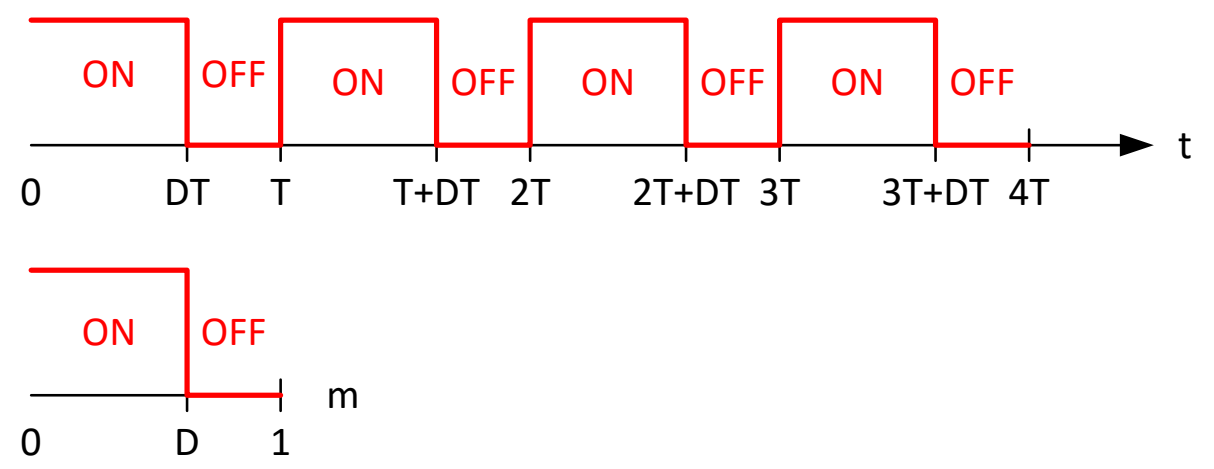

Figure 4-8. Time-domain and $m$-domain Switching Transitions 


\subsubsection{Standard Boost Converter}

The standard boost converter's switch-off state equation (4-6) contains two terms not present in the switch-on state equation (4-3). Applying the standard boost switching function (4-36) to the switch-off equation models the transition in the $m$-domain.

$$
f_{b}(m)=\left\{\begin{array}{l}
0, \text { for } 0 \leq m<D \\
1, \text { for } D \leq m<1
\end{array}\right.
$$

The standard boost $m$-domain state equation (4-37) describes the converter's behavior during a generalized, steady-state switching cycle.

$$
\left[\begin{array}{c}
\frac{d i_{L, n}}{d m} \\
\frac{d v_{o, n}}{d m}
\end{array}\right]=\left[\begin{array}{cc}
0 & -f_{b}(m) \frac{T}{L} \\
f_{b}(m) \frac{T}{C} & -\frac{T}{C R}
\end{array}\right]\left[\begin{array}{c}
i_{L, n} \\
v_{o, n}
\end{array}\right]+\left[\begin{array}{c}
\frac{T}{L} \\
0
\end{array}\right] V_{I N}
$$

\subsubsection{Modified Boost Converter}

The modified boost switch-on state equation (4-17) contains two terms not present in the switch-off state equation (4-18). Applying the modified boost switching function (4-38) to the switch-on equation models the transition in the $m$-domain.

$$
f_{m b}(m)=\left\{\begin{array}{l}
1, \text { for } 0 \leq m<D \\
0, \text { for } D \leq m<1
\end{array}\right.
$$

The modified boost $m$-domain state equation (4-39) describes the converter's behavior during a generalized, steady-state switching cycle.

$$
\left[\begin{array}{c}
\frac{d i_{L 1, n}}{d m} \\
\frac{d i_{L 2, n}}{d m} \\
\frac{d v_{C 1, n}}{d m} \\
\frac{d v_{o, n}}{d m}
\end{array}\right]=\left[\begin{array}{cccc}
0 & 0 & -\frac{T}{L_{1}} & -\frac{T}{L_{1}} \\
0 & 0 & \frac{T}{L_{2}} & f_{m b}(m) \frac{T}{L_{2}} \\
\frac{T}{C_{1}} & -\frac{T}{C_{1}} & 0 & 0 \\
\frac{T}{C_{2}} & -f_{m b}(m) \frac{T}{C_{2}} & 0 & -\frac{T}{C_{2} R}
\end{array}\right]\left[\begin{array}{c}
i_{L 1, n} \\
i_{L 2, n} \\
v_{C 1, n} \\
v_{o, n}
\end{array}\right]+\left[\begin{array}{c}
\frac{T}{L_{1}} \\
0 \\
0 \\
0
\end{array}\right] V_{I N}(4-39)
$$




\subsection{Numerical m-Domain State Equation Solutions}

Matlab's ode45 function provides numerical state equation solutions. Solving the system of first-order differential equations requires initial conditions (ICs). State variable average values, obtained through circuit analysis, provide initial condition estimates. Under steady-state conditions, each state variable's final value during the switch-off state equals its initial value during the switch-on state. Iteration gradually reduces the solutions' steady-state error; the difference between final switch-off value and initial switch-on value.

\subsubsection{Initial Condition Estimates}

A converter's state variable averages depend on the average voltages and currents associated with its reactive components. During steady-state operation, the average voltage across an inductor and the average current through a capacitor both approach zero. Under these conditions, the average inductor currents and capacitor voltages relate to the converter's known input and output parameters.

Table 4-1 summarizes the average voltage and current associated with the standard boost converter's inductor and capacitor.

Table 4-1. Standard Boost Converter Component Averages

\begin{tabular}{|c|c|c|}
\hline Component & Voltage & Current \\
\hline L & $0 \mathrm{~V}$ & IIN \\
\hline $\mathrm{C}$ & VouT & $0 \mathrm{~A}$ \\
\hline
\end{tabular}

Table 4-2 summarizes the average voltage and current associated with the modified boost converter's reactive components. 
Table 4-2. Modified Boost Converter Component Averages

\begin{tabular}{|c|c|c|}
\hline Component & Voltage & Current \\
\hline $\mathrm{L}_{1}$ & $0 \mathrm{~V}$ & $\mathrm{I}_{\mathrm{IN}}$ \\
\hline $\mathrm{L}_{2}$ & $0 \mathrm{~V}$ & $\mathrm{I}_{\mathrm{IN}}$ \\
\hline $\mathrm{C}_{1}$ & $\mathrm{~V}_{\text {IN }}-\mathrm{V}_{\text {OUT }}$ & $0 \mathrm{~A}$ \\
\hline $\mathrm{C}_{2}$ & $\mathrm{~V}_{\text {OUT }}$ & $0 \mathrm{~A}$ \\
\hline
\end{tabular}

Table 4-3 lists the estimated initial condition for each state variable in the standard and modified boost converters, based on functional requirements and the associated DC transfer functions.

Table 4-3. State Equation Initial Condition Estimates

\begin{tabular}{|c|c|c|c|}
\hline \multicolumn{2}{|c|}{ Standard Boost Converter } & \multicolumn{2}{c|}{ Modified Boost Converter } \\
\hline State Variable & Estimate & State Variable & Estimate \\
\hline \multirow{2}{*}{$\mathrm{i}_{\mathrm{L}}$} & \multirow{2}{*}{$5 \mathrm{~A}$} & $\mathrm{i}_{\mathrm{L} 1}$ & $5 \mathrm{~A}$ \\
\cline { 2 - 4 } & \multirow{2}{*}{$\mathrm{v}_{\mathrm{O}}$} & $\mathrm{i}_{\mathrm{L} 2}$ & $5 \mathrm{~A}$ \\
\hline \multirow{2}{*}{$20 \mathrm{~V}$} & $\mathrm{v}_{\mathrm{C} 1}$ & $-14 \mathrm{~V}$ \\
\cline { 2 - 4 } & & $\mathrm{v}_{\mathrm{O}}$ & $20 \mathrm{~V}$ \\
\hline
\end{tabular}

These functional converter design parameters provide reasonable initial condition estimates that allow the iterative state equation solution to converge.

\subsubsection{Iterative State Equation Solution}

Custom Matlab functions implement the iterative state equation solution process for both the standard and modified boost converters. Each function requires converter design information, including component values, switching period, input voltage, output voltage, and output power. Component values and switching period populate the state equation matrices, while input-output parameters provide the initial condition estimates for each state variable. The scripts decouple the state equation into switch-on and switchoff equations, facilitating Matlab's ode45 function, and return the concatenated solution over the $m$-domain after iteration converges. 
Figure 4-9 depicts the iteration process, controlled by the steady-state error. Once the final state variable values of the switch-off solution match the initial values of the switch-on solution, within $0.0001 \%$, the function stops iterating.

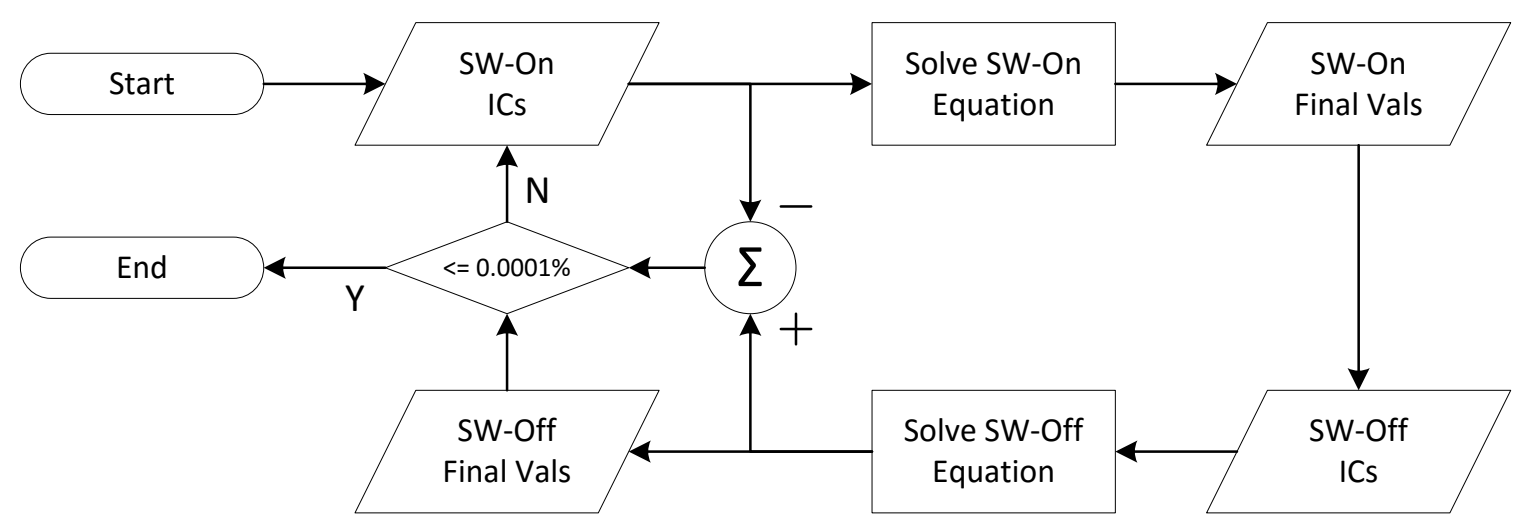

Figure 4-9. Iterative Numerical State Equation Solution

APPENDICES

MA contains the Matlab files boost_cycle.m and boost_mod_cycle.m, which implement the iterative state equation solution functions for the standard and modified boost converters.

\subsection{Modified Boost Design Process}

The baseline design restricts modified boost converter design choices. These parameters, detailed in Chapter 3, set switching frequency and output capacitance $\left(\mathrm{C}_{2}\right)$ directly and constrain the modified topology's total inductance. Dividing the specified total inductance between $\mathrm{L}_{1}$ and $\mathrm{L}_{2}$, and sizing the additional capacitor $\mathrm{C}_{1}$ remain the only topology design choices.

Design constraints limit the converter's total inductance at $10 \mu \mathrm{H}$, the sum of $\mathrm{L}_{1}$ and $\mathrm{L}_{2}$. This design process considers three allocations of $10 \mu \mathrm{H}$ between $\mathrm{L}_{1}$ and $\mathrm{L}_{2}$ : a 50/50 split, a 25/75 split, and a 75/25 split. Converter resonant frequencies and physical 
size limit the $\mathrm{C}_{1}$ value range. The converter's resonant behavior determines the minimum $\mathrm{C}_{1}$ value keeping the highest resonant frequency below the $200-\mathrm{kHz}$ switching frequency. Setting the maximum $\mathrm{C}_{1}$ value at $50 \mu \mathrm{F}$, the specified converter output capacitance, limits the modified boost converter's additional physical size. Matlab informs final component value selection, based on input current ripple performance predicted by the numerical state space equation solutions.

\subsubsection{Resonant Frequencies}

The modified boost converter topology complicates resonant frequency analysis. The standard topology contains one resonance during the switch-off state. Inspection suggests multiple resonances in the modified boost converter during the switch-of state. Figure 4-10 illustrates an AC simulation of the modified boost converter's switch-on and switch-off circuits used to observe the converter's resonant frequencies.

Each circuit's input impedance characteristics indicate resonant behavior. Figure

4-11 portrays the switch-on circuit's two resonant frequencies and the switch-off circuit's three resonant frequencies with $\mathrm{C}_{1}$ equal to $1 \mu \mathrm{F}$. The impedance curves align at higher frequencies, suggesting the circuits share two similar resonances. However, these resonant frequencies do not match exactly; they separate as $C_{1}$ value increases. 


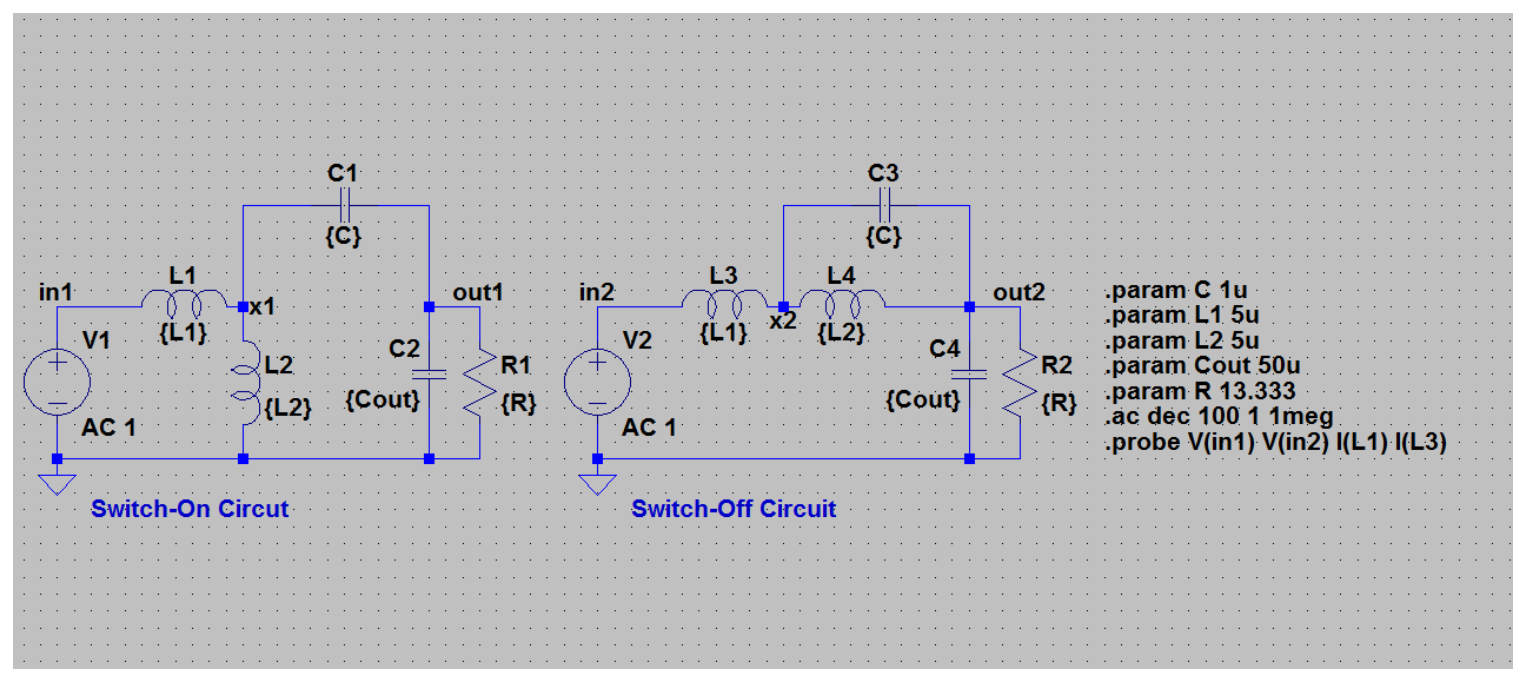

Figure 4-10. LTSpice Modified Boost Converter Resonance Simulation

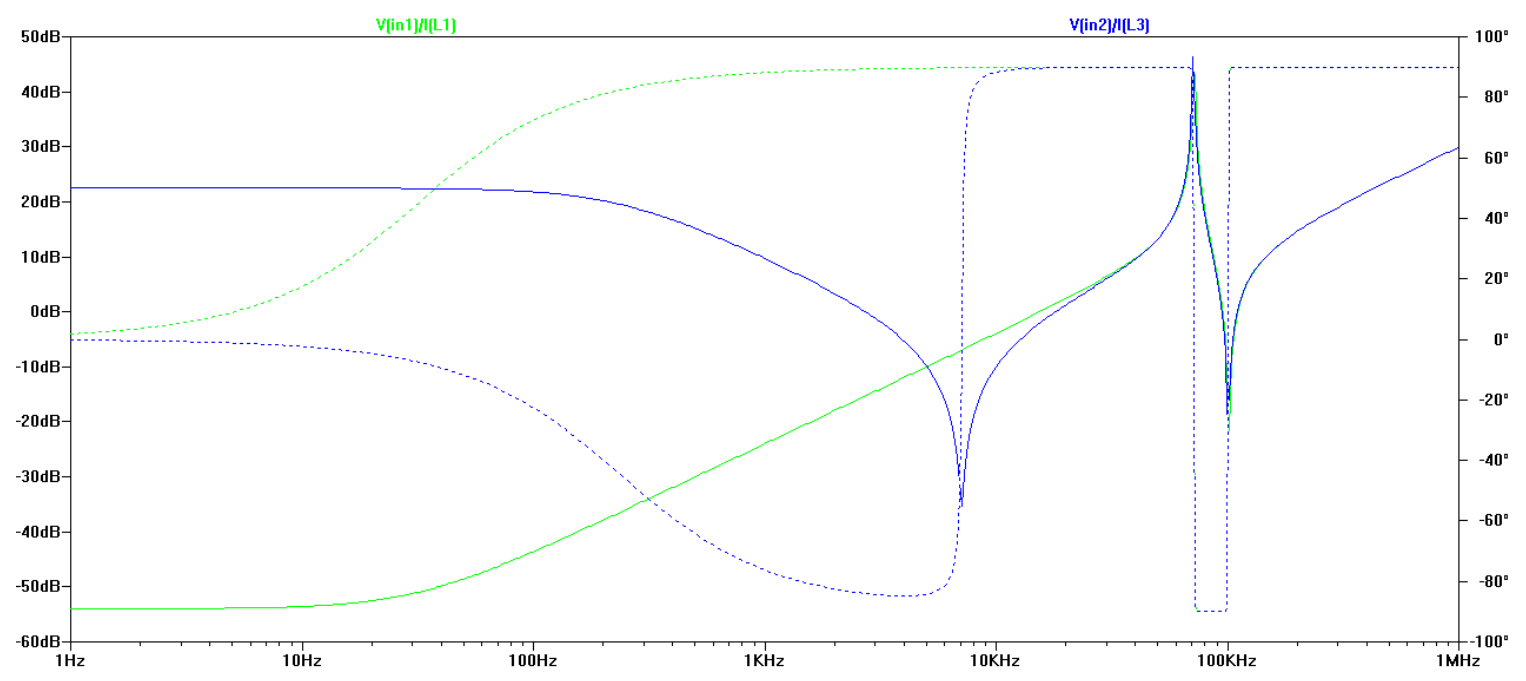

Figure 4-11. LTSpice Modified Boost Converter Simulated Input Impedance

Figure 4-12 plots the converter's highest resonant frequency, obtained from the

Figure 4-10 simulation, over a range of $C_{1}$ values. These data suggest $C_{1}$ values greater than $1 \mathrm{uF}$ prevent the converter's maximum resonant frequency from exceeding the 200$\mathrm{kHz}$ switching frequency. The data also indicate that the inductance split between $\mathrm{L}_{1}$ and $\mathrm{L}_{2}$ impacts resonant frequency less as $\mathrm{C}_{1}$ value approaches output capacitance value. 


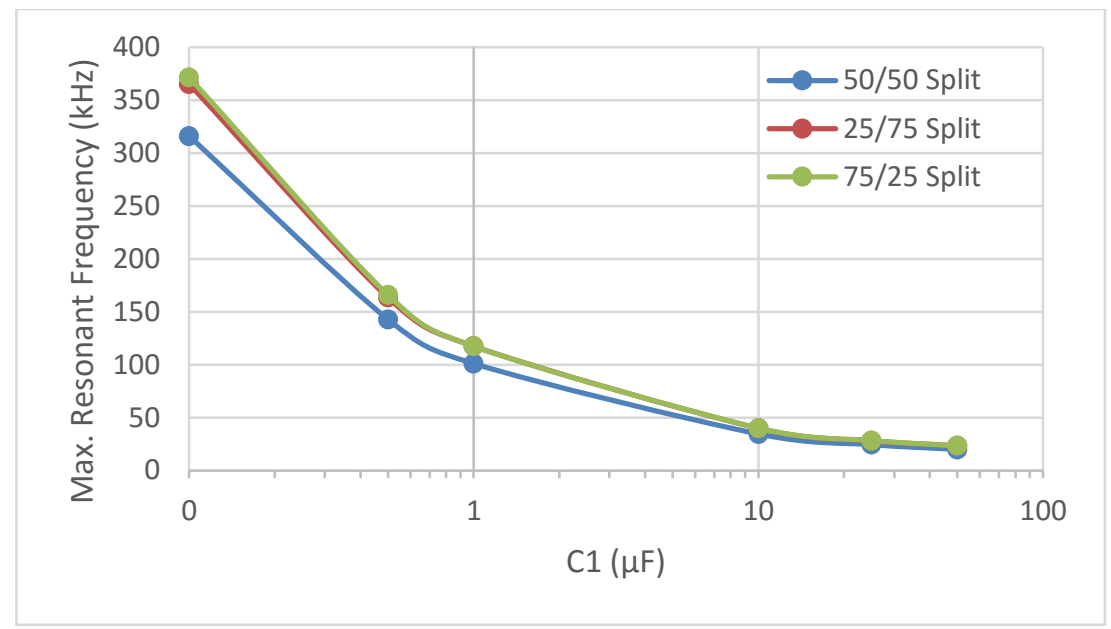

Figure 4-12. Max. Modified Boost Resonant Frequency versus $\mathrm{C}_{1}$ Value

\subsubsection{Component Sizing}

The $\mathrm{L}_{1}$ current state variable predicts the converter's input current ripple performance. Matlab provides the numerical state equation solution, calculating ripple performance using the maximum, minimum, and average $\mathrm{L}_{1}$ current values. Appendix $\mathrm{A}$ contains the script boost_mod_design_comp.m, executing these calculations for all three $\mathrm{L}_{1} / \mathrm{L}_{2}$ inductance splits over the selected $\mathrm{C}_{1}$ value range. Figure $4-13$ charts the converter's performance based on component sizing.

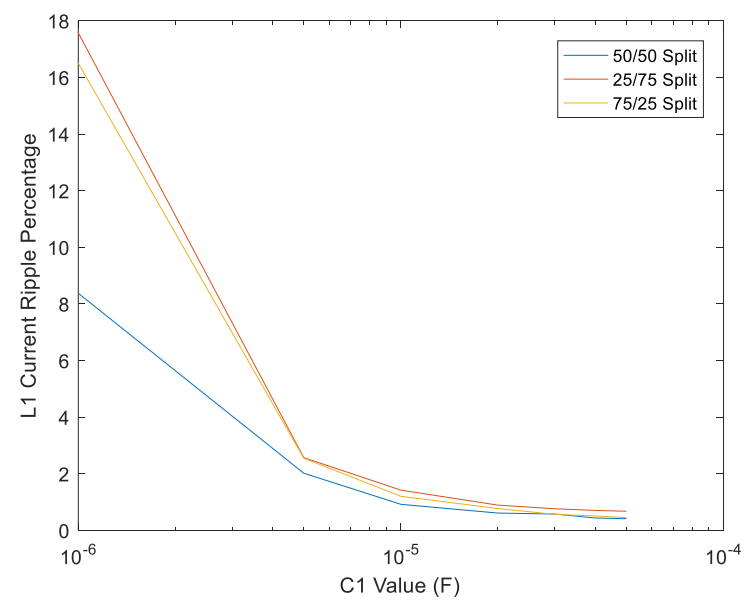

Figure 4-13. Modified Boost Converter Component Sizing Chart 
These performance predictions agree with a simplistic explanation of the input current ripple. A larger $\mathrm{C}_{1}$ value reduces the voltage ripple across $\mathrm{L}_{1}$, and smaller $\mathrm{v}_{\mathrm{L} 1}$ changes induce smaller $\mathrm{i}_{\mathrm{L} 1}$ changes. The $\mathrm{L}_{1} / \mathrm{L}_{2}$ inductance split's impact on current ripple performance and maximum resonant frequency decrease as $\mathrm{C}_{1}$ value approaches output capacitance value. Selecting a 50/50 inductance split simplifies component selection. Table 4-4 lists the modified boost converter design parameters chosen based on predicted input current ripple performance.

Table 4-4. Modified Boost Converter Component Values

\begin{tabular}{|c|c|}
\hline Component & Selected Nominal Value \\
\hline $\mathrm{L}_{1}$ & $5 \mu \mathrm{H}$ \\
\hline $\mathrm{L}_{2}$ & $5 \mu \mathrm{H}$ \\
\hline $\mathrm{C}_{1}$ & $30 \mu \mathrm{F}$ \\
\hline $\mathrm{C}_{2}$ & $50 \mu \mathrm{F}$ \\
\hline
\end{tabular}

\subsection{Design Simulation}

The numerical state equation solution method provides limited design simulation by directly solving for each state variable over a single, steady-state switching cycle. These waveforms provide all necessary information, either directly or indirectly, to physically implement the converter. Given specific converter design parameters, a Matlab-simulation script performs iterative state equation solution, plots the state variable waveforms, and calculates relevant state variable measurements indicating converter performance. Comparing each converter's Matlab-simulation against theoretical DC performance and a complementary LTSpice simulation, evaluates the $m$-domain state equation model's efficacy. Table 4-5 summarizes the simulated converter designs, including functional parameters and component values. Section 4.5.3 compares both simulation technique's relevant converter performance measurements. 
Table 4-5. Converter Design Parameter Summary

\begin{tabular}{|c|c|c|c|}
\hline \multicolumn{2}{|c|}{ Standard Boost Design } & \multicolumn{2}{c|}{ Modified Boost Design } \\
\hline $\mathrm{V}_{\text {IN }}$ & $6 \mathrm{~V}$ & $\mathrm{~V}_{\text {IN }}$ & $6 \mathrm{~V}$ \\
\hline $\mathrm{V}_{\text {OUT }}$ & $20 \mathrm{~V}$ & $\mathrm{~V}_{\text {OUT }}$ & $20 \mathrm{~V}$ \\
\hline PoUT $_{\text {OUT }}$ & $30 \mathrm{~W}$ & PoUT & $30 \mathrm{~W}$ \\
\hline $\mathrm{fSW}_{\mathrm{SW}}$ & $200 \mathrm{kHz}$ & $\mathrm{f}_{\mathrm{SW}}$ & $200 \mathrm{kHz}$ \\
\hline $\mathrm{R}$ & $13.333 \Omega$ & $\mathrm{R}$ & $13.333 \Omega$ \\
\hline \multirow{2}{*}{$\mathrm{L}$} & \multirow{2}{*}{$10 \mu \mathrm{H}$} & $\mathrm{L}_{1}$ & $5 \mu \mathrm{H}$ \\
\cline { 3 - 4 } & \multirow{2}{*}{$50 \mu \mathrm{F}$} & $\mathrm{L}_{2}$ & $5 \mu \mathrm{H}$ \\
\hline \multirow{2}{*}{$\mathrm{C}$} & & $\mathrm{C}_{1}$ & $30 \mu \mathrm{F}$ \\
\hline & & $\mathrm{C}_{2}$ & $50 \mu \mathrm{F}$ \\
\hline
\end{tabular}

\subsubsection{Matlab Simulation}

The boost_sim.m script in Appendix A simulates the standard boost design's performance. Figure 4-14 portrays the Matlab-simulated inductor current and capacitor voltage in the standard boost converter design. The simulated waveforms take the expected shape Section 2.5.5 presents.
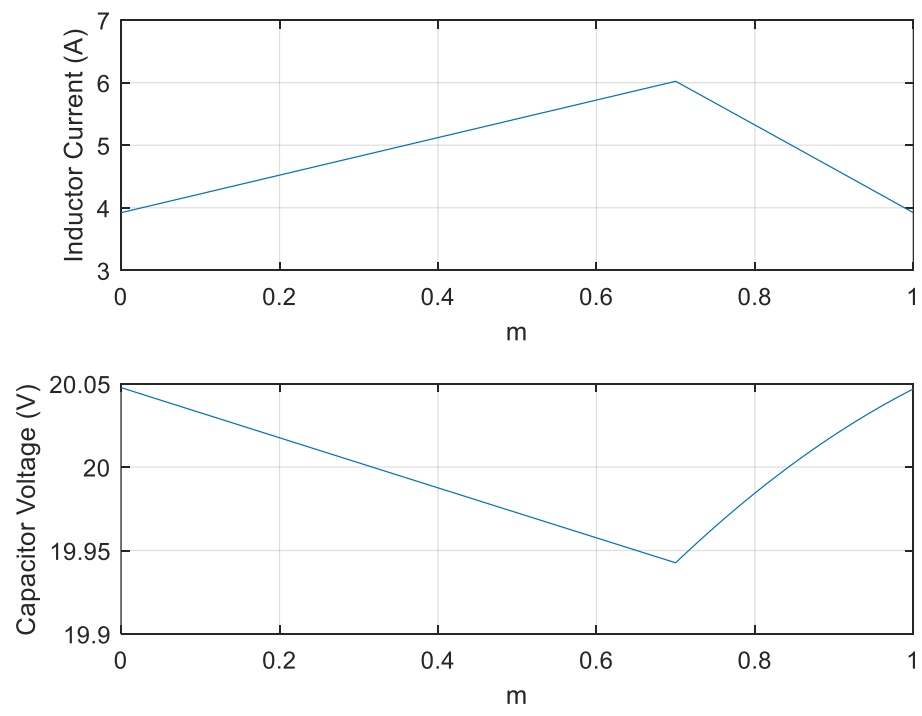

Figure 4-14. Matlab State Variable Waveforms for Standard Boost 
Table 4-6 compares relevant Matlab simulation measurements and theoretical standard boost converter design values. The simulated average state variable values match theoretical values within one percent, while the peak-to-peak and percent ripple values match to five percent error. Appendix B contains complete standard boost measurements obtained through Matlab-simulation.

Table 4-6. Matlab and Theoretical Standard Boost Design Performance

\begin{tabular}{|c|c|c|c|c|c|c|}
\hline \multirow{2}{*}{} & \multicolumn{3}{|c|}{ Inductor Current (A) } & \multicolumn{3}{c|}{ Capacitor Voltage (V) } \\
\cline { 2 - 7 } & Matlab & Theory & $\%$ Diff & Matlab & Theory & $\%$ Diff \\
\hline Average & 4.9591 & 5 & $-0.818 \%$ & 19.998 & 20 & $-0.01 \%$ \\
\hline Peak-Peak & 2.1 & 2 & $5 \%$ & 0.105 & 0.1 & $5 \%$ \\
\hline \% Ripple & $42.346 \%$ & $40 \%$ & $5.865 \%$ & $0.5249 \%$ & $0.5 \%$ & $4.98 \%$ \\
\hline
\end{tabular}

The boost_mod_sim.m script in Appendix A simulates the modified boost design's performance. Figure 4-15 presents the simulated inductor current waveforms, demonstrating agreement between the state equation model and the simplistic circuit analysis. The voltage across L1 approaches zero, and the small voltage ripple produced by current through $\mathrm{C} 1$ induces small current ripple through L1. The voltage across L2 approaches the standard boost converter's inductor voltage, but at half the total inductance of the standard boost design, L2 experiences twice the current ripple. These waveforms indicate the modified design's ability to contain switching noise, presenting only a small current ripple at the converter input.

Figure 4-16 depicts both capacitor voltage waveforms, demonstrating voltage ripple performance comparable to the standard boost design. The iterative state equation solution method favors minimizing $\mathrm{L}_{1}$ current's steady-state error, the difference between initial and final values, based on the state design goal. Both capacitor voltage waveforms suffer larger steady-state error due to the chosen hierarchy. 

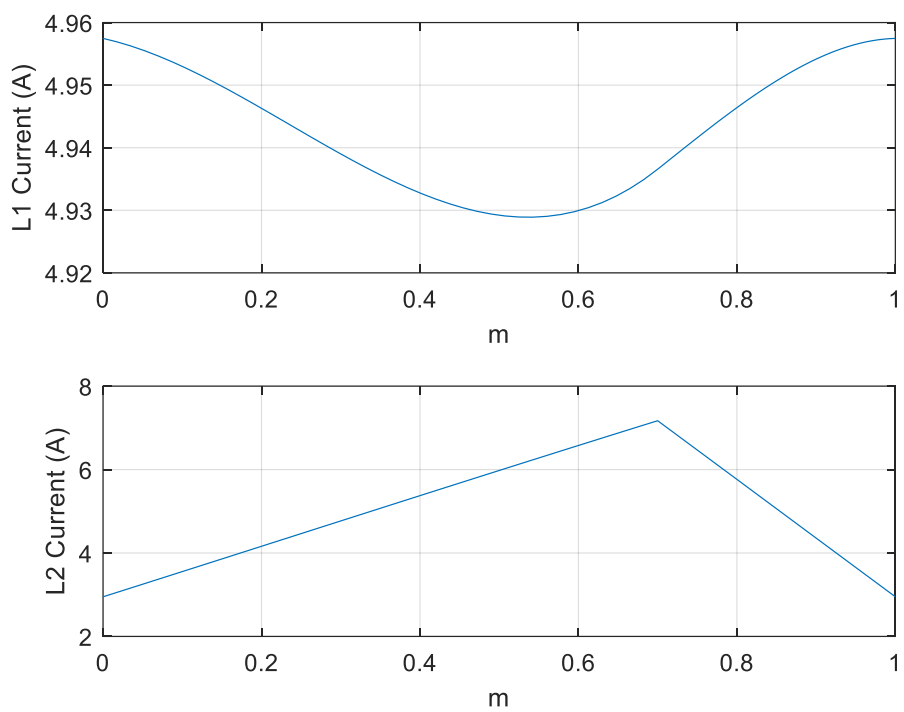

Figure 4-15. Matlab Modified Boost Inductor Current Waveforms
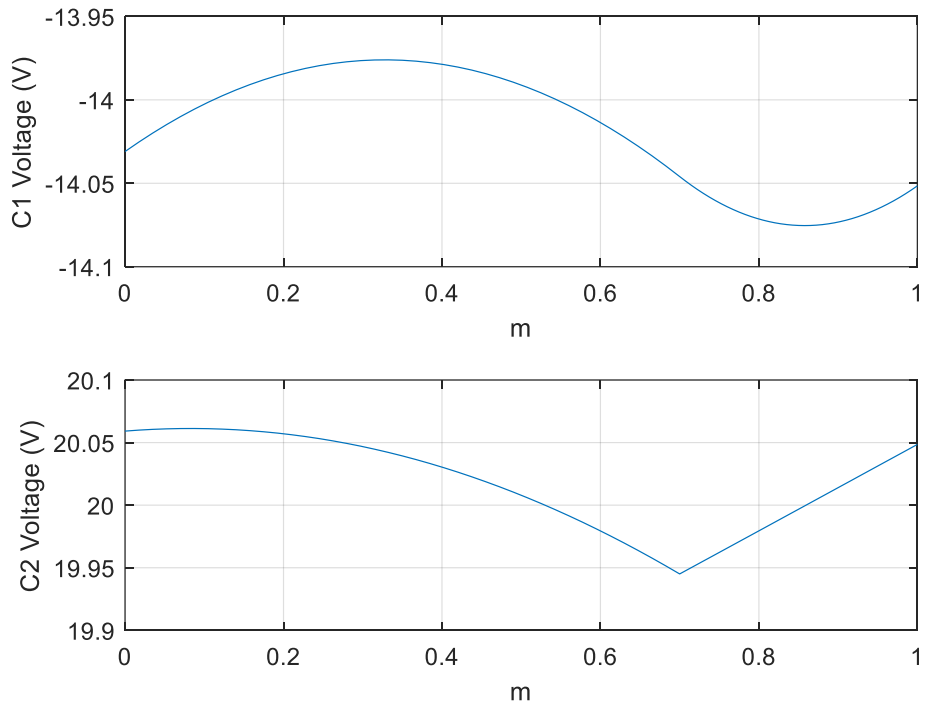

Figure 4-16. Matlab Modified Boost Capacitor Voltage Waveforms

The simulation script determines capacitor current waveforms calculated from inductor current solutions and the known DC output current, using KCL relationships during each switching state. Figure 4-17 shows simulated capacitor current waveforms which help determine capacitor current ratings. Under ideal steady-state conditions, average capacitor current approaches zero. These waveforms exhibit non-zero averages 
and indicate the Matlab-simulation's functional limitations; small state variable solution error compounds through further calculation required to determine related waveforms.
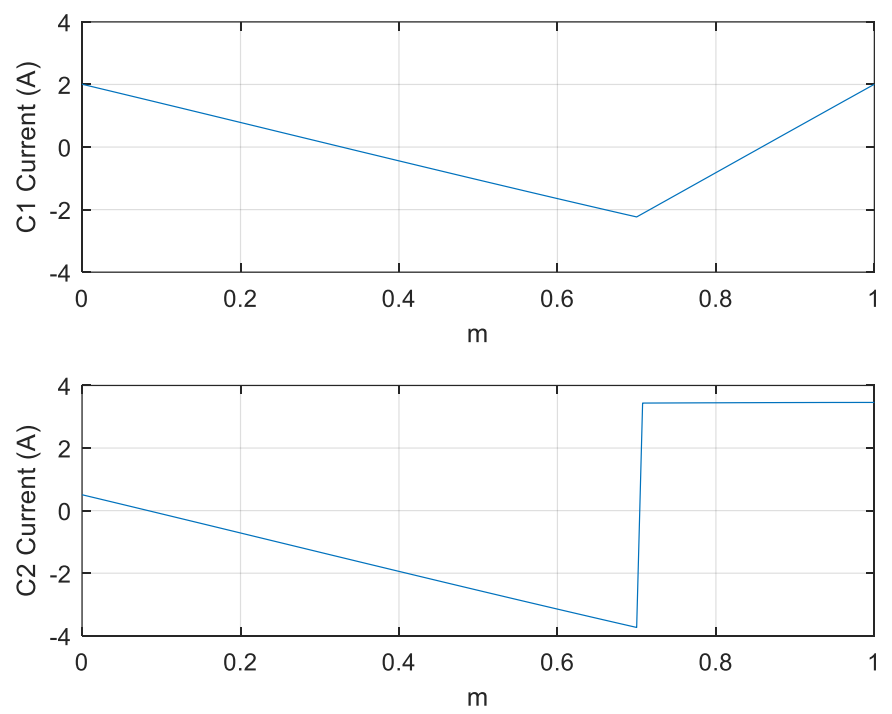

Figure 4-17. Matlab Modified Boost Capacitor Current Waveforms

Table 4-7 compares simulated average state variable values and theoretical state variable averages derived from DC circuit analysis and functional converter parameters. Despite favoring minimal inductor current steady-state error, the Matlab simulation predicts average state variable values within approximately one percent of theory. Appendix B contains complete Matlab simulation performance measurements.

Table 4-7. Matlab and Theoretical Modified Boost Design DC Performance

\begin{tabular}{|c|c|c|c|c|}
\hline & L $_{\mathbf{1}}$ Current (A) & L $_{2}$ Current (A) & C $_{1}$ Voltage $(\mathbf{V})$ & C $_{2}$ Voltage (V) \\
\hline Matlab & 4.9446 & 5.0384 & -14.032 & 20.012 \\
\hline Theory & 5 & 5 & -14 & 20 \\
\hline \%Diff & $-1.108 \%$ & $0.768 \%$ & $0.2286 \%$ & $0.6 \%$ \\
\hline
\end{tabular}




\subsubsection{LTSpice Simulation}

LTSpice transient simulations provide complete benchmark comparison against the Matlab-based simulations. Both converter spice simulations use non-ideal switches and open-loop PWM control. The measure command captures the relevant converter performance data over the simulation's final $50 \mathrm{~ms}$, ten switching cycles; average and peak-to-peak measurements determine Spice-simulated ripple percentage. Appendix B contains complete LTSpice performance measurements for both standard and modified boost designs.

Figure 4-18 depicts the LTSpice transient simulation of the standard boost converter design. Figure 4-19 shows the standard boost state variable waveforms over the transient simulation's final ten switching cycles. These waveforms indicate approximate ripple performance similar to the Matlab simulation.

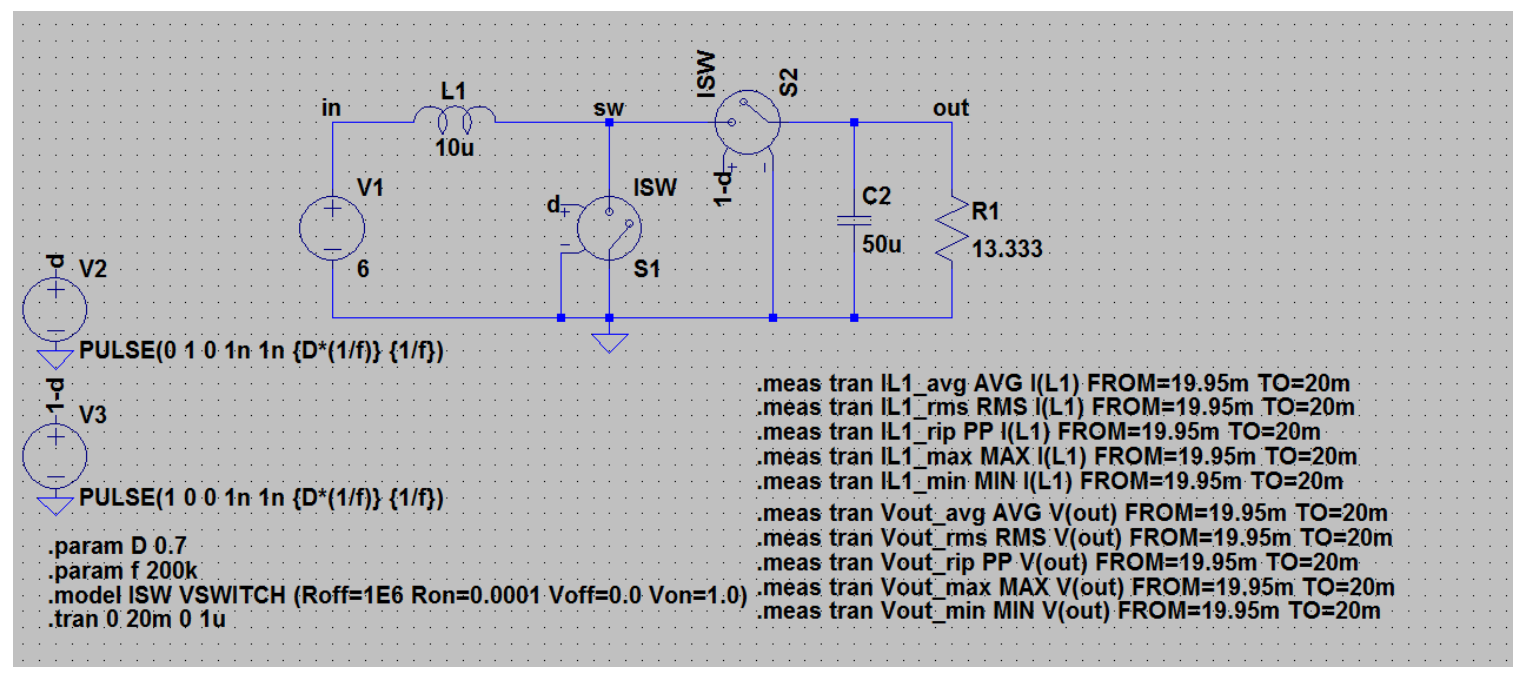

Figure 4-18. LTSpice Standard Boost Transient Simulation 


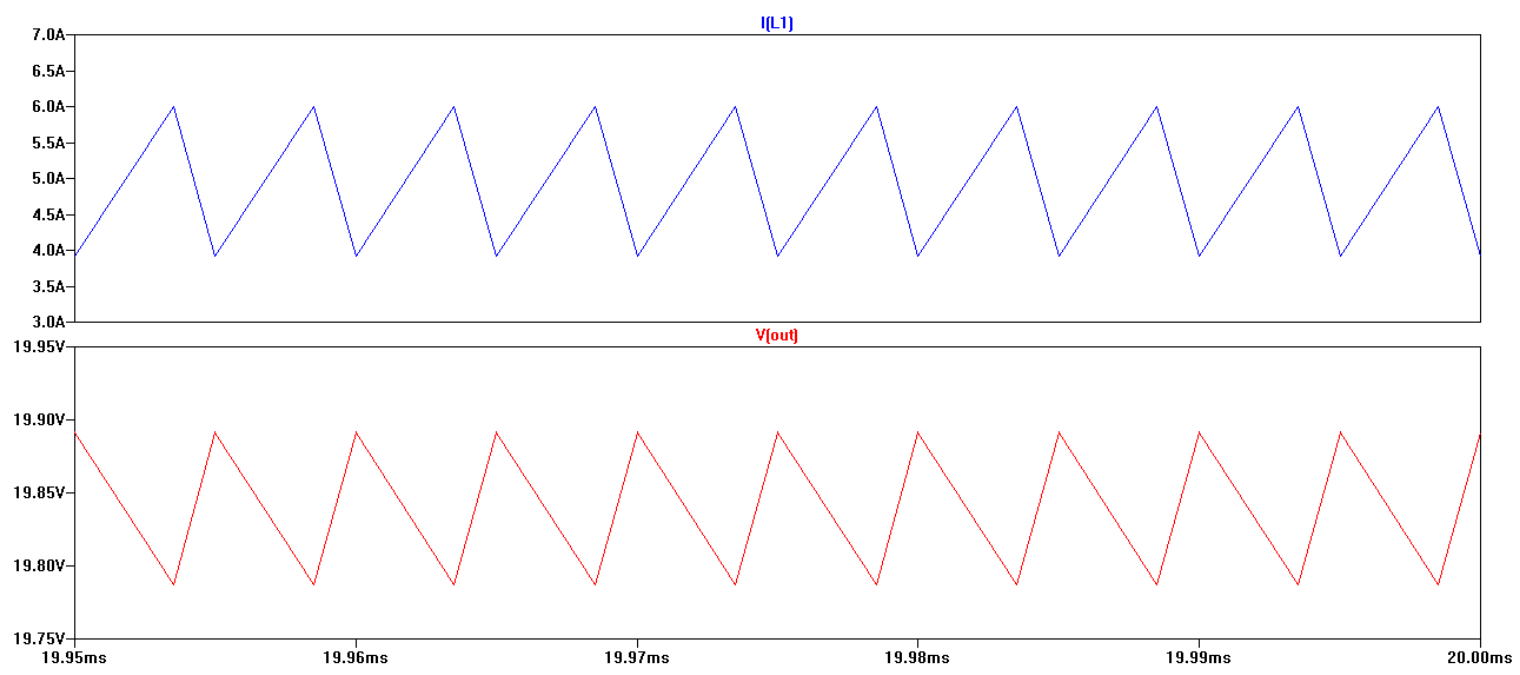

Figure 4-19. LTSpice State Variable Waveforms for Standard Boost

Figure 4-20 shows the LTSpice transient simulation for the modified boost

converter design. Figure 4-21 presents the LTSpice modified boost inductor current waveforms, again demonstrating the design's small input current ripple. LTSpice also predicts $\mathrm{L}_{2}$ current ripple twice the standard boost design's value.

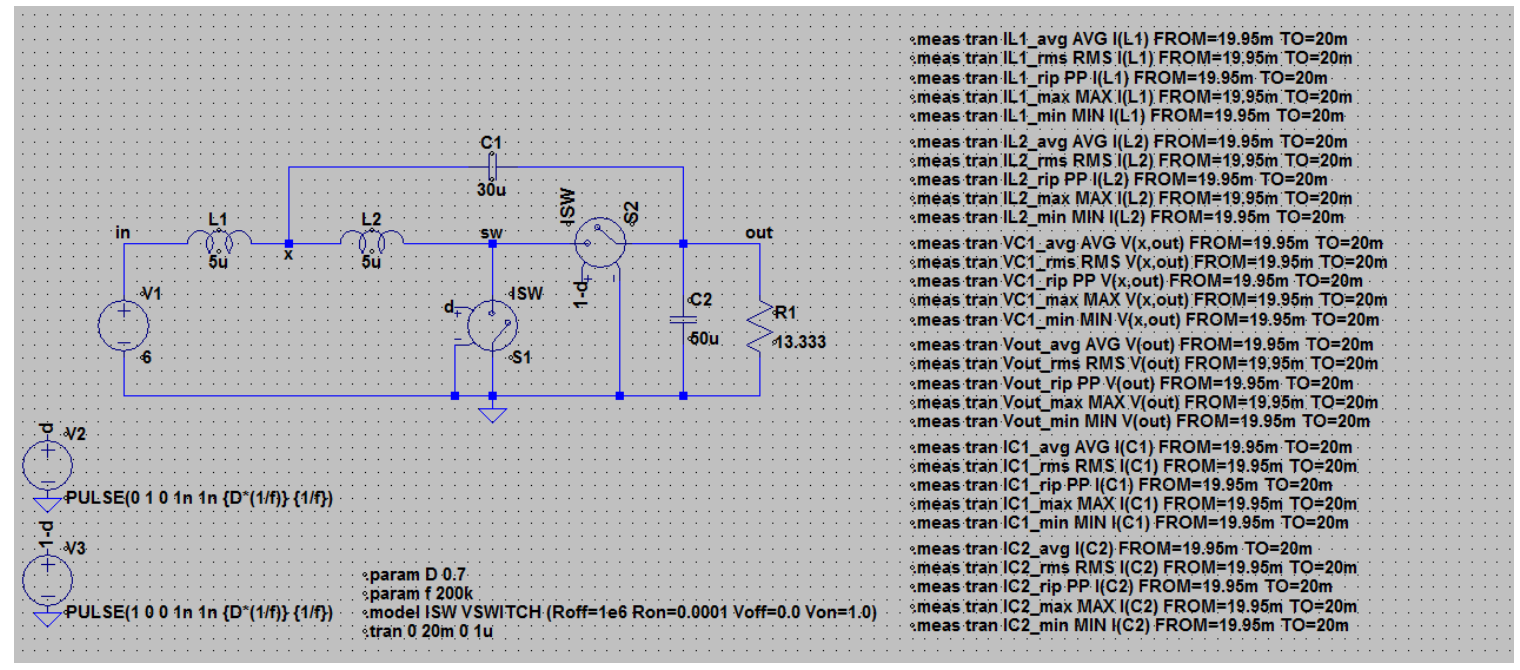

Figure 4-20. LTSpice Modified Boost Transient Simulation 


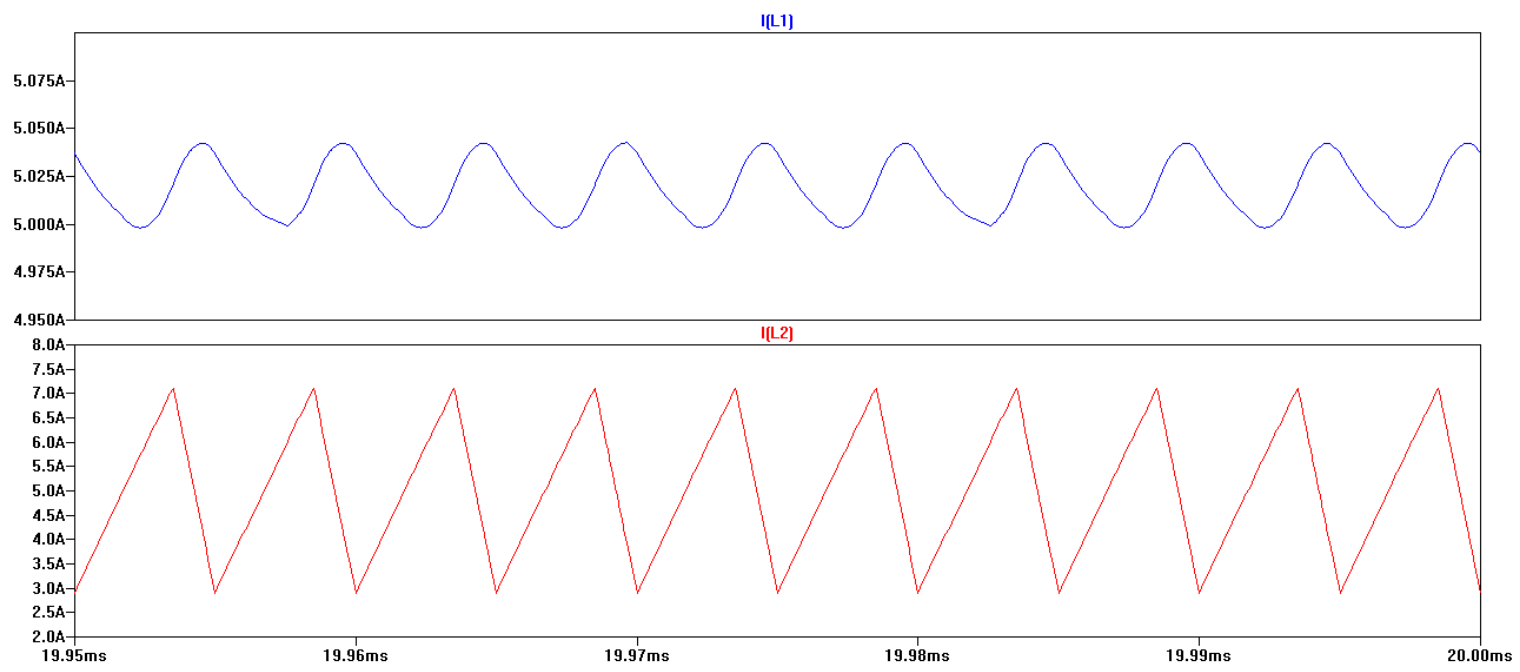

Figure 4-21. LTSpice Modified Boost Inductor Current Waveforms

Figure 4-22 depicts the modified boost capacitor waveforms, demonstrating output capacitor voltage ripple equivalent to the standard boost design. The LTSpice simulation measures $\mathrm{C}_{1}$ voltage between nodes $x$ and out shown in Figure 4-20.

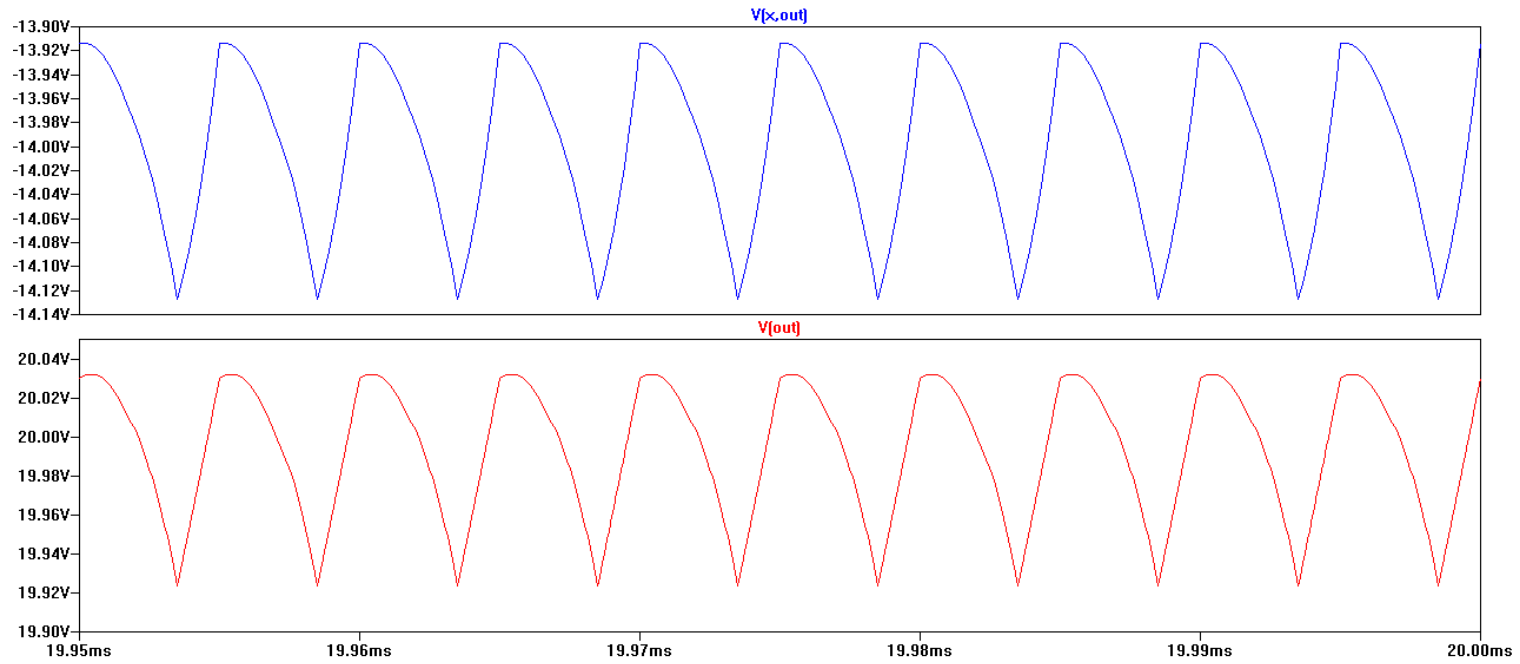

Figure 4-22. LTSpice Modified Boost Capacitor Voltage Waveforms Figure 4-23 shows the LTSpice modified boost design's large capacitor current ripple, like the Matlab modified boost simulation. 


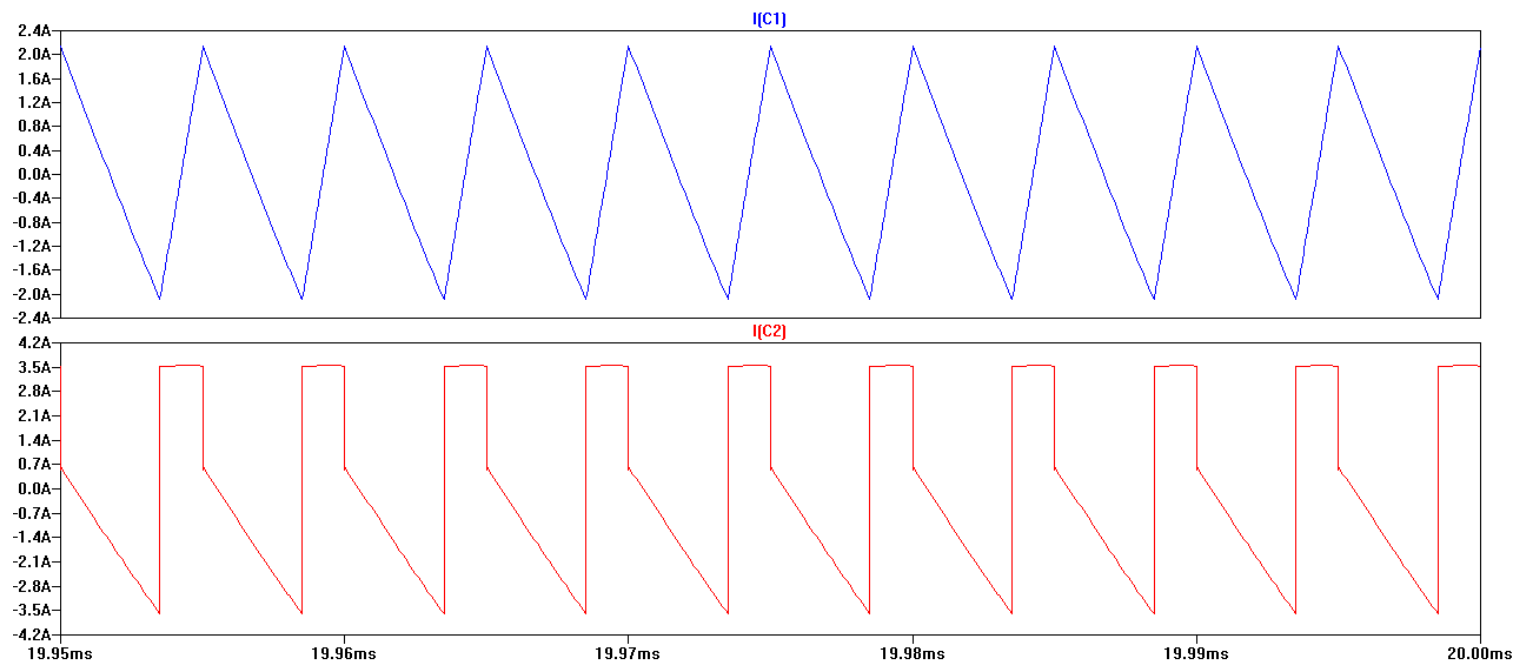

Figure 4-23. LTSpice Modified Boost Capacitor Current Waveforms

\subsubsection{Simulation Comparison}

Selected relevant measurements form a comparative basis between simulation methods. Average state variable measurements verify each design's DC behavior. Peakto-peak and percent ripple state variable measurements, relative to measured averages, quantify each design's ripple performance. The modified boost design RMS capacitor current measurements pertain to component current rating requirements. LTSpice measurements serve as nominal values when calculating percent differences.

Table 4-8 compares the simulated standard boost design's DC and ripple performance measurements. Both simulations match within 1\%, across all three measurements.

Table 4-8. Standard Boost Simulation Measurement Comparison

\begin{tabular}{|c|c|c|c|c|c|c|}
\hline \multirow{2}{*}{} & \multicolumn{3}{|c|}{ Inductor Current (A) } & \multicolumn{3}{c|}{ Capacitor Voltage (V) } \\
\cline { 2 - 7 } & Matlab & LTSpice & \%Diff & Matlab & LTSpice & \%Diff \\
\hline Average & 4.9591 & 4.9627 & $-0.07 \%$ & 19.998 & 19.839 & $0.80 \%$ \\
\hline Peak-Peak & 2.1 & 2.0827 & $0.83 \%$ & 0.105 & 0.1042 & $0.77 \%$ \\
\hline \%Ripple & $42.346 \%$ & $41.967 \%$ & $0.90 \%$ & $0.525 \%$ & $0.525 \%$ & $-0.06 \%$ \\
\hline
\end{tabular}


Table 4-9 compares the modified boost design state variable and capacitor current measurements. Average $\mathrm{L}_{1}$ current matches within three halves of a percent, and the other state variable average measurements match within half of a percent. LTSpice predicts significantly larger $\mathrm{L}_{1}$ current ripple and $\mathrm{C}_{1}$ voltage ripple; given the small absolute peakto-peak values, the difference between simulations carries less importance. Simulated $\mathrm{C}_{1}$ RMS currents match within two percent, and $\mathrm{C}_{2}$ RMS currents match within $12 \%$ despite the Matlab simulation measuring non-zero average capacitor current, an imperfect steady-state condition.

Table 4-9. Modified Boost Simulation Measurement Comparison

\begin{tabular}{|c|c|c|c|c|c|c|}
\hline & \multicolumn{3}{|c|}{ L1 Current (A) } & \multicolumn{3}{|c|}{$\mathrm{L}_{2}$ Current (A) } \\
\hline & Matlab & LTSpice & $\%$ Diff & Matlab & LTSpice & $\%$ Diff \\
\hline Average & 4.9446 & 5.0188 & $-1.48 \%$ & 5.0384 & 5.0183 & $0.40 \%$ \\
\hline Peak-Peak & 0.0286 & 0.0444 & $-35.59 \%$ & 4.2209 & 4.2098 & $0.26 \%$ \\
\hline \multirow[t]{3}{*}{ \% Ripple } & $0.578 \%$ & $0.885 \%$ & $-34.69 \%$ & $83.77 \%$ & $83.889 \%$ & $-0.14 \%$ \\
\hline & \multicolumn{3}{|c|}{ C1 $_{1}$ Voltage $(\mathrm{V})$} & \multicolumn{3}{|c|}{$\mathrm{C}_{2}$ Voltage $(\mathrm{V})$} \\
\hline & Matlab & LTSpice & $\%$ Diff & Matlab & LTSpice & $\%$ Diff \\
\hline Average & -14.032 & -13.999 & $0.24 \%$ & 20.012 & 19.993 & $0.10 \%$ \\
\hline Peak-Peak & 0.0993 & 0.2134 & $-53.47 \%$ & 0.1162 & 0.1084 & $7.20 \%$ \\
\hline \multirow[t]{3}{*}{ \% Ripple } & $0.708 \%$ & $1.524 \%$ & $-53.57 \%$ & $0.581 \%$ & $0.542 \%$ & $7.10 \%$ \\
\hline & \multicolumn{3}{|c|}{$\mathrm{C}_{1}$ Current $(\mathrm{A})$} & \multicolumn{3}{|c|}{$\mathrm{C}_{2}$ Current $(\mathrm{A})$} \\
\hline & Matlab & LTSpice & $\%$ Diff & Matlab & LTSpice & $\%$ Diff \\
\hline RMS & 1.2429 & 1.2242 & $1.53 \%$ & 2.8323 & 2.5308 & $11.91 \%$ \\
\hline
\end{tabular}

Both simulation's produce similarly shaped converter waveforms, except standard boost output voltage and modified boost $\mathrm{C}_{1}$ voltage. Theoretically, the standard boost output voltage follows a roughly quadratic trajectory during the switch-off state, as Figure 2-16 shows charge accumulating at a decreasing rate due to negative current slope. This analysis assumes output voltage ripple exerts a negligible effect on load current. The LTSpice simulation produces non-ideal load current, consequently affecting the output 
voltage waveform. Additionally, solution uniqueness affects the state equation simulation model. The iterative, numerical solution method simply finds a set of solutions exhibiting steady-state error, difference between initial and final values over a switching cycle, below a predefined threshold. The iterative method does not guarantee a unique solution. However, Sections 4.5.1 and 0 demonstrate general waveform similarity, for both converter designs, across simulation methods.

Though Matlab and LTSpice simulation results differ in some respects, both methods predict significant input current ripple reduction between standard boost and modified boost designs. Table 4-10 summarizes input current ripple performance across both topology's equivalent design, projecting reduction from a $40 \%$ baseline to below $1 \%$ ripple.

Table 4-10. Simulated Boost Converter Input Current Ripple Reduction

\begin{tabular}{|c|c|c|c|c|}
\hline \multirow{2}{*}{} & \multicolumn{2}{|c|}{ Standard Boost } & \multicolumn{2}{c|}{ Modified Boost } \\
\cline { 2 - 5 } & Peak-Peak (A) & \%Ripple & Peak-Peak (A) & \%Ripple \\
\hline Matlab & 2.1 & $42.346 \%$ & 0.0286 & $0.578 \%$ \\
\hline LTSpice & 2.0827 & $41.967 \%$ & 0.0444 & $0.885 \%$ \\
\hline
\end{tabular}




\section{HARDWARE}

The converters' hardware implementation covers power component selection, switching controller design, and printed circuit board (PCB) assembly. Hardware testing determines each converter's performance based upon state variable measurements. Implementation priorities include minimizing non-topological differences and characterizing steady-state, CCM operation.

\subsection{Power Components}

Each converter's power component ratings must exceed expected voltage and current conditions based on theory or simulation. Most components experience similar voltage and current stresses in both topologies. The modified boost topology primarily impacts $\mathrm{L}_{2}, \mathrm{C}_{1}$, and output capacitor $\left(\mathrm{C}_{2}\right)$ current ratings.

\subsubsection{Inductors}

Both converter implementations use Wuerth Elektronik's WE-FAMI series through-hole, shielded power inductors [34]. The modified boost converter contains two 4.7 $\mu \mathrm{H}$ inductors chosen to occupy less PCB area than the standard boost converter's single $10 \mu \mathrm{H}$ inductor. Table 5-1 summarizes important properties for each inductor selected.

Table 5-1. WE-FAMI Series Inductor Properties

\begin{tabular}{|c|c|c|c|c|c|c|}
\hline Use & Inductance & IDC & Isat $_{\text {Max DCR }}$ & Tol. & Footprint \\
\hline Modified Boost & $4.7 \mu \mathrm{H}$ & $6.5 \mathrm{~A}$ & $9.6 \mathrm{~A}$ & $12.5 \mathrm{~m} \Omega$ & $20 \%$ & $60.82 \mathrm{~mm}^{2}$ \\
\hline Standard Boost & $10 \mu \mathrm{H}$ & $8.9 \mathrm{~A}$ & $12.4 \mathrm{~A}$ & $9.5 \mathrm{~m} \Omega$ & $20 \%$ & $172 \mathrm{~mm}^{2}$ \\
\hline
\end{tabular}

Both inductors meet the design's current requirements. The DC current rating exceeds the $5 \mathrm{~A}$ average current though each inductor in the standard boost and modified 
boost. The modified boost's $\mathrm{L}_{2}$ maximum current of approximately $7 \mathrm{~A}$, remains below the inductor saturation rating.

\subsubsection{Capacitors}

Both converter implementations use multilayer ceramic capacitors (MLCCs) in the power path. Using MLCCs mitigates the capacitor equivalent series resistance's (ESR) effects ranging from increased output voltage ripple to parasitic control-loop zeros. This choice keeps power-path capacitors closer to the ideal components assumed during analysis and simulation. Configuring multiple MLCCs in parallel accommodates large ripple current. MLCCs, current-limited only by heat dissipation, offer a smaller, cheaper solution than electrolytic capacitors. Table 5-2 describes the worst-case current through each power-path capacitor, based on Matlab simulation, and the corresponding MLCC configuration.

Table 5-2. Power-Path Capacitor Current and MLCC Configuration

\begin{tabular}{|c|c|c|c|c|}
\hline Component & \multicolumn{2}{|c|}{ Worst-Case Current } & Value & Configuration \\
\hline Input Capacitor & Standard Boost & $0.614 \mathrm{~A}_{\mathrm{RMS}}$ & $44 \mu \mathrm{F}$ & $22 \mu \mathrm{F}$ x 2 \\
\hline Modified Boost $\mathrm{C}_{1}$ & Modified Boost & $2.8323 \mathrm{~A}_{\mathrm{RMS}}$ & $28.2 \mu \mathrm{F}$ & $4.7 \mu \mathrm{F} \times 6$ \\
\hline Output Capacitor & Modified Boost & $1.2429 \mathrm{~A}_{\mathrm{RMS}}$ & $47 \mu \mathrm{F}$ & $4.7 \mu \mathrm{F}$ x 10 \\
\hline
\end{tabular}

Table 5-3 lists properties of both MLCCs implementing power-path capacitors.

Table 5-3. Power-Path MLCC Properties

\begin{tabular}{|c|c|c|c|c|c|}
\hline Component & Capacitance & VDC Rating & Dielectric & Tol. & SMD Package \\
\hline Input Capacitor & $22 \mu \mathrm{F}$ & $10 \mathrm{~V}$ & X7R & $20 \%$ & 1210 \\
\cline { 1 - 5 } Modified Boost $C_{1}$ & \multirow{2}{*}{$4.7 \mu \mathrm{F}$} & $25 \mathrm{~V}$ & X7R & $10 \%$ & 1206 \\
\cline { 1 - 5 } Output Capacitor & & & & \\
\hline
\end{tabular}




\subsubsection{Switch and Diode}

The switching components experience similar stresses in both converter designs. Both topologies expose no more than the output voltage across both switching devices. Additionally, both devices carry the same average currents in each converter. Each converter implementation uses a IRF60B217 n-channel MOSFET switch and a MBR10100G Schottky diode [35] [36]. Table 5-4 summarizes each component's ratings and expected operating conditions. Voltage rating margins accommodate parasitic ringing at a converter's switching node. Current rating margins ensure power dissipation within component packaging capabilities.

Table 5-4. Switching Component Rating Margins

\begin{tabular}{|c|c|c|c|}
\hline \multicolumn{2}{|c|}{ IRF60B217 MOSFET } & \multicolumn{2}{|c|}{ MBR10100G Diode } \\
\hline \multicolumn{2}{|c|}{ Peak Drain-Source Voltage $\left(\mathrm{V}_{\mathrm{DS}}\right)$} & \multicolumn{2}{|c|}{ Peak Repetitive Reverse Voltage $\left(\mathrm{V}_{\mathrm{rrm}}\right)$} \\
\hline Rating & $60 \mathrm{~V}$ & Rating & $100 \mathrm{~V}$ \\
\hline Expected & $20 \mathrm{~V}$ & Expected & $20 \mathrm{~V}$ \\
\hline Margin & $40 \mathrm{~V}$ & Margin & $80 \mathrm{~V}$ \\
\hline \multicolumn{2}{|c|}{ Continuous Drain Current $\left(\mathrm{I}_{\mathrm{D}}\right)$} & \multicolumn{2}{|c|}{ Average Forward Current $\left(\mathrm{I}_{\mathrm{F}}\right)$} \\
\hline Rating & $60 \mathrm{~A}$ & Rating & $10 \mathrm{~A}$ \\
\hline Expected & 3.5 & Expected & $1.5 \mathrm{~A}$ \\
\hline Margin & $56.5 \mathrm{~A}$ & Margin & $8.5 \mathrm{~A}$ \\
\hline
\end{tabular}

\subsection{Switching Controller}

Both converters use an identical control circuit built around the LM3478 low-side, current-mode switching controller [37]. Large inductor current in both designs disqualify most internal switch devices and relatively low switching frequency further limits controller selection. The LM3478 balances control features and external component requirements; providing variable switching frequency but fixed soft-start, under-voltage 
lockout, over-voltage protection, and short-circuit protection. Table 5-5 describes each LM3478 pin's function.

Table 5-5. LM3487 Pin Descriptions [37]

\begin{tabular}{|c|c|l|}
\hline Pin Name & Pin No. & \multicolumn{1}{c|}{ Description } \\
\hline I $_{\text {SEN }}$ & 1 & Current sense input. Connect to low-side sense resistor. \\
\hline COMP & 2 & Control loop compensation. Connect RC-network. \\
\hline FB & 3 & Output feedback. Set to 1.26 V with output voltage divider. \\
\hline AGND & 4 & Analog ground. \\
\hline PGND & 5 & Power ground. \\
\hline DR & 6 & Gate drive. Connect to external MOSFET gate terminal. \\
\hline FA/SD & 7 & $\begin{array}{l}\text { Frequency adjust and shutdown. Grounded resistor sets } \\
\text { switching frequency. Pull high for 30 } \mu \text { s to shut down. }\end{array}$ \\
\hline$V_{\text {IN }}$ & 8 & Power input. Connect 2.97 V to 40 V supply. \\
\hline
\end{tabular}

External components configure the essential control functions in the LM3478, including switching frequency, current limit, output voltage, and loop compensation.

\subsubsection{Switching Frequency}

A resistor connected between the FA/SD pin and ground sets the internal oscillator frequency. The LM3478 datasheet provides the frequency adjust resistor equation (5-1) [37].

$$
\begin{gathered}
R_{F A}=4.503 \cdot 10^{11} \cdot f^{-1.26} \\
R_{F A}=4.503 \cdot 10^{11} \cdot(200 \mathrm{kHz})^{-1.26} \approx 94.2 \mathrm{k} \Omega
\end{gathered}
$$

The standard values $93.1 \mathrm{k} \Omega$ and $1.13 \mathrm{k} \Omega$ connected serially implement resistance corresponding to a $200 \mathrm{kHz}$ switching frequency.

\subsubsection{Sense Resistor}

The controller's current feedback loop determines inductor current indirectly. A low-side current sense resistor provides a voltage proportional to the inductor current 
while the switch conducts. This voltage applied to the ISEN pin determines when the controller turns the switch off.

A sense resistor sets the inductor current limit enforced by the controller's current feedback loop. Figure 5-1 depicts the LM3478 low-side sense resistor configuration. The ISEN pin receives a voltage proportional to the inductor current while the switch conductions. PWM logic resets the DR pin when ISEN voltage exceeds an internallygenerated control signal, turning off the converter's switch [37].

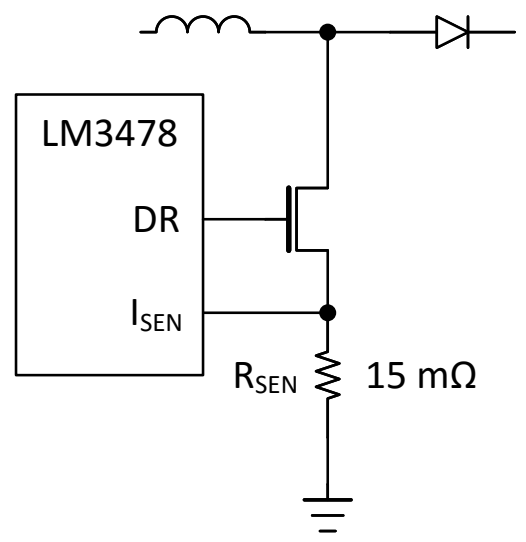

Figure 5-1. LM3478 Current Sense Resistor

Sizing the sense resistor determines the peak current value required to trip the controller's internal limit. The datasheet suggests a $20 \%$ margin above peak switch current (5-2) [37]. The standard boost design requires a 7.2A current limit; simulation results suggest this also covers the modified boost design.

$$
\begin{gathered}
I_{S W(\text { limit })}=1.2 \cdot\left(I_{I N}+\frac{\Delta i_{L}}{2}\right) \\
I_{S W(\text { limit })}=1.2 \cdot\left(5 \mathrm{~A}+\frac{2 \mathrm{~A}}{2}\right)=7.2 \mathrm{~A}
\end{gathered}
$$

The controller's internal current feedback parameters also affect the sense resistor value. Table 5-6 lists several internal LM3478 current feedback parameters. These values 
describe the voltage required to trigger the current limit. The LM3478 provides an internal slope compensation ramp, preventing sub-harmonic oscillation during operation at duty cycles above 50\% [37].

Table 5-6. LM3478 Current Sense Feedback Parameters [37]

\begin{tabular}{|c|c|c|c|l|}
\hline \multirow{2}{*}{ Parameter } & \multicolumn{3}{|c|}{ Value (mV) } & \multicolumn{1}{c|}{ Description } \\
\cline { 2 - 4 } & Min. & Typ. & Max. & \multicolumn{1}{|c|}{. } \\
\hline $\mathrm{V}_{\text {SENSE }}$ & 135 & 156 & 180 & Current sense threshold voltage. \\
\hline $\mathrm{V}_{\mathrm{SL}}$ & 52 & 92 & 132 & Internal compensation ramp voltage. \\
\hline $\mathrm{V}_{\text {SLratio }}$ & 0.3 & 0.49 & 0.7 & $\mathrm{~V}_{\text {SL }} / \mathrm{V}_{\text {SENSE }}$ ratio. \\
\hline $\mathrm{V}_{\mathrm{SC}}$ & 250 & 343 & 415 & Short-circuit current limit voltage. \\
\hline
\end{tabular}

The desired current limit and LM3478 current feedback parameters determine the required sense resistor value (5-3) [37]. Both converters use a $15 \mathrm{~m} \Omega$ sense resistor.

$$
\begin{gathered}
R_{\text {SEN }}=\frac{V_{\text {SENSE }}-\left(D \cdot V_{\text {SENSE }} \cdot V_{\text {SLratio }}\right)}{I_{\text {SW }(\text { limit })}} \\
R_{\text {SEN }}=\frac{0.156 \mathrm{~V}-(0.7 \cdot 0.156 \mathrm{~V} \cdot 0.49)}{7.2 \mathrm{~A}}=14.235 \mathrm{~m} \Omega
\end{gathered}
$$

An upper limit prevents the sense resistance from affecting the current feedback loop stability (5-4), without adding additional, external slope compensation [37].

$$
\begin{gathered}
R_{S E N}<\frac{2 V_{S L} \cdot f \cdot L}{V_{O U T}-2 V_{I N}} \\
R_{S E N}<\frac{2 \cdot(0.092 \mathrm{~V} \cdot 200 \mathrm{kHz} \cdot 10 \mu \mathrm{H})}{20 \mathrm{~V}-12 \mathrm{~V}}<46 \mathrm{~m} \Omega
\end{gathered}
$$

The selected $15 \mathrm{~m} \Omega$ sense resistor falls well below the stability threshold.

\subsubsection{Output Voltage Divider}

Programming the converter's output requires a voltage divider sized to provide $1.26 \mathrm{~V}$ at the feedback (FB) pin, matching an internal reference [37]. The feedback signal and reference voltage drive an error amplifier. The error signal offsets the current limit 
threshold voltage, approaching zero as the controller achieves output regulation. Figure 5-2 depicts the feedback network designed to program a $20 \mathrm{~V}$ output.

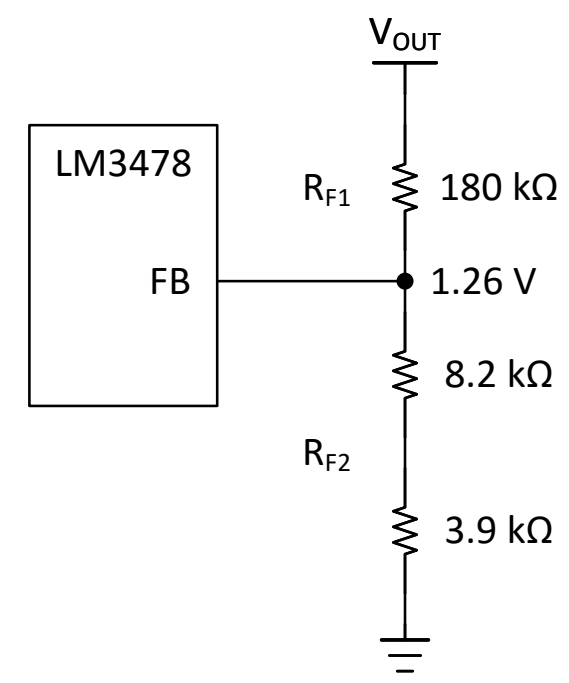

Figure 5-2. Output Voltage Feedback Divider

The datasheet provides an equation for $\mathrm{R}_{\mathrm{F} 2}(5-2)$, which rearranged specifies the ratio of $R_{F 1}$ to $R_{F 2}(5-3)$.

$$
\begin{gathered}
R_{F 2}=\frac{(1.26 \mathrm{~V}) \cdot R_{F 1}}{\left(V_{\text {OUT }}-1.26 \mathrm{~V}\right)} \\
\frac{R_{F 1}}{R_{F 2}}=\frac{V_{\text {OUT }}}{1.26 \mathrm{~V}}-1
\end{gathered}
$$

The Figure 5-2 network achieves the ratio required to program a $20 \mathrm{~V}$ output using standard, $1 \%$ tolerance resistor values.

$$
\frac{R_{F 1}}{R_{F 2}}=\frac{20 \mathrm{~V}}{1.26 \mathrm{~V}}-1=14.873 \approx \frac{180 \mathrm{k} \Omega}{(8.2 \mathrm{k} \Omega+3.9 \mathrm{k} \Omega)}=14.876
$$

\subsubsection{Loop Compensation}

Current-mode control eases the LM3478 compensation requirements. A type-I integrator sufficiently compensates most LM3478 boost applications [38]. Figure 5-3 
shows the loop compensator design, adding both a pole and a zero to the control-tooutput transfer function.

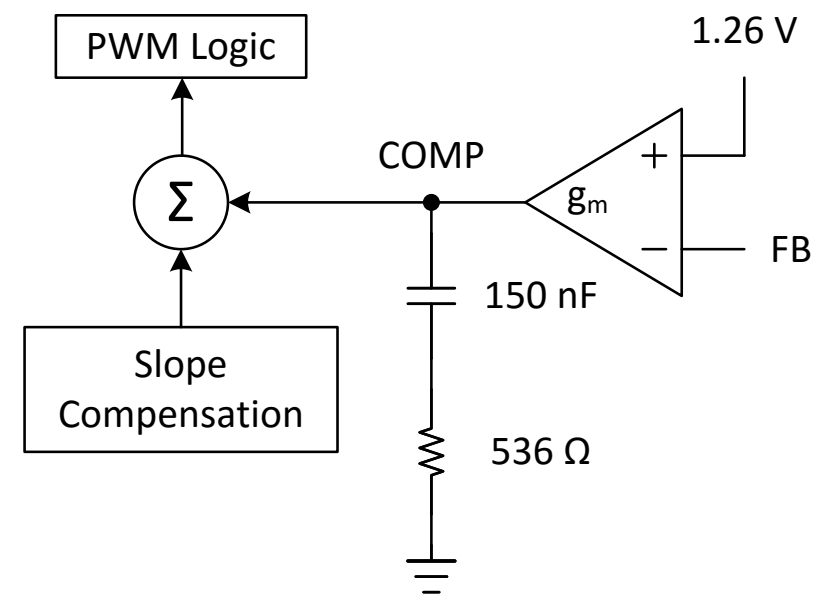

Figure 5-3. LM3478 Type-I Loop Compensator

The selected compensator design provides adequate performance during steadystate converter testing. Further optimization falls outside the steady-state hardware operation scope. Appendix C fully documents compensator design calculations per Texas Instruments guidelines [38].

\subsection{Implementation and Testing}

Eagle CAD provides the schematic capture and PCB layout tools to complete hardware implementation. Matching the converters' operating conditions to the highest achievable degree minimizes the impact of non-topological factors on performance measurements. This task raises significant challenges, but the results demonstrate the modified boost topology's ability to reduce input current ripple. 


\subsubsection{Schematics}

The converter schematics reflect designed similarities, using identical components and connections. The topological power-path modification creates the only significant difference between the two schematics. Figure 5-4 and Figure 5-5 show simplified schematics of the standard and modified boost converters. For simplicity, $\mathrm{C}_{\mathrm{IN}}$ and $\mathrm{C}$ OUT refer to the multiple MLCCs comprising the input and output capacitors. Likewise, $\mathrm{C}_{1}$ refers to the multiple MLCCs comprising the modified boost's auxiliary capacitor. Each inductor carries the reference designator associated with the theoretical circuit; $\mathrm{L}$ in the standard boost and $\mathrm{L}_{1}$ and $\mathrm{L}_{2}$ in the modified boost. The simplified schematics also condense the frequency adjust and output feedback networks made up of multiple resistors.

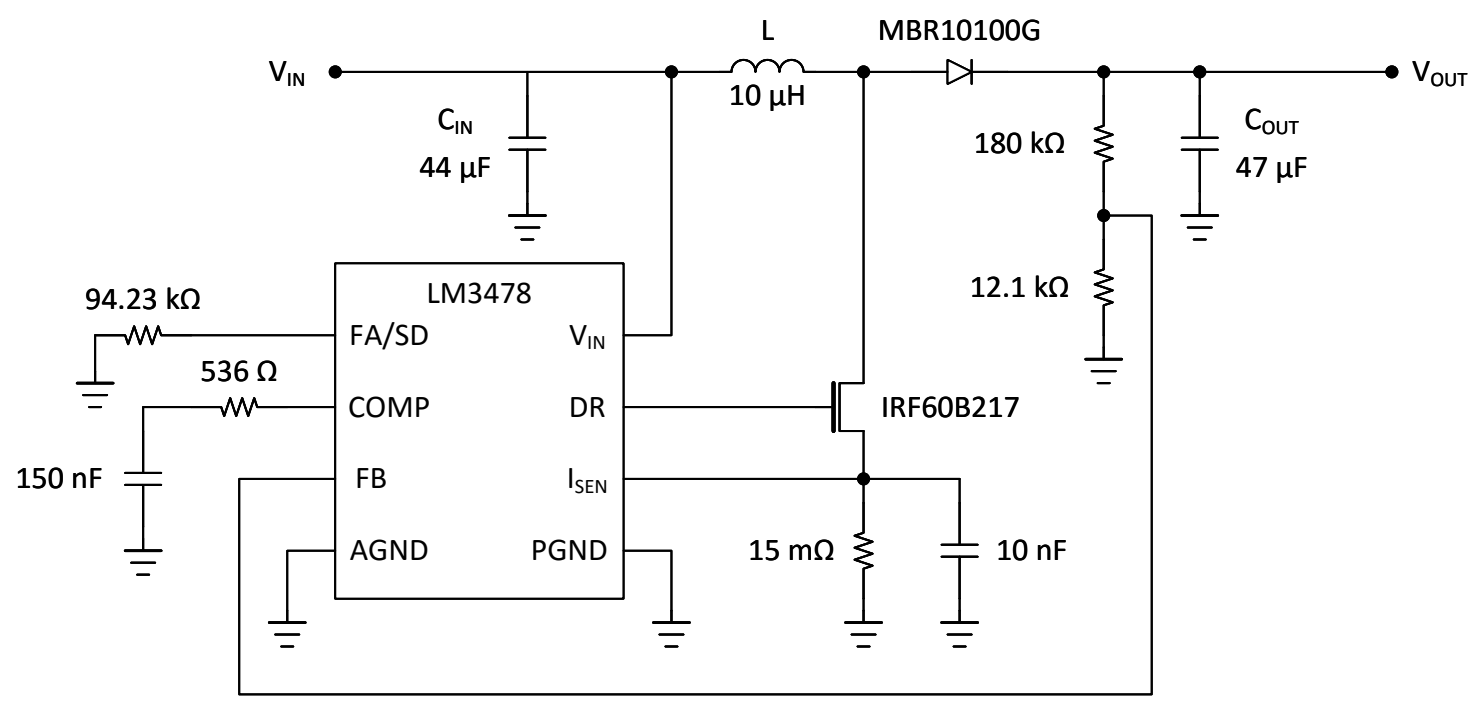

Figure 5-4. Simplified Standard Boost Design Schematic 


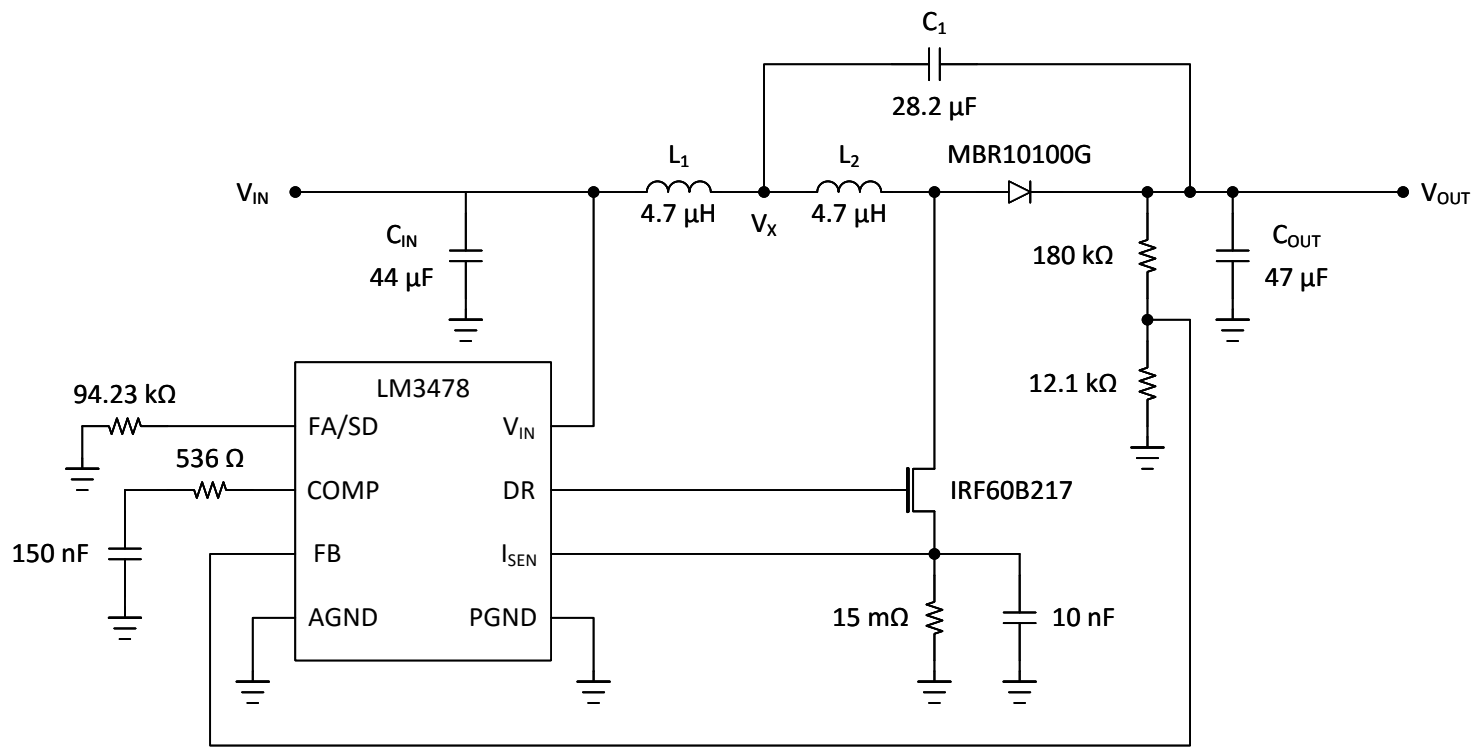

Figure 5-5. Simplified Modified Boost Design Schematic

Appendix D presents the complete schematics produced using Eagle CAD and the electrical bill of materials, detailing component ratings and tolerances.

\subsubsection{PCB Layout}

Each converter occupies half of the two-layer board. The control circuits receive identical layout and both power paths generally follow a 'U' shape. Copper polygons connect power components, minimizing conduction losses along the power path. Both converters share a ground plane that resembles a ' 3 ' enclosing the power paths on top and bottom layers. Figure 5-6 highlights these PCB attributes. Appendix D contains large images of both PCB layers. 


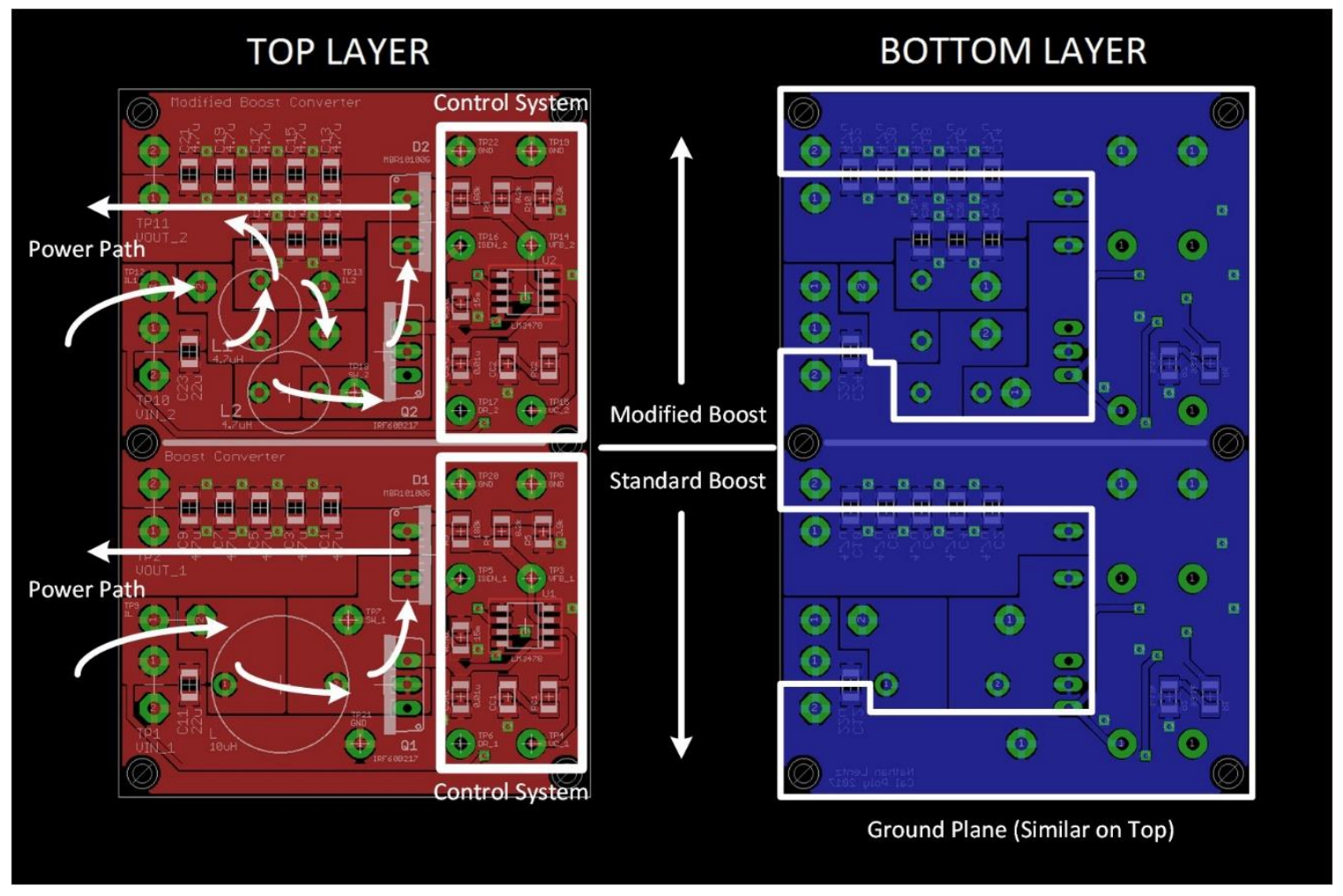

Figure 5-6. Top and Bottom PCB Layers Annotated

Figure 5-7 shows both converters assembled on the PCB, before adding currentprobe wire loops.

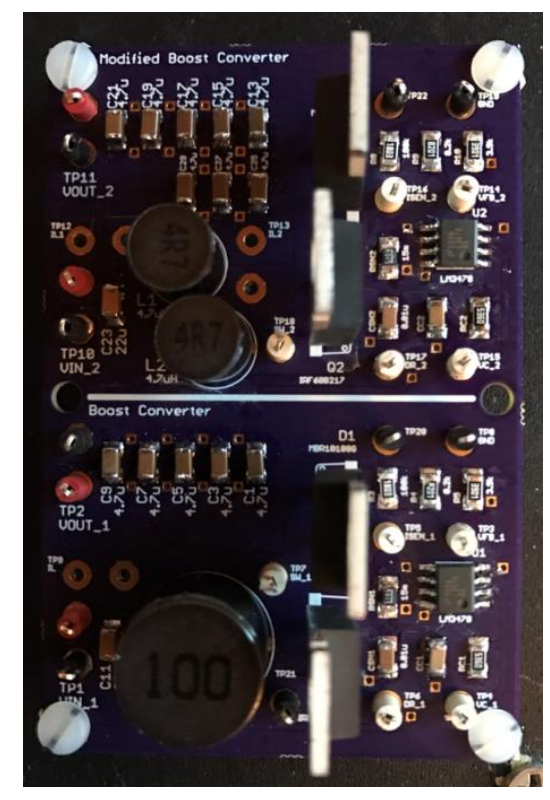

Figure 5-7. Assembled PCB (Top View) 


\subsubsection{Test Configuration}

The hardware test configuration contains a Goodwill Instruments GPR-6060D DC power supply, two Rigol DM3058E multimeters, a Teledyne LeCroy HD4096 oscilloscope, and a BK Precision 8510 electronic load. The power supply and electronic load indicate DC input and output current. The multimeters measure DC voltage directly at each converter's input and output terminals. The oscilloscope, triggered by the converter's gate drive signal, primarily provides state variable measurements.

Figure 5-8 depicts each instrument's connection to the standard boost converter.

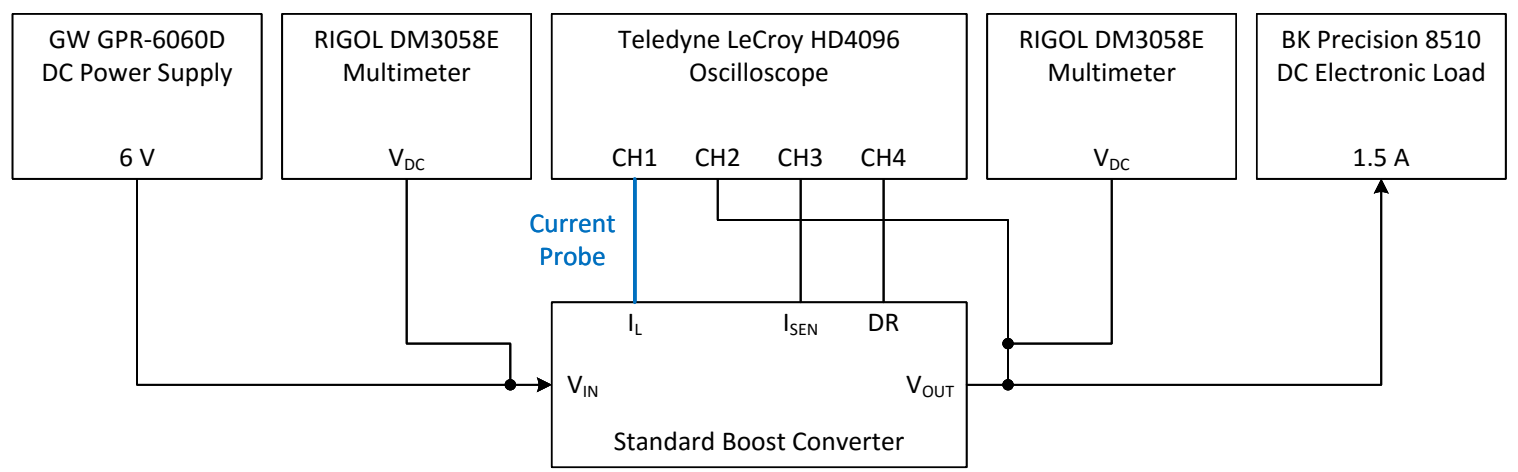

Figure 5-8. Standard Boost Converter Hardware Test Connections

Figure 5-9 illustrates the modified boost converter's connections to each test instrument. Oscilloscope connections vary depending on the state variable measurement. The scope's current probe alternates between the PCB's $\mathrm{L}_{1}$ and $\mathrm{L}_{2}$ current measurement loops. The $\mathrm{CH} 3$ scope probe contacts the current sense voltage test point during $\mathrm{L}_{2}$ current measurements. The scope measures $C_{1}$ voltage as the difference between the $V_{x}$ voltage on $\mathrm{CH} 3$ and the output voltage on $\mathrm{CH} 2$. 


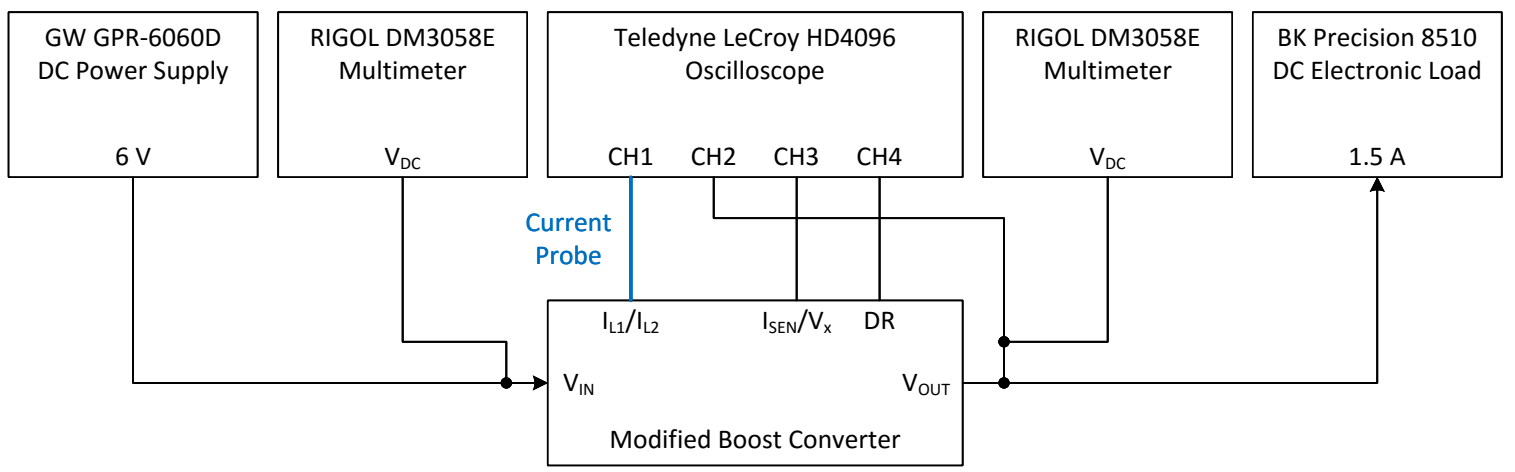

Figure 5-9. Modified Boost Converter Hardware Test Connections

During initial testing, the controller's current limit prevented both converters from achieving nominal output voltage at full load conditions. Large inductor current ripple carried through the sense resistor triggered the current sense voltage threshold, limiting PWM duty cycle and lowering output voltage. The modified design's larger $\mathrm{L}_{2}$ current ripple limits the duty cycle more than the standard design's inductor current ripple, causing a difference in output voltage. Lowering the sense resistor value raises the controller's current limit, alleviating the output voltage difference at full load. Table 5-7 compares the output voltage difference after dropping the sense resistance from $15 \mathrm{~m} \Omega$ to $12 \mathrm{~m} \Omega$.

Table 5-7. Converter Output Voltage Difference at Full Load

\begin{tabular}{|c|c|c|}
\hline Sense Resistor & $15 \mathrm{~m} \Omega$ & $12 \mathrm{~m} \Omega$ \\
\hline Standard Boost VouT & $16.23 \mathrm{~V}$ & $18.39 \mathrm{~V}$ \\
\hline Modified Boost Vout & $15.3 \mathrm{~V}$ & $17.86 \mathrm{~V}$ \\
\hline Difference & $0.93 \mathrm{~V}$ & $0.53 \mathrm{~V}$ \\
\hline
\end{tabular}

Table 5-8 compares each converter's DC characteristics measured at full load after reducing the current sense resistance. Considering tolerances and parasitic effects, the difference between full-load DC characteristics proves acceptable. The primary comparison metric, input current ripple percentage, remains unaffected by a small DC input current difference. 
Table 5-8. Converter Full Load DC Characteristics Comparison

\begin{tabular}{|c|c|c|c|c|c|c|c|}
\hline & $\begin{array}{c}\text { VIN } \\
(\mathbf{V})\end{array}$ & $\begin{array}{c}\text { IIN } \\
(\mathbf{A})\end{array}$ & $\begin{array}{c}\text { PIN } \\
(\mathbf{W})\end{array}$ & $\begin{array}{c}\text { VouT } \\
(\mathbf{V})\end{array}$ & $\begin{array}{c}\text { IouT } \\
(\mathbf{A})\end{array}$ & $\begin{array}{c}\text { PouT } \\
(\mathbf{W})\end{array}$ & Efficiency \\
\hline Standard Boost & 5.27 & 6.08 & 32.04 & 18.39 & 1.5 & 27.58 & $86.08 \%$ \\
\hline Modified Boost & 5.3 & 5.81 & 30.79 & 17.86 & 1.5 & 26.79 & $87.01 \%$ \\
\hline Difference & -0.03 & 0.27 & 1.25 & 0.53 & 0 & 0.79 & $-0.93 \%$ \\
\hline
\end{tabular}

Figure 5-10 describes each test point used testing the converter assemblies. The $\mathrm{V}_{\mathrm{X}}$ node's wire lead connects at the beginning of the $\mathrm{L}_{2}$ current-probe loop. Both final assemblies contain $12 \mathrm{~m} \Omega$ sense resistors.

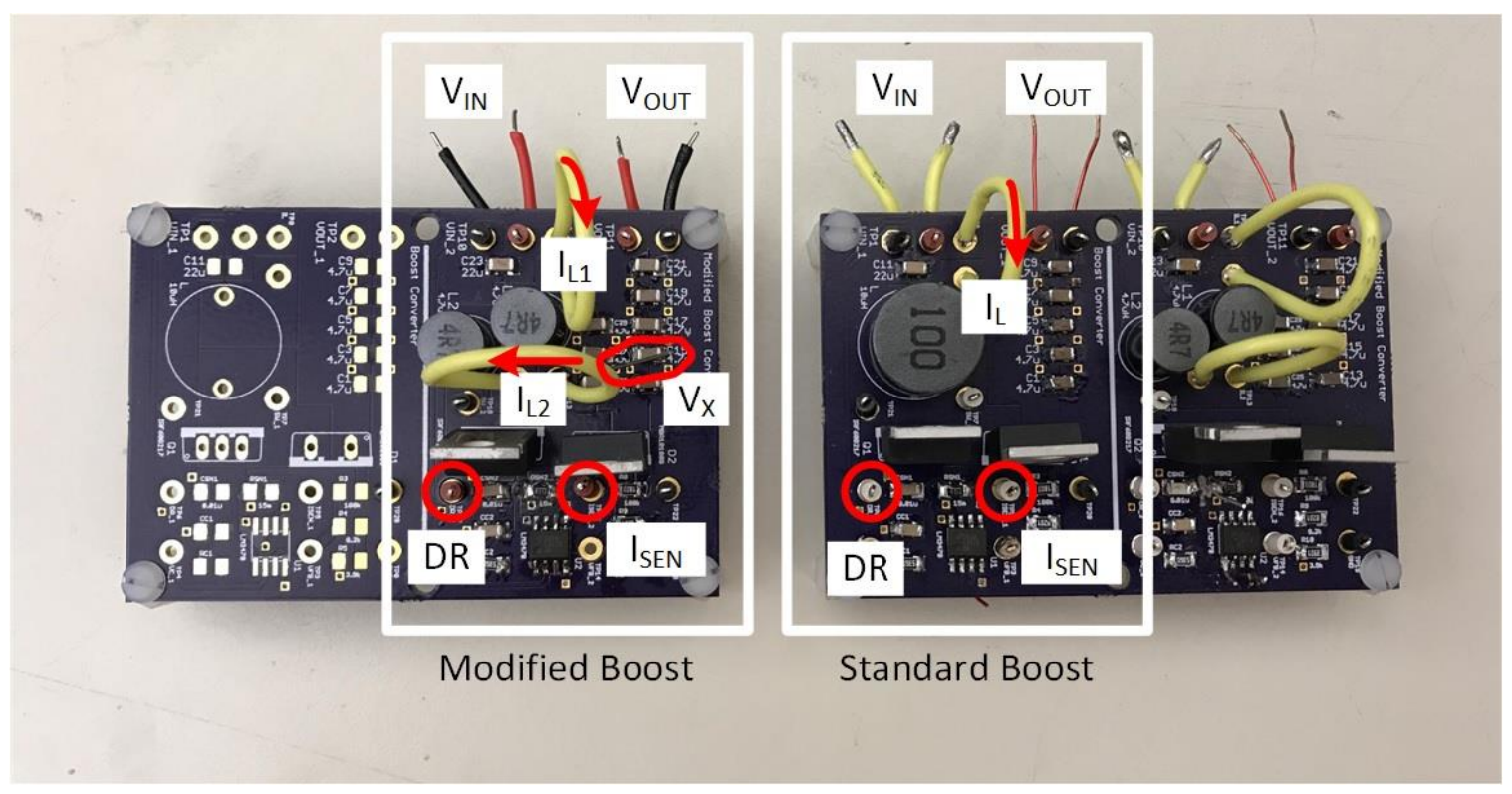

Figure 5-10. Final Converter Assembly Test Points

Figure 5-11 depicts the complete test configuration on the laboratory bench. The DC power supply and electronic load connect to the converter's mounted input and output terminals, minimizing current path resistance. Multimeters and the output voltage scope probe connect to the additional wire leads. 


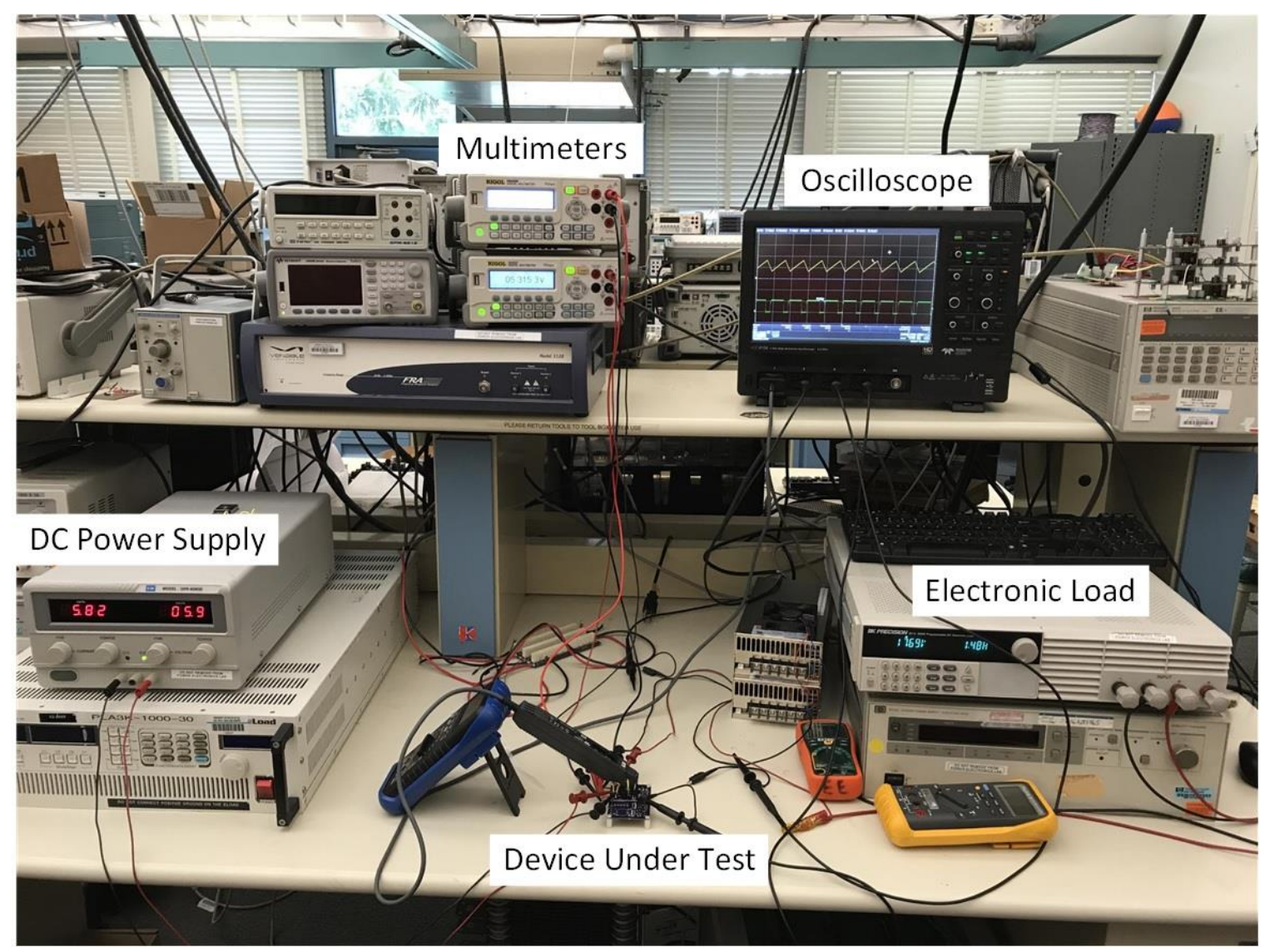

Figure 5-11. Laboratory Test Configuration

\subsubsection{State Variable Measurements}

Both converter state variable measurements rely on a combination of built-in scope measurement functions and manual cursor measurements, applied under appropriate signal coupling conditions. Table 5-9 summarizes the method used for each measurement. Parasitic ringing eliminates the scope's ability to autonomously measure maximum, minimum, and peak to peak voltage values; cursor measurements better represent topological performance. 
Table 5-9. State Variable Oscilloscope Measurement Methods

\begin{tabular}{|c|c|c|c|c|}
\hline \multirow{2}{*}{ Measurement } & \multicolumn{2}{|c|}{ Current } & \multicolumn{2}{c|}{ Voltage } \\
\cline { 2 - 5 } & Coupling & Cursors & Coupling & Cursors \\
\hline Average & DC & N & DC & N \\
\hline RMS & DC & N & DC & N \\
\hline AC RMS & AC & N & AC & N \\
\hline Maximum & DC & N & AC & Y \\
\hline Minimum & DC & N & AC & Y \\
\hline Peak-Peak & DC & N & AC & Y \\
\hline
\end{tabular}

Figure 5-12 depicts the standard boost hardware's inductor current waveform.

The current exhibits the expected triangular shape, but the $75.5 \%$ duty cycle and 185.8 $\mathrm{kHz}$ switching frequency differ from nominal values.

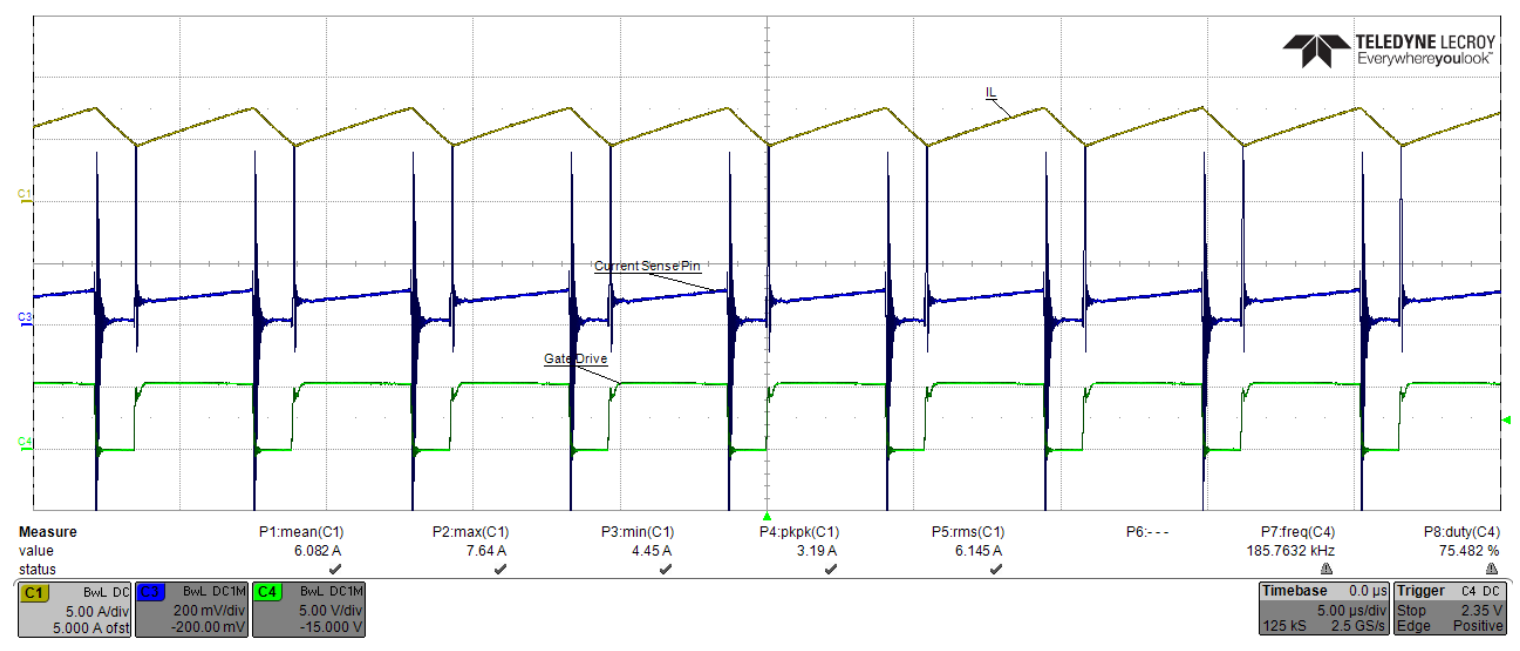

Figure 5-12. Standard Boost Hardware Inductor Current

Figure 5-13 illustrates the standard boost output voltage measurement. Ignoring the implementation's parasitic ringing, the waveform follows the expected characteristic trends; negative linear slope with the switch on, and concave down quadratic with the switch off. 


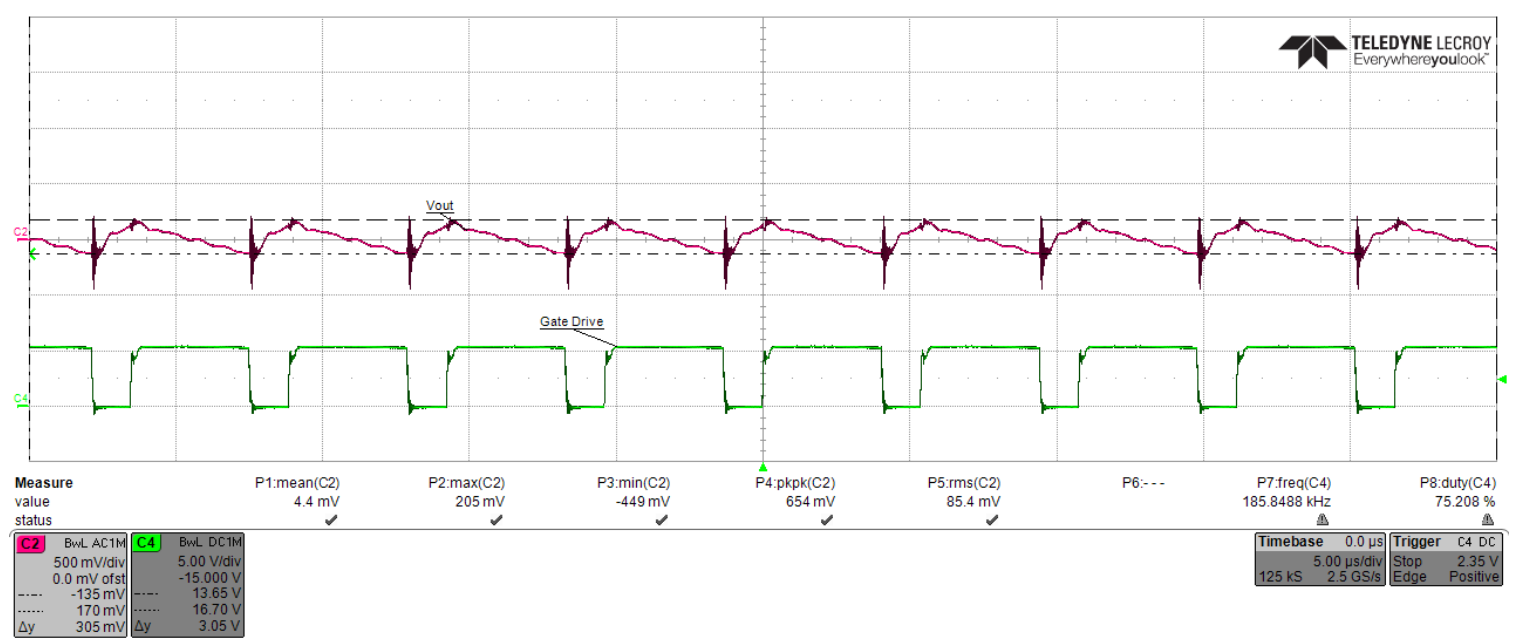

Figure 5-13. Standard Boost Hardware Output Voltage (AC Coupling)

Table 5-10 lists the standard boost design's hardware state variable measurements. The converter's power loss increases the average inductor current and switching duty cycle. Inductance tolerance, increased duty cycle, and decreased switching frequency account for the 52.45\% current ripple. Increased inductor current ripple flows through the output capacitor, raising the output voltage ripple.

Table 5-10. Standard Boost Converter Hardware Test Results

\begin{tabular}{|c|c|c|}
\hline & $\mathbf{I}_{\mathbf{L}}$ (A) & $\mathbf{V}_{\text {out }}$ (V) \\
\hline Average & 6.082 & 18.231 \\
\hline RMS & 6.145 & 18.232 \\
\hline AC RMS & 0.897 & 0.0854 \\
\hline Max. & 7.64 & 18.401 \\
\hline Min. & 4.45 & 18.096 \\
\hline Peak-Peak & 3.19 & 0.305 \\
\hline \%Ripple & $52.45 \%$ & $1.67 \%$ \\
\hline
\end{tabular}

Figure 5-14 shows the modified boost $\mathrm{L}_{1}$ current measurement. The waveform looks almost triangular, but curves before the switch turns off. Like the standard boost, the $74.333 \%$ duty cycle and $192.66 \mathrm{kHz}$ switching frequency differ from nominal values. 


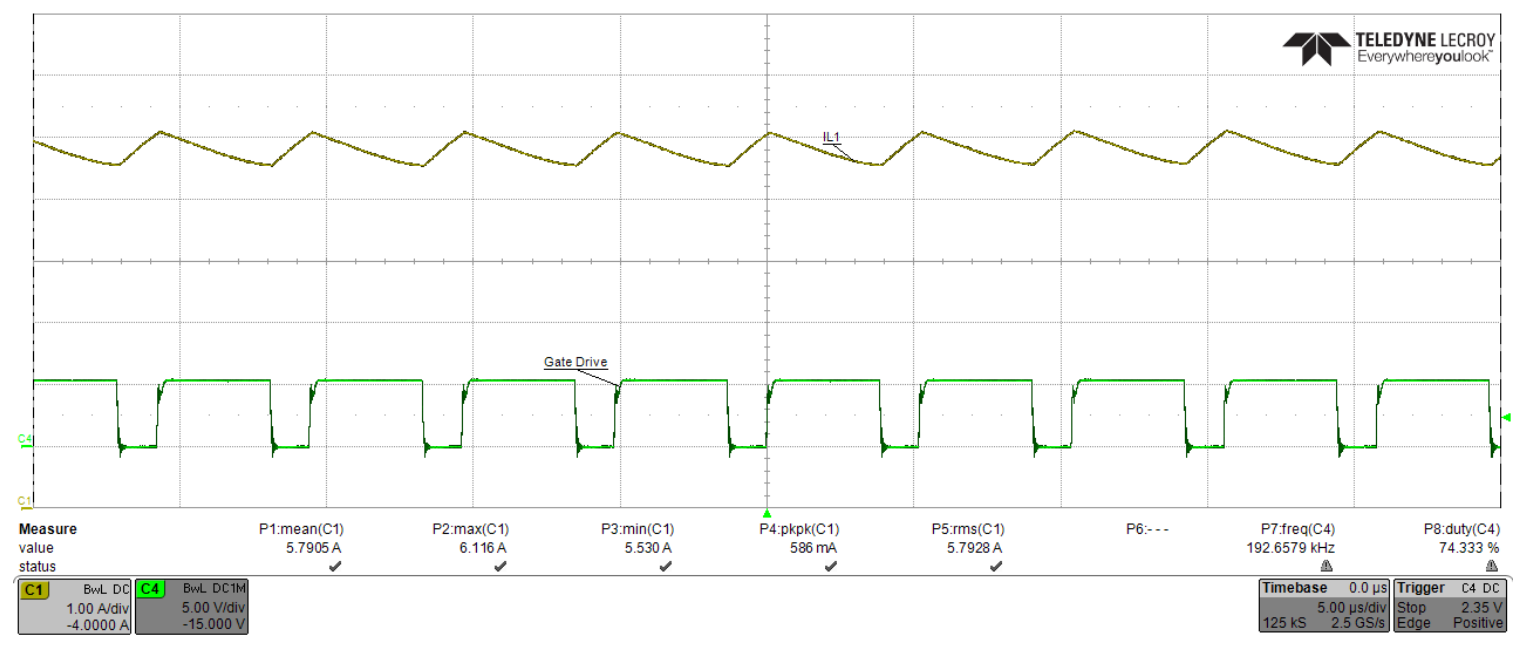

Figure 5-14. Modified Boost Hardware $\mathrm{L}_{1}$ Current

Figure 5-15 portrays the modified boost $\mathrm{L}_{2}$ current waveform, precisely matching a triangular shape.

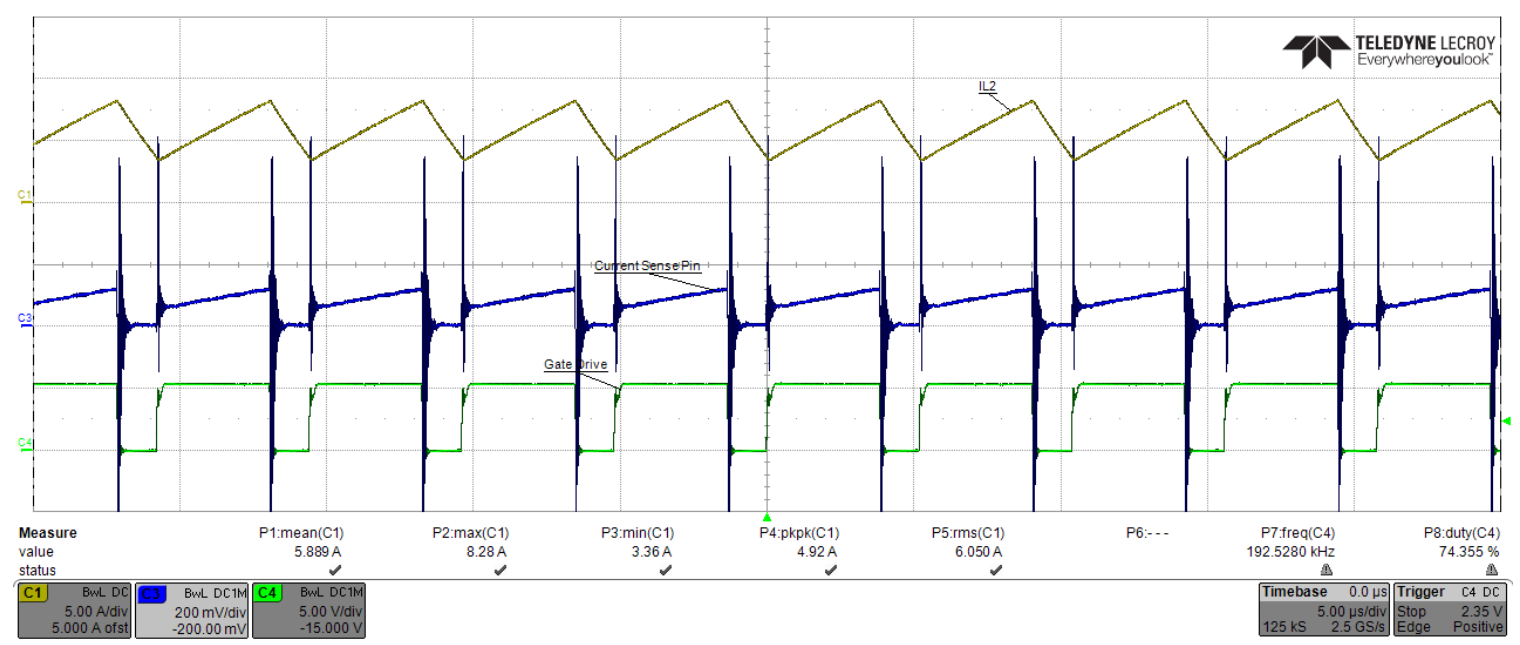

Figure 5-15. Modified Boost Hardware $\mathrm{L}_{2}$ Current

Figure 5-16 illustrates $\mathrm{C}_{1}$ voltage measurement for the modified boost converter.

This measurement determines voltage between the $V_{X}$ and $V_{\text {out }}$ nodes using the scope's math function. Parasitic ringing affects both nodes, and the resulting voltage differential. Small oscillations obscure the underlying waveform shape, which only vaguely resembles simulation results. 


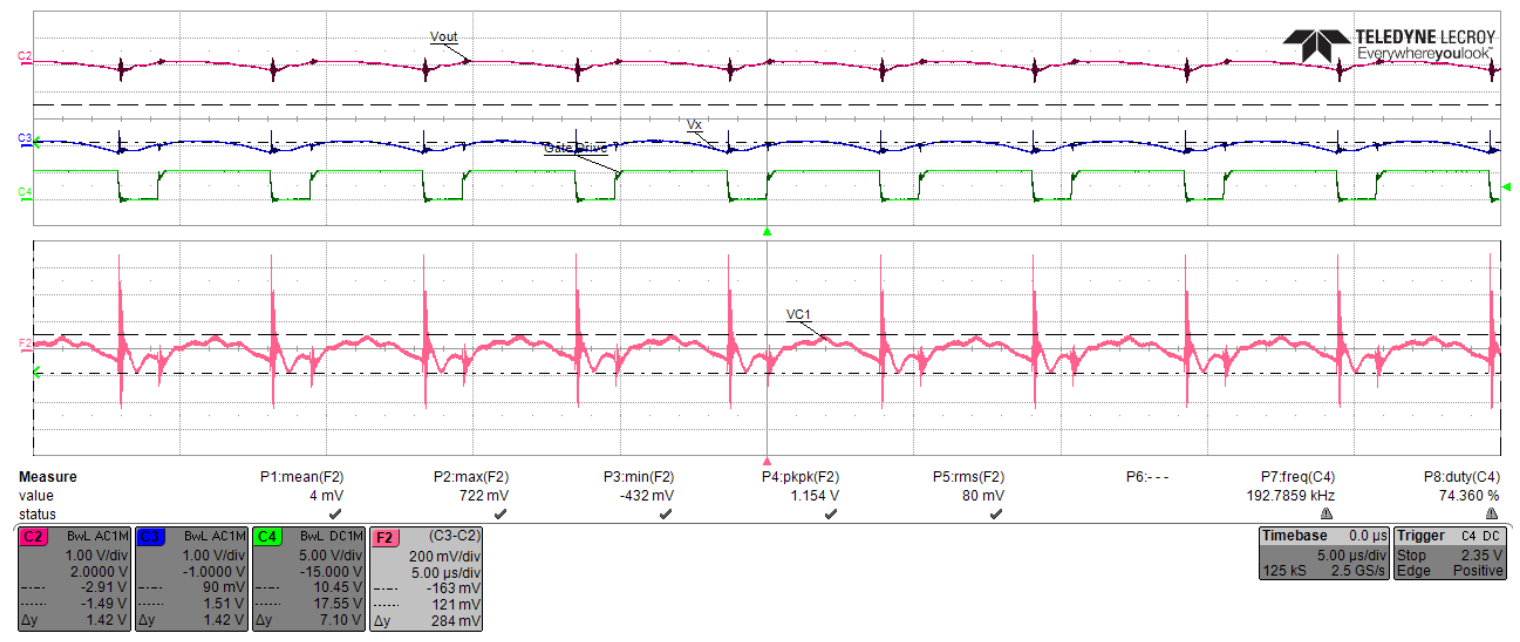

Figure 5-16. Modified Boost Hardware $\mathrm{C}_{1}$ Voltage (AC Coupling)

Figure 5-17 contains the modified boost converter's output voltage measurement.

Ignoring parasitic oscillation and small oscillations, the general waveform shape resembles a quadratic curve with the switch on, and a linear slope with the switch off.

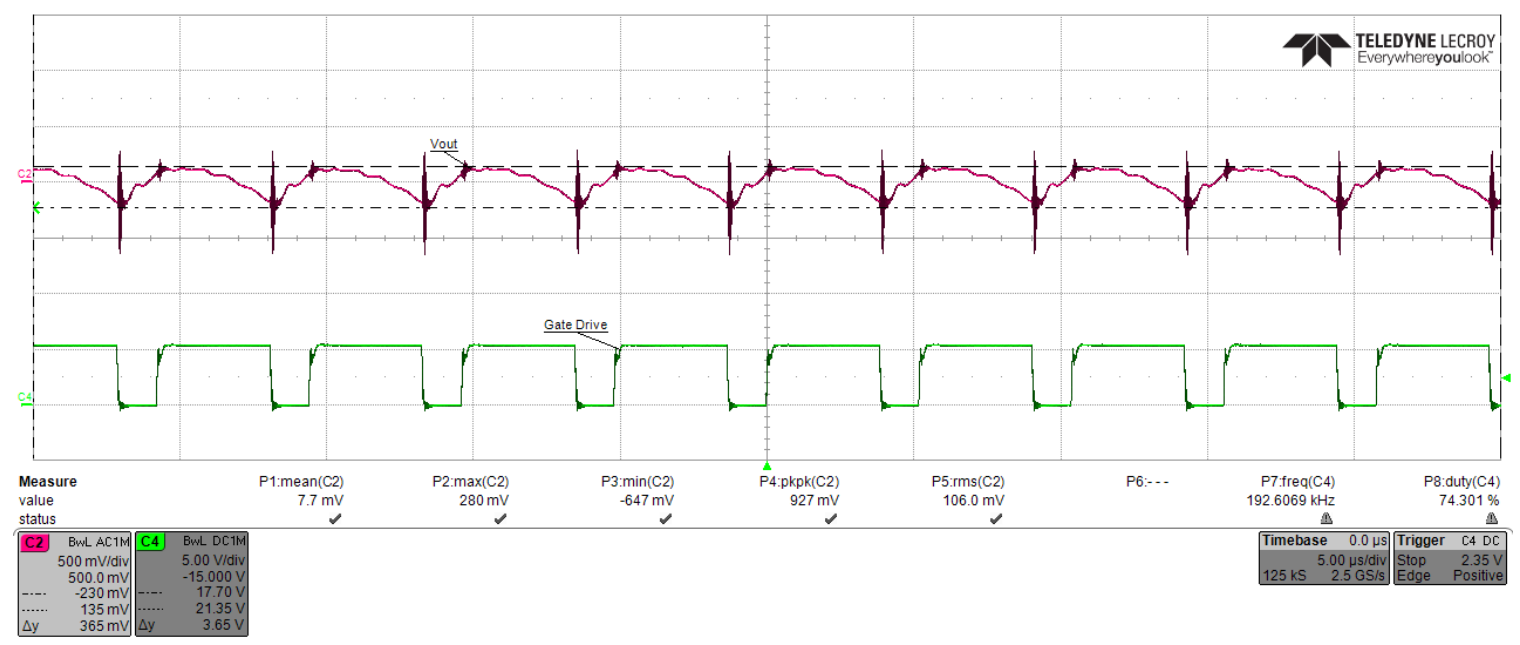

Figure 5-17. Modified Boost Hardware Output Voltage (AC Coupling)

Table 5-11 lists the modified boost converter state variable measurements. Like the standard converter, power dissipation increased the average inductor currents and duty cycle. Inductor tolerances, increased duty cycle, and decreased switching frequency impact peak-to-peak $\mathrm{L}_{2}$ current ripple; larger average $\mathrm{L}_{2}$ current keeps the percent ripple 
close to the nominal $80 \%$ value. Despite non-ideal output voltage regulation, the $\mathrm{C} 1$ voltage remains consistent with the converter's DC characteristics; the difference between average input voltage $(5.3 \mathrm{~V})$ and output voltage. Larger L2 ripple current also increases $\mathrm{C}_{1}$ and output voltage ripple.

Table 5-11. Modified Boost Converter Hardware Test Results

\begin{tabular}{|c|c|c|c|c|}
\hline & IL1 (A) & IL2 (A) & VC1 $_{\text {(V) }}$ & V out (V) \\
\hline Average & 5.7905 & 5.889 & -12.512 & 17.825 \\
\hline RMS & 5.7928 & 6.05 & 12.512 & 17.825 \\
\hline AC RMS & 0.1636 & 1.41 & 0.08 & 0.106 \\
\hline Max. & 6.116 & 8.349 & -12.391 & 17.96 \\
\hline Min. & 5.53 & 3.469 & -12.675 & 17.595 \\
\hline Peak-Peak & 0.586 & 4.88 & 0.284 & 0.365 \\
\hline \% Ripple & $10.12 \%$ & $82.87 \%$ & $2.27 \%$ & $2.05 \%$ \\
\hline
\end{tabular}

\subsubsection{Irregular Conduction Limitations}

Theoretically, raising the controller's current limit further, by lowering sense resistance, allows both converters to regulate output voltage closer to the nominal value at full load. In practice, operating too far below the controller's current limit caused irregular conduction patterns. Figure 5-18 shows the standard boost converter's irregular periodic conduction under $800 \mathrm{~mA}$ loading. 


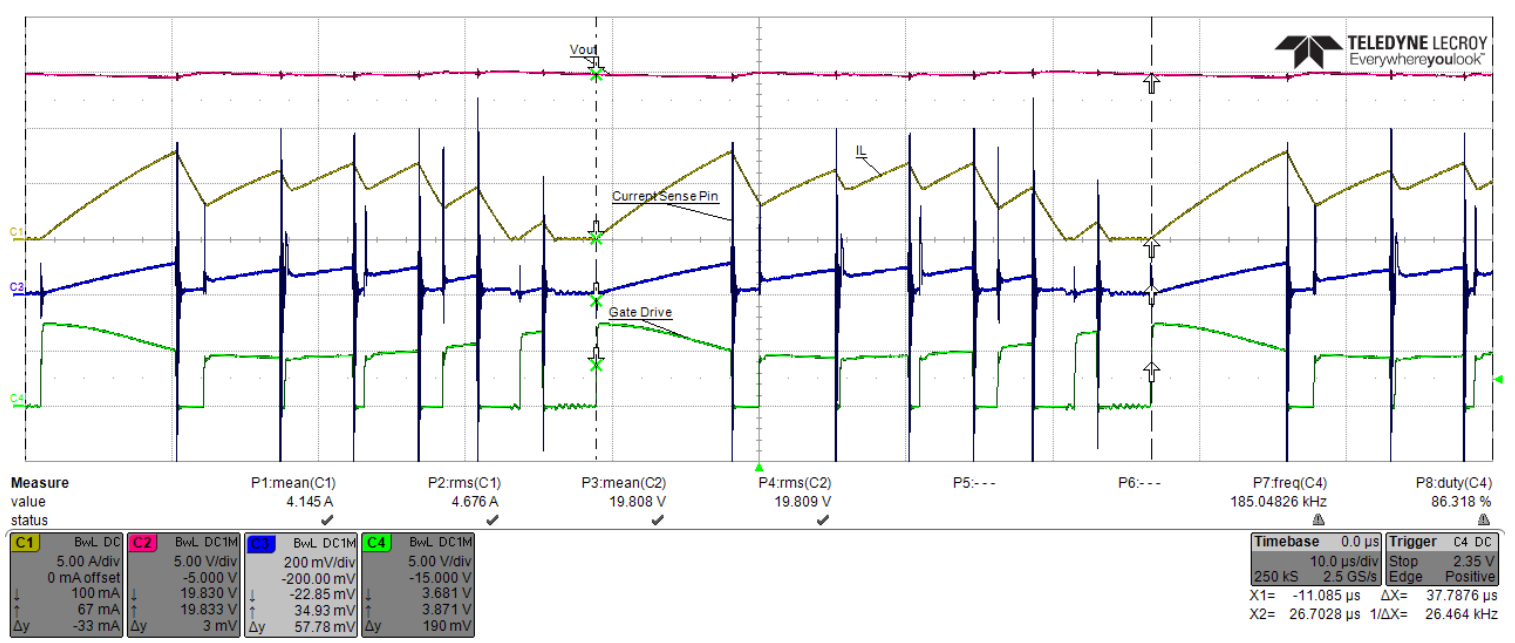

Figure 5-18. Standard Boost Subharmonic Oscillation at $800 \mathrm{~mA} \mathrm{Load}$

Figure 5-19 shows the modified boost converter's irregular conduction pattern under 1.1 A loading.

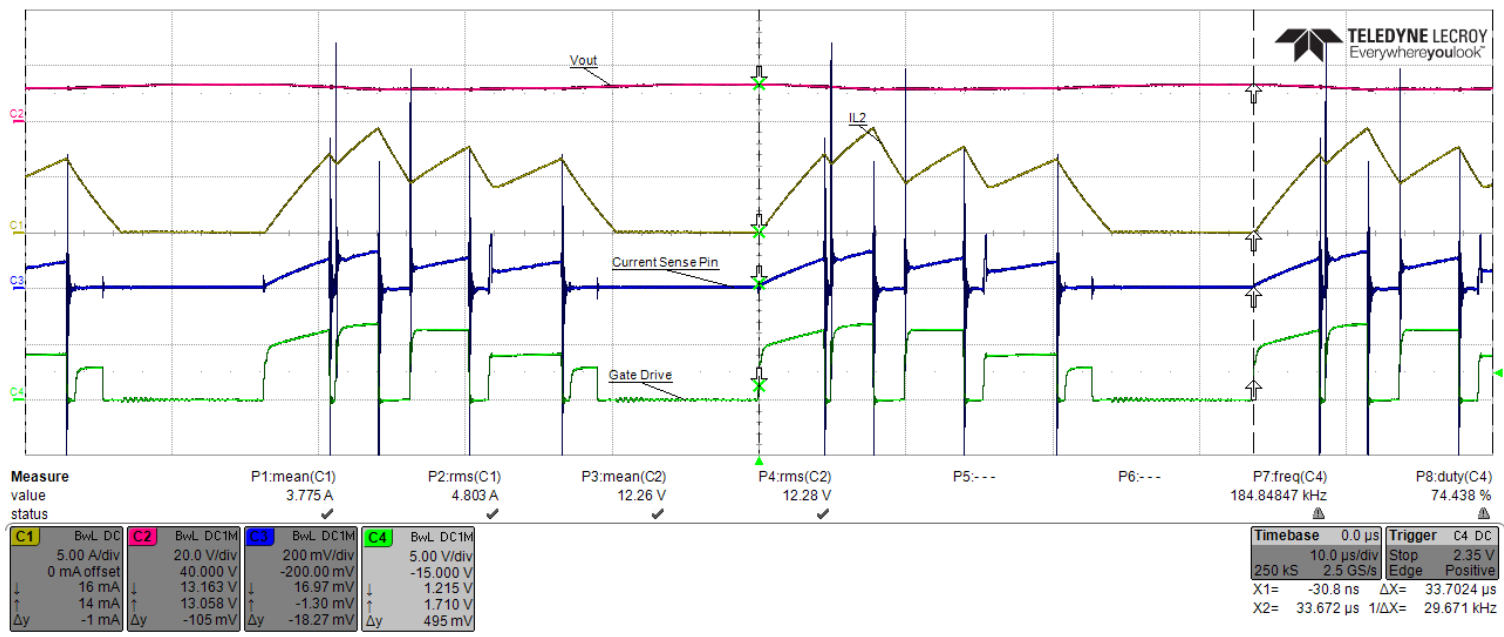

Figure 5-19. Modified Boost Subharmonic Oscillation at 1.1 A Load

The inductor currents resemble the subharmonic oscillations that occur in currentcontrolled converters at duty cycle above 50\% [37]. The LM3478 provides internal slope compensations to prevent subharmonic oscillation. The datasheet establishes a sense resistance limit (5-4), beyond which additional slope compensation becomes necessary. The converter parameters establish a $46 \mathrm{~m} \Omega$ sense resistance limit, well above the 
original $(15 \mathrm{~m} \Omega)$ and final $(12 \mathrm{~m} \Omega)$ implemented values. Despite similar appearances, subharmonic oscillation does not completely explain the irregular conduction patterns.

Both converters exhibit similarly irregular inductor current, suggesting the control system, identical in each converter, causes the behavior. This issue prevents further improving output voltage regulation at full load. Neither converter could achieve steadystate, CCM operation under 1.5 A loading with a sense resistor less than $12 \mathrm{~m} \Omega$.

\subsection{Performance Comparison}

Several hardware factors forcing non-ideal operation affected the two converters differently. Average output voltage at full load, dependent on the controller's current limit, differs by $0.53 \mathrm{~V}$ (Table 5-7). Larger peak current through the switch caused lower output voltage in the modified boost converter. The controller's internal current limit tolerance also impacts the output voltage difference for better or worse. Switching frequency averages $185.7 \mathrm{kHz}$ in the standard boost and $192.6 \mathrm{kHz}$ in the modified boost. The difference, $6.9 \mathrm{kHz}$ (3.72\%), falls outside the frequency adjust resistor network's $2 \%$, implicating internal oscillator tolerances. Parasitic resistances along the power path, due to layout or component tolerances, cause conduction losses. Switching losses change with frequency, parasitic MOSFET capacitance, and diode reverse recovery. Converter efficiency, the accumulation of these loss factors, differs by $0.93 \%$ (Table 5-8); most importantly affecting the average inductor currents.

Despite these differences, the modified boost converter hardware demonstrates a significant input current ripple reduction on a percent basis. Table 5-12 summarizes the input current performance of each converter. 
Table 5-12. Hardware Input Current Ripple Comparison

\begin{tabular}{|c|c|c|c|}
\hline & Standard Boost & Modified Boost & Difference \\
\hline Average & $6.082 \mathrm{~A}$ & $5.7905 \mathrm{~A}$ & $0.2915 \mathrm{~A}$ \\
\hline Peak-Peak & $3.19 \mathrm{~A}$ & $0.586 \mathrm{~A}$ & $2.604 \mathrm{~A}$ \\
\hline \%Ripple & $52.45 \%$ & $10.12 \%$ & $42.33 \%$ \\
\hline
\end{tabular}

The converters' average inductor current exceeds the nominal 5 A value. Peak-topeak current ripple also tops simulated values (Table 4-10). Relative to the simulations, both hardware measures increase almost proportionally in each converter; the corresponding hardware current ripple percentages both calculate approximately $10 \%$ above simulated values. Thus, the modified boost converter provides consistent input current ripple reduction, $41.08 \%$ to $42.33 \%$, across simulation and hardware. Figure 5-20 illustrates this trend.

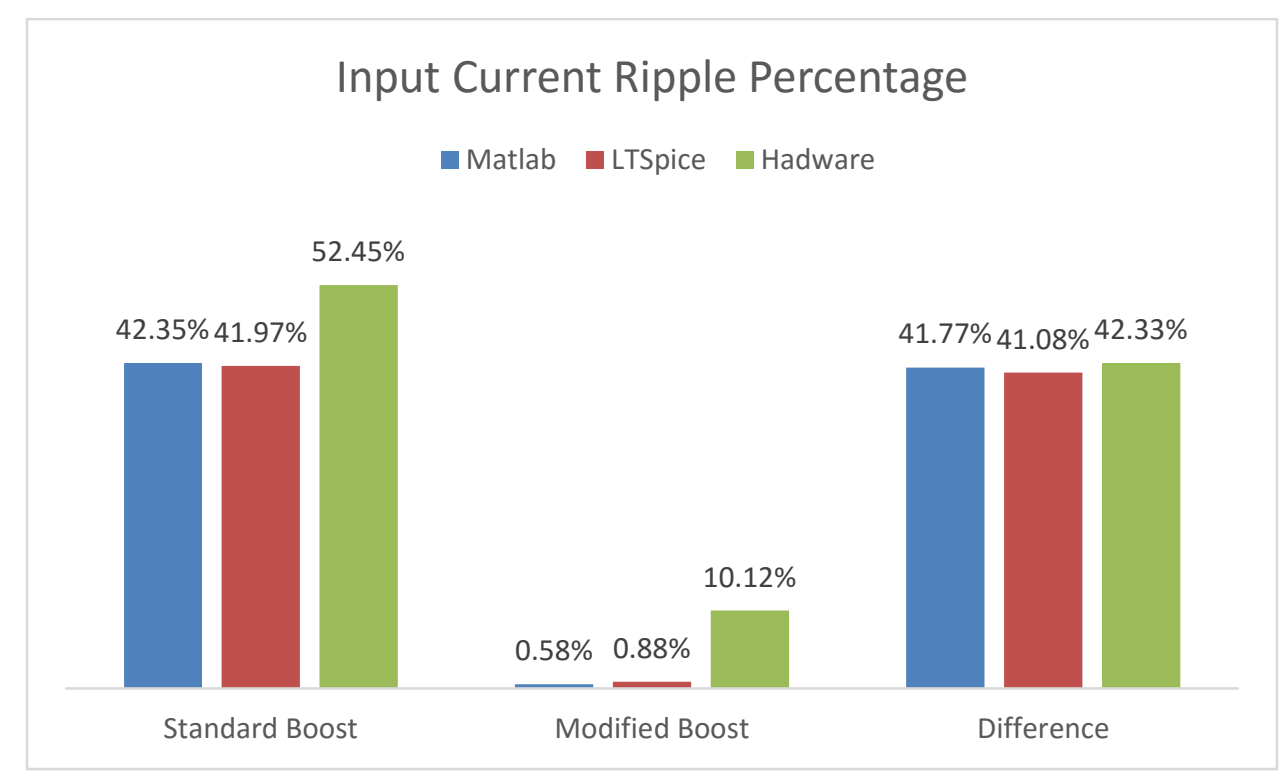

Figure 5-20. Input Current Ripple Performance in Simulation and Hardware 


\section{CONCLUSION}

This thesis demonstrates the significant input current ripple reduction, approximately $40 \%$, provided by Karanam's modified boost converter. The topological modification prevents complete analysis using simplistic DC/DC converter techniques. A state-space analysis describes the converter's steady-state, CCM operation and numerical state-equation solutions provide theoretical current ripple measurements. This approach produces results consistent with a standard LTSpice simulation.

Hardware realities created differing output voltage conditions under full load. Current through each converter exceeds theoretical expectations due to power dissipation. Minimizing the difference between the converters' DC output voltage required adjusting the switching controller's current limit. Lowering the current sense resistance raises the current limit, improving output regulation. An unexplained control system property prevents CCM operation under 1.5 A loading, with a sense resistor lower than $12 \mathrm{~m} \Omega$. This prevents ideal output voltage regulation in both converters. During final testing, the converters average output voltages differed by $0.53 \mathrm{~V}$, the maximally equivalent operating condition achieved.

The hardware performance measurements reflect the impact of component tolerances and parasitic effects. Percent input current ripple increased in both converters, compared against simulated predictions. Regardless, the percent current ripple reduction, between the standard and modified boost topologies, remains consistent across hardware; 41.77\%, 41.08\%, and 42.33\% in Matlab, LTSpice, and hardware. The consistency demonstrates the topological modification's benefit, in theory and practice. 
Reducing a boost converter's input current ripple generally benefits many applications. The modified boost converter either reduces input ripple, given a fixed input capacitance, or reduces the input capacitance required to ensure a specified input ripple. The modified topology does not require additional inductance or a significant board area increase. These characteristics all benefit noise-sensitive, space- and cost-constrained systems such as solar PV microinverters or battery-powered portable electronics.

Widespread application of Karanam's modified boost converter faces significant challenges. This thesis concerned only the converter's steady-state, CCM operation. Future work must also examine steady-state, DCM operation using a new or similar analysis technique. An optimized, iterative state-equation solution method would benefit any future CCM or DCM analysis. While functional, the method this work proposes provides minimal computational efficiency. These future analyses may provide optimized design procedures necessary to repeatedly implement the modified boost topology. The converter's transient characteristics also merit further investigation. Modelling the voltage- and current-mode control transfer functions would inform controller selection and optimal loop compensation. This future work will decide the circumstances where Karanam's modified boost converter provides the most benefit. 


\section{REFERENCES}

[1] U.S. Energy Information Administration, "International Energy Output 2016," 11 May 2016. [Online]. Available: https://www.eia.gov/outlooks/ieo/.

[2] P. T. Krein, "Introduction," in Power Electronics Handbook, Burlington, MA, Elsevier, 2011, pp. 1-14.

[3] S. Maniktala, Switching Power Supplies A to Z, Burlington, MA: Elsevier, 2006.

[4] P. Sripodok and C. Jettanasen, "Mitigation of Conducted and Radiated EMI Generation in High-Frequency Switching Devices," in Proc. of the Int. MultiConference of Engineers and Computer Scientists 2015 Vol II, Hong Kong, 2015.

[5] S. Wu, K. Kam, D. Pommerenke, B. Cornelius, H. Shi, M. Herndon and J. Fan, "Investigation of Noise Coupling from Switching Power Supply to Signal Nets," in 2010 IEEE Symp. on Electromagnetic Compatibility (EMC), Fort Lauderdale, 2010.

[6] S. Jeon, J.-H. Kwon, B. C. Kim, J.-I. Moon, S.-M. Kim, S.-W. Kim and I.-K. Cho, "Study of Noise Reduction from SMPS in the Wireless Power Transmission System," in Proc. of the 2016 Int. Symp. on Antennas and Propagation, Okinawa, 2016.

[7] K. Koo, J. Kim, M. Kim and J. Kim, "Impact of PCB Design on Switching noise and EMI of Synchronouse DC-DC buck Converter," in 2010 IEEE Int. Symp. on Electromagnetic Compatibility (EMC), Fort Lauderdale, 2010.

[8] N. D. Benavides and P. L. Chapman, "Modeling the Effect of Voltage Ripple on the Power Output of Photovoltaic Modules," IEEE Trans. on Industrial Electronics, vol. 55, no. 7, pp. 2638-2643, 2008.

[9] D. M. K. Schofield, M. P. Foster and D. A. Stone, "Impact of Ripple Current on the Average Output Power of Solar Cells," in 6th IET Int. Conf. on Power Electronics, Machines, and Drives, 2012.

[10] Y. Yu and J. J. Beiss, "Some design aspects concerning input filters for DC-DC converters," in IEEE Power Electronics Specialists Conf., 1971.

[11] R. D. Middlebrook, "Input Filter Considerations in Design and Application of Switching Regulators," in IEEE Industry Applications Soc. Ann. Meeting, Chicago, IL, 1976.

[12] R. D. Middlebrook, "Design techniques for preventing input-filter oscillations in switched-mode regulators," in 5th Nat. Solid State Power Conversion Conf., San Francisco, CA, 1978. 
[13] Y. Jang and R. W. Erickson, "Physical Origins of Input Filter Oscillations in Current Programmed Converters," IEEE Trans. on Power Electronics, vol. 7, no. 4, pp. 725 733, 1992.

[14] R. W. Erickson, "Optimal Single Resistor Damping of Input Filters," in Fourteenth Annual Applied Power Electronics Conference and Exposition, 1999.

[15] X. Yu and M. Salato, "An Optimal Minimum-Component DC-DC Converter Input Filter Design and Its Stability Analysis," IEEE Trans. on Power Electronics, vol. 29, no. 2, pp. 829-840, 2014.

[16] T. K. Phelps and W. S. Tate, "Optimizing Passive Input Filter Design," in Proc. of the Sixth National Solid-State Power Conversion Conference, Miami Beach, FL, 1979.

[17] M. U. Iftikhar, D. Sadarnac and C. Karimi, "Input Filter Design for Control Loop Stability of DC-DC Converters," in IEEE Int. Symp. on Industrial Electronics, 2007.

[18] F. C. Lee and Y. Yu, "Input-Filter Design for Switching Regulators," IEEE Trans. on Aerospace and Electronic Systems, Vols. AES-15, no. 5, pp. 627-634, 1979.

[19] C. A. Nwosu and G. C. Asomba, "Mitigation of Stability Problem in a Boost Converter having an Input Filter," The Pacific Journal of Science and Technology, vol. 9, no. 2, pp. 328-336, 2008.

[20] D. Baba, "Texas Instruments," 2012. [Online]. Available: http://www.ti.com/lit/an/slyt449/slyt449.pdf. [Accessed 20 April, 2017].

[21] X. Zhou, P.-L. Wong, P. Xu, F. C. Lee and A. Q. Huang, "Investigation of Candidate VRM Topologies for Future Microprocessors," IEEE Trans. on Power Electronics, vol. 15, no. 6, pp. 1172-1182, 2000.

[22] P. Xu, J. Wei and F. C. Lee, "Multiphase Coupled-Buck Converter - A Novel High Efficient 12 V Voltage Regulator Module," IEEE Trans. on Power Electronics, vol. 18, no. 1, pp. 74-82, 2003.

[23] Taufik, R. Prasetyo, D. Dolan and D. Garinto, "A New Multiphse Multi-Interleaving Buck Converter with Bypass LC," in 36th Ann. Conf. on IEEE Industrial Electronics Society, Glendale, 2010.

[24] Taufik, T. Gunawan, D. Dolan and M. Anwari, "Design and Analysis of Two-Phase Boost DC-DC Converter," Int. Journal of Electrical, Computer, Energetic, Electronic and Communication Engineering, vol. 4, no. 7, pp. 1065-1069, 2010.

[25] Y. Talaat, O. Hegazy, A. Amin and P. Lataire, "Control and Analysis of Multiphase Interleaved DC/DC Boost Converter for Photovoltaic Systems," in 2014 Ninth Int. Conf. on Ecological Vehicles and Renewable Energies (EVER), Monte-Carlo, 2014. 
[26] P. K. Sahu, B. P. Ganthia, A. Mohanty and A. K. Panda, "A Multiphase Interleaved Boost Converter for Grid-connected PV System," in 2016 Int. Conf. on Microelectronics, Computing and Communications (MicroCom), Durgapur, 2016.

[27] Taufik, "Introduction to Power Electronics: EE 410", San Luis Obispo, 2015.

[28] J. Wang, W. G. Dunford and K. Mauch, "Modified Boost Converter with Continuous Inductor Current Mode and Ripple Free Input Current," in 27th Ann. IEEE Power Electronics Specialists Conf., Baveno, 1996.

[29] X. Liang, J. Zhao, M. Xia and K. Qu, "Novel High Step-Up Boost Converter with Charge Pump Capacitor," in Proc. of 2013 35th Int. Telecommunications Energy Conf., Hamburg, 2013.

[30] S. M. Manias, G. Kostakis and A. Kandianis, "Novel Boost Converter Topologies With Zero Switching Losses for DC-DC and AC-DC Applications," in 26th Ann. IEEE Power Electronics Specialists Conf., Atlanta, 1995.

[31] L. Duguay, N. Guerrera and M. Ammari, "Novel Boost Converter for Small Power Rectifiers," in 19th Int. Telecommunications Energy Conf., Melbourne, 2002.

[32] V. Karanam, "A Novel Boost Converter with Input-Output Bypass Capacitor", San Luis Obispo, CA: California Polytechnic State Univ. , 2016.

[33] S. Sanakhan, H. M. Mahery, E. Babei and M. Sabahi, "Stability Analysis of Boost DC-DC Converter Using Z-Transform," in 2012 IEEE 5th India Int. Conf. on Power Electronics, Delhi, 2012.

[34] Wurth Elektronik, "WE-FAMI THT Power Inductor," 2017. [Online]. Available: http://katalog.we-online.de/en/pbs/WE-FAMI.

[35] Infineon, "IRF60B217 Datasheet," 5 Jan 2016. [Online]. Available: http://www.mouser.com/ds/2/196/irf60b217-935861.pdf.

[36] ON Semiconductor, "MBR10100G Datasheet," Jan 2012. [Online]. Available: https://www.onsemi.com/pub/Collateral/MBR1080-D.PDF.

[37] Texas Instruments, "LM3478 Datasheet," Dec 2014. [Online]. Available: http://www.ti.com/lit/ds/symlink/lm3478q-q1.pdf.

[38] Texas Instruments, "AN-1286 Compensation for the LM3478 Boost Controller," Apr 2013. [Online]. Available: http://www.ti.com/lit/an/snva067c/snva067c.pdf. 


\section{APPENDICES}

\section{A. MATLAB Scripts}

\section{boost_cycle.m}

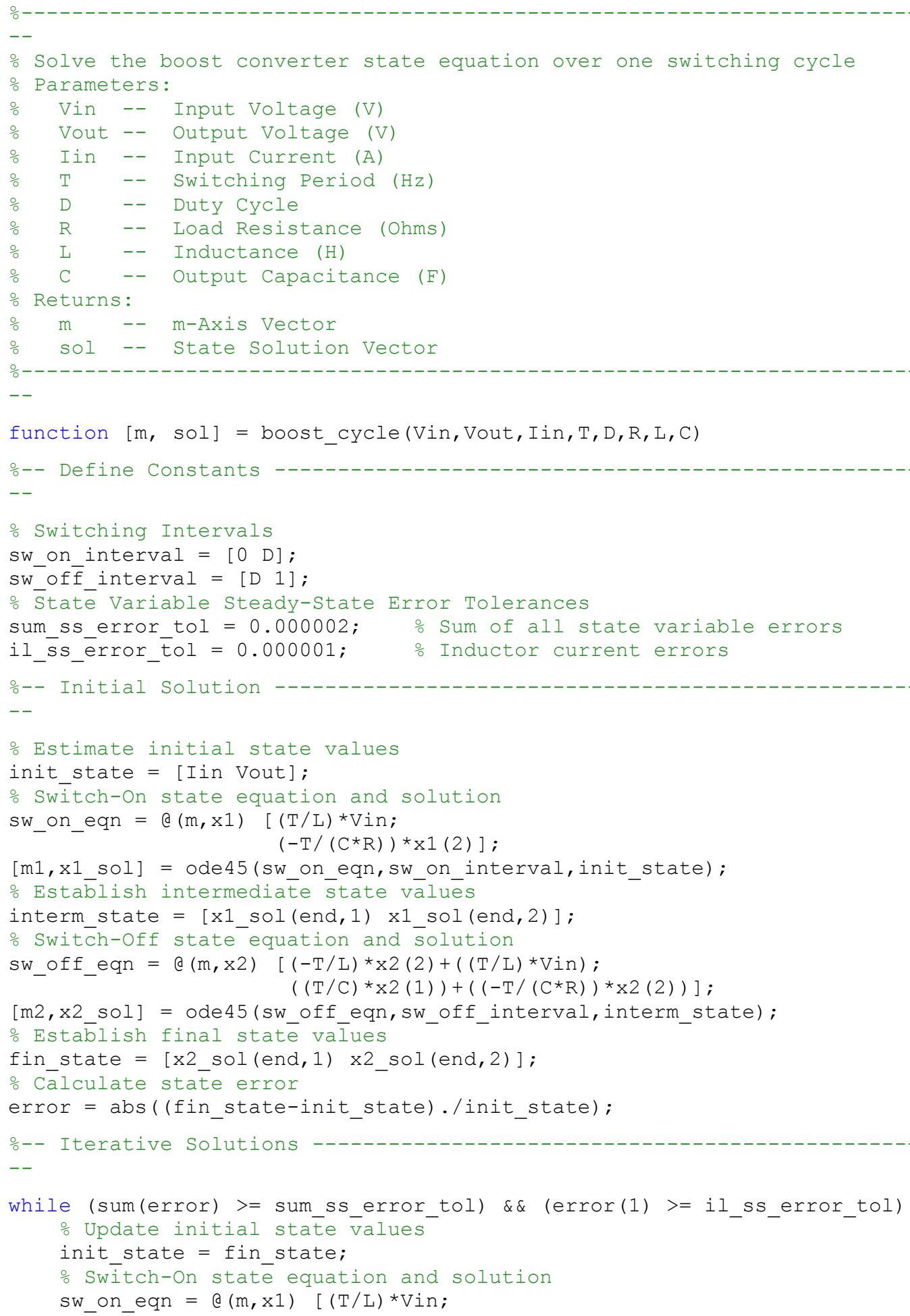




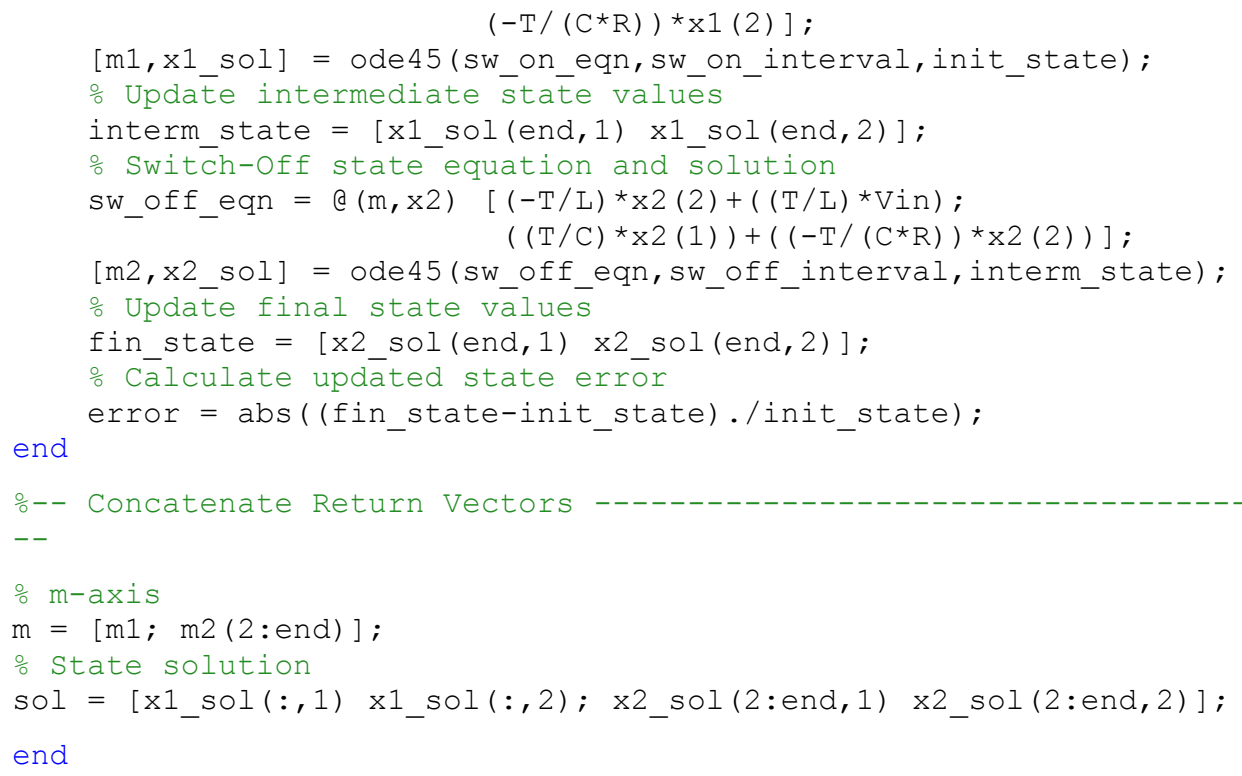

\section{boost_mod_cycle.m}

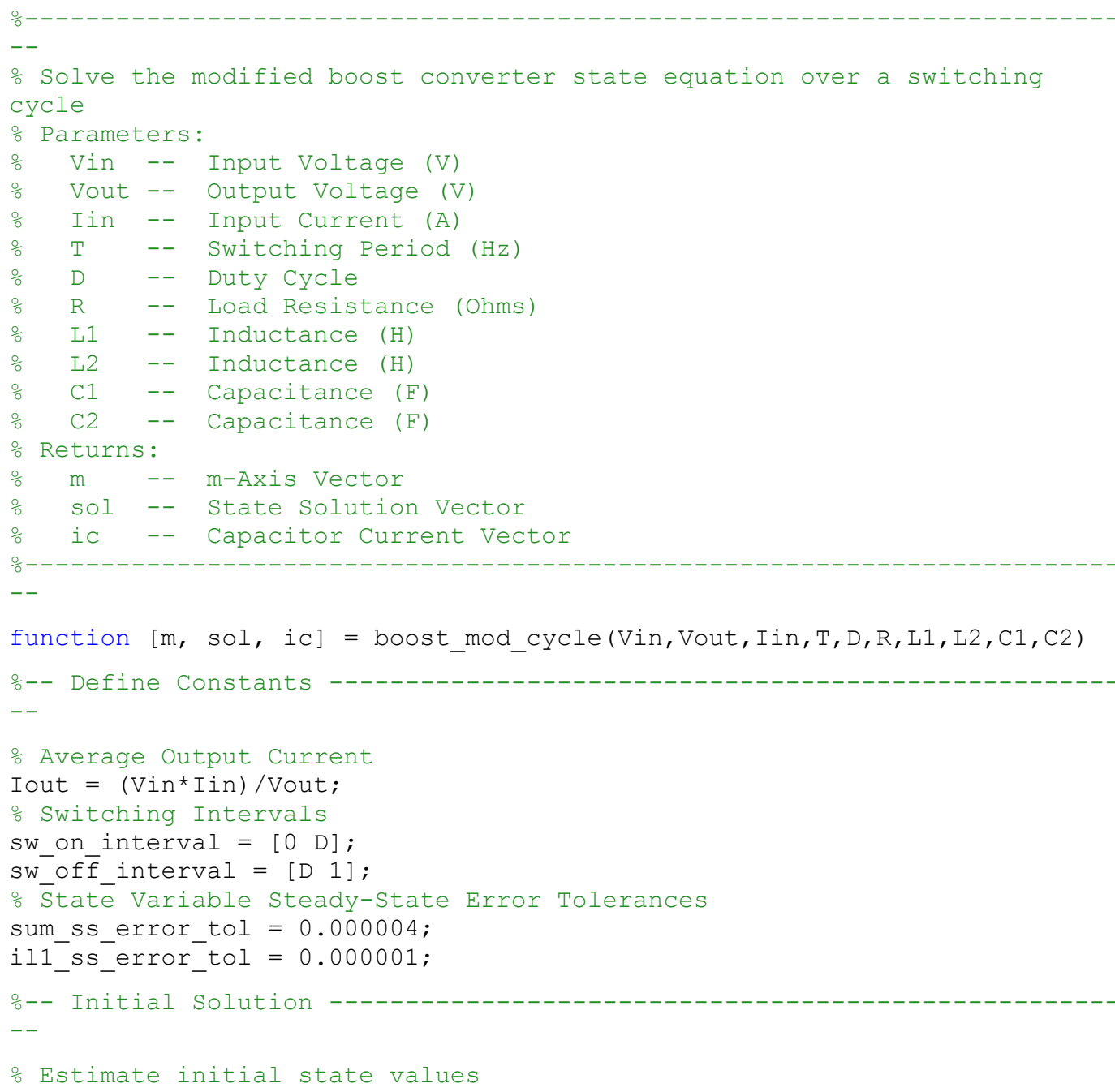




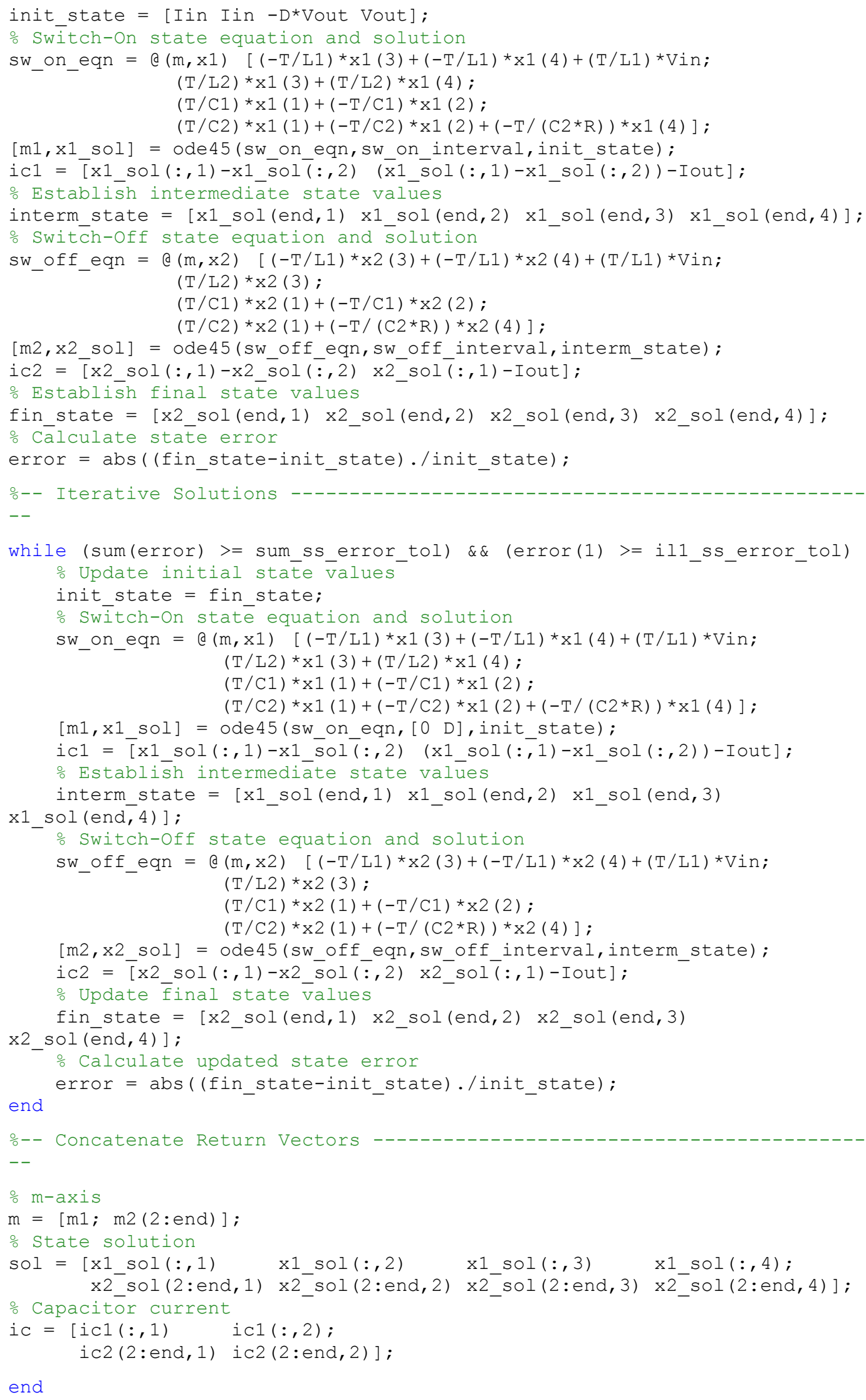




\section{boost_mod_design_comp.m}

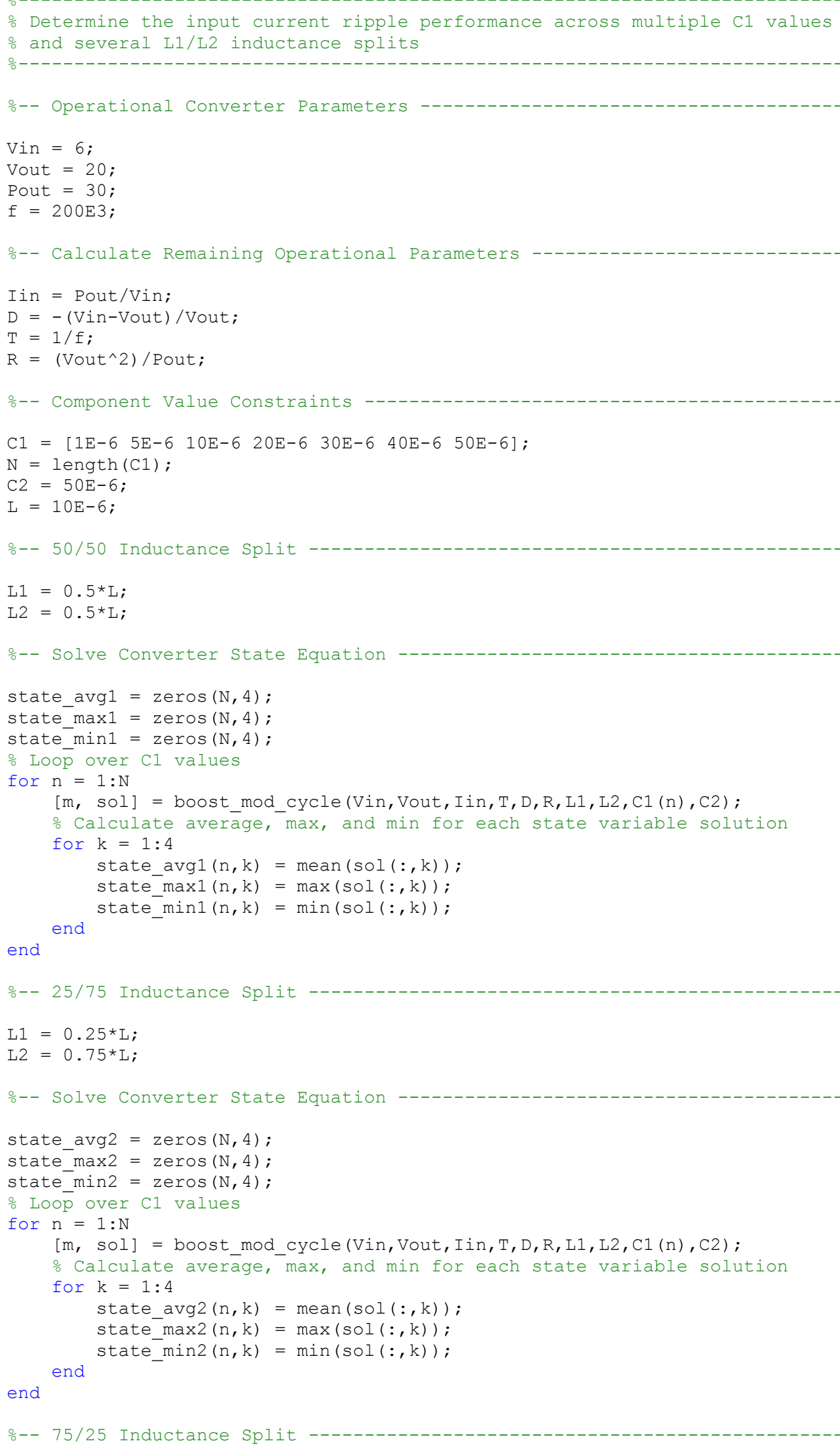




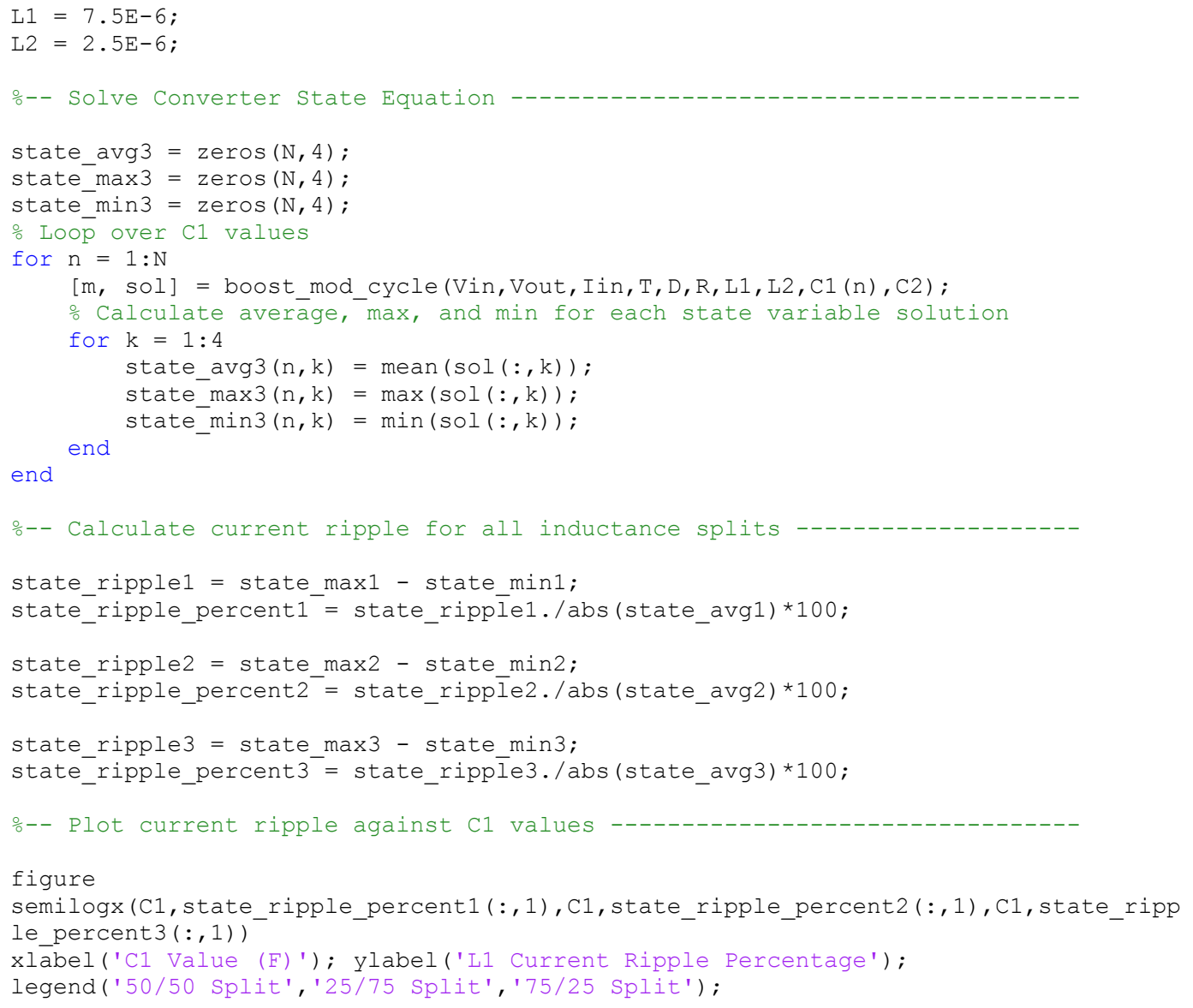

\section{boost_sim.m}

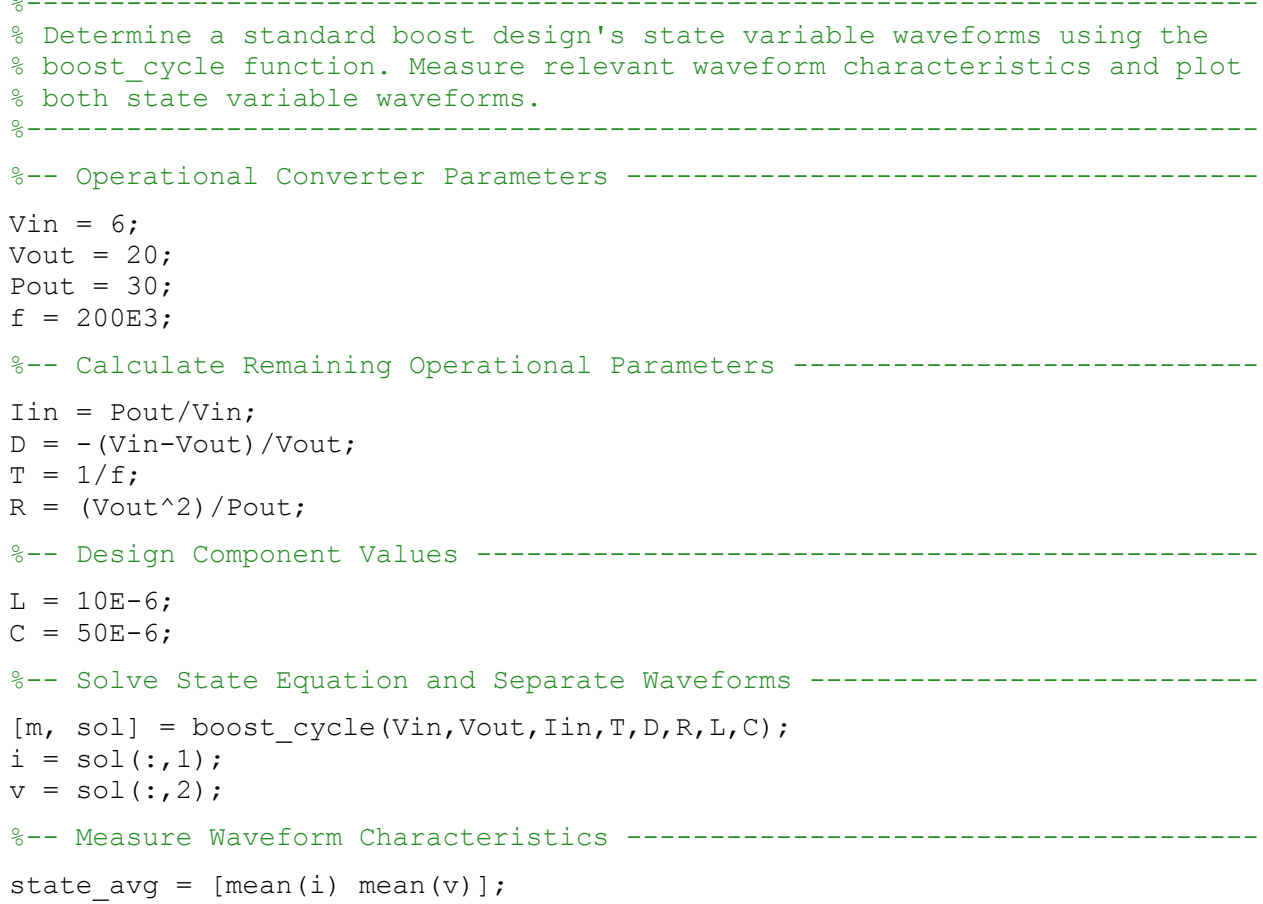




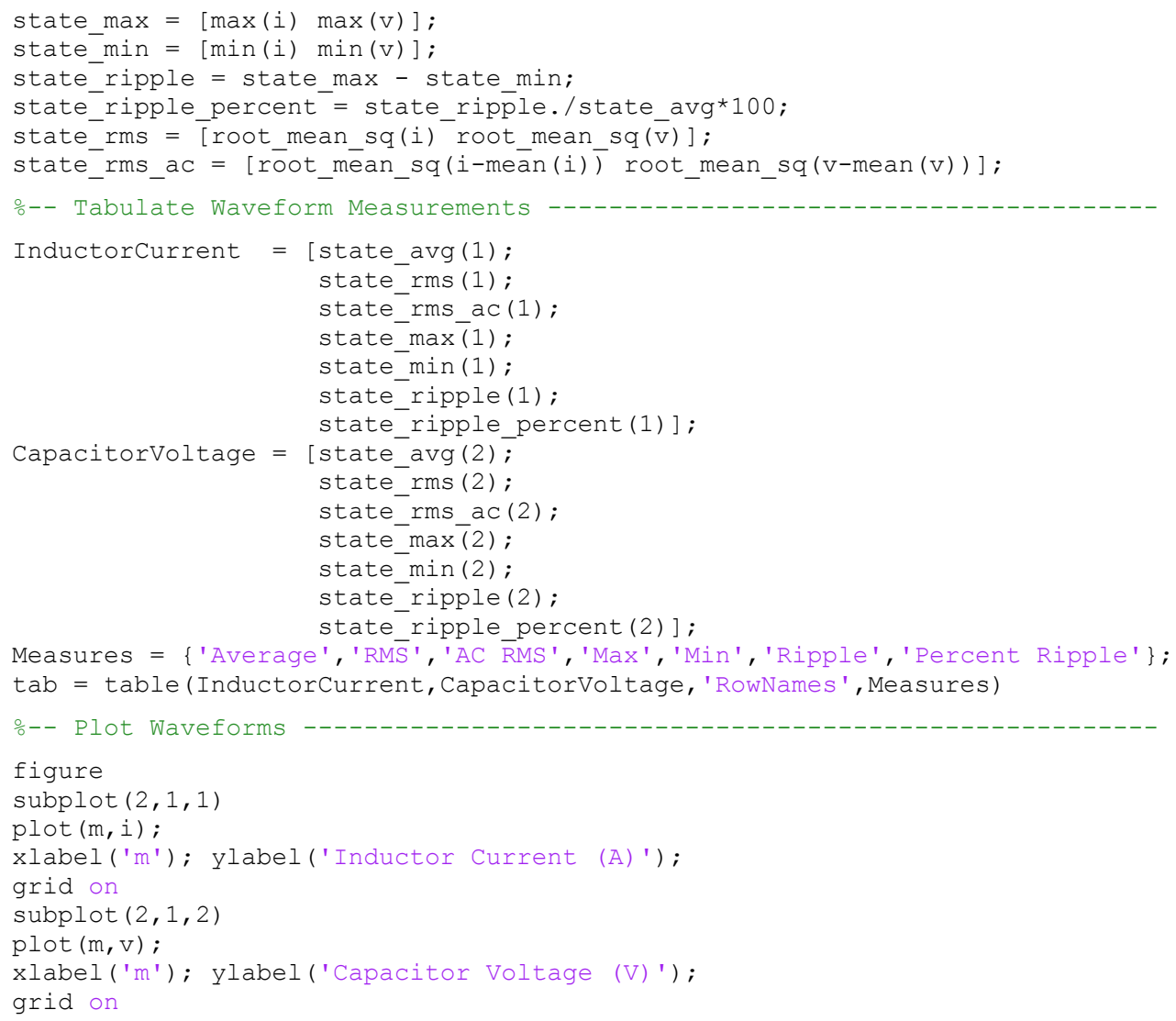

\section{boost_mod_sim.m}

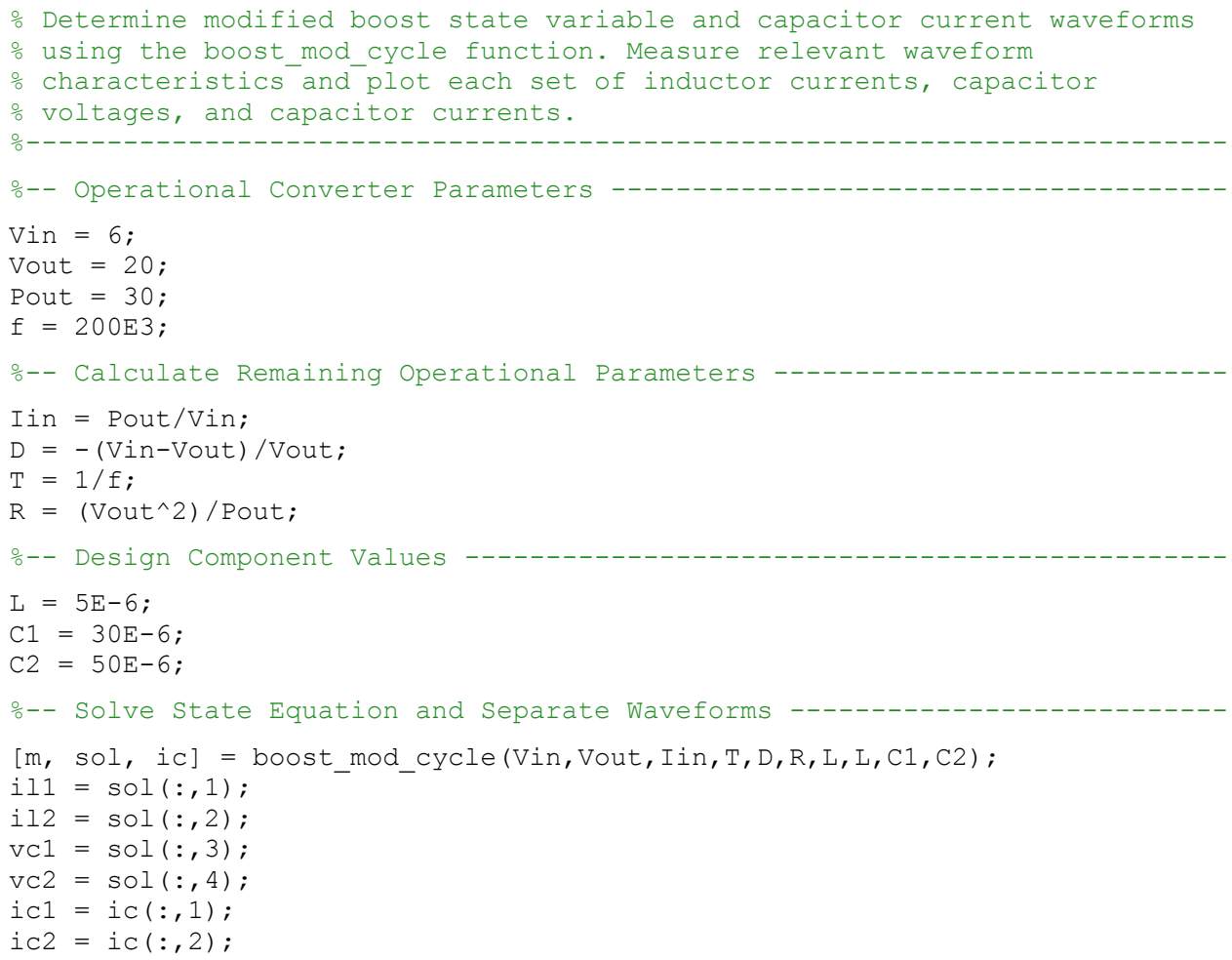




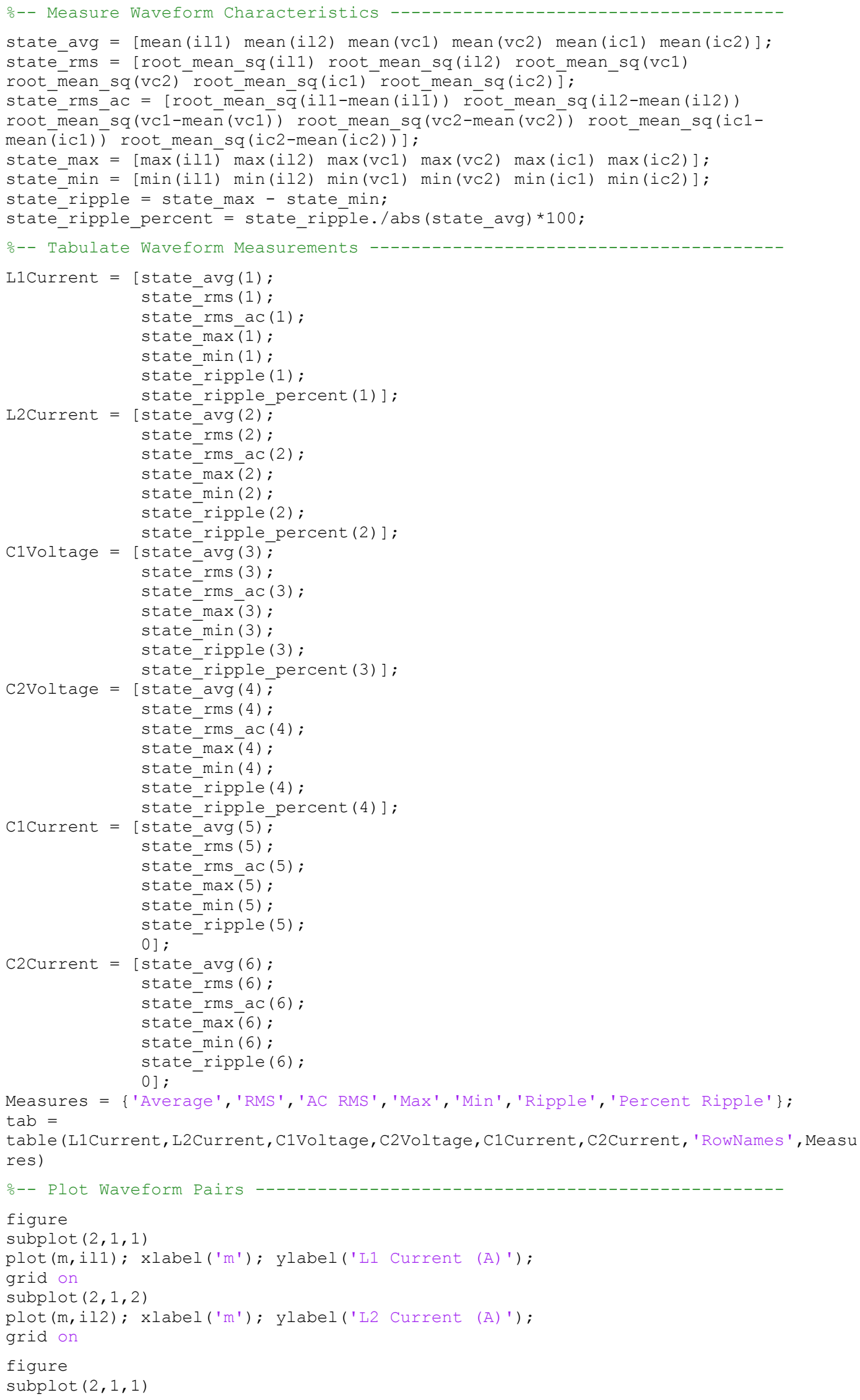


plot (m,vcl); xlabel('m'); ylabel('Cl Voltage (V)'); grid on

subplot $(2,1,2)$

plot (m,vc2); xlabel('m'); ylabel('C2 Voltage (V)'); grid on

figure

subplot $(2,1,1)$

plot (m,icl); xlabel('m'); ylabel('Cl Current (A)'); grid on

subplot $(2,1,2)$

plot (m,ic2); xlabel('m'); ylabel('C2 Current (A)'); grid on 


\section{B. Design Simulation Data}

\section{Matlab}

Table B-1 lists the complete Matlab standard boost design simulation measurement set.

Table B-1. Matlab-simulated Standard Boost Design Measurements

\begin{tabular}{|c|c|c|}
\hline & Inductor Current (A) & Capacitor Voltage (V) \\
\hline Average & 4.9591 & 19.998 \\
\hline RMS & 4.997 & 19.998 \\
\hline AC RMS & 0.6139 & 0.0307 \\
\hline Max. & 6.0215 & 20.048 \\
\hline Min. & 3.9215 & 19.943 \\
\hline Peak-Peak & 2.1 & 0.105 \\
\hline \%Ripple & $42.346 \%$ & $0.5249 \%$ \\
\hline
\end{tabular}

Table B-2 lists the complete Matlab modified boost design simulation measurement set.

Table B-2. Matlab-Simulated Modified Boost Design Measurements

\begin{tabular}{|c|c|c|c|c|c|c|}
\hline & $\begin{array}{c}\mathbf{L}_{1} \\
\text { Current }\end{array}$ & $\begin{array}{c}\mathbf{L}_{2} \\
\text { Current }\end{array}$ & $\begin{array}{c}\mathbf{C}_{1} \\
\text { Voltage }\end{array}$ & $\begin{array}{c}\mathbf{C}_{2} \\
\text { Voltage }\end{array}$ & $\begin{array}{c}\mathbf{C}_{1} \\
\text { Current }\end{array}$ & $\begin{array}{c}\mathbf{C}_{2} \\
\text { Current }\end{array}$ \\
\hline Average & $4.9446 \mathrm{~A}$ & $5.0384 \mathrm{~A}$ & $-14.032 \mathrm{~V}$ & $20.012 \mathrm{~V}$ & $-0.0938 \mathrm{~A}$ & $0.8794 \mathrm{~A}$ \\
\hline RMS & $4.9446 \mathrm{~A}$ & $5.1876 \mathrm{~A}$ & $14.032 \mathrm{~V}$ & $20.012 \mathrm{~V}$ & $1.2429 \mathrm{~A}$ & $2.8323 \mathrm{~A}$ \\
\hline AC RMS & $0.0096 \mathrm{~A}$ & $1.2353 \mathrm{~A}$ & $0.0375 \mathrm{~V}$ & $0.0359 \mathrm{~V}$ & $1.2429 \mathrm{~A}$ & $2.6923 \mathrm{~A}$ \\
\hline Max. & $4.9575 \mathrm{~A}$ & $7.1709 \mathrm{~A}$ & $-13.976 \mathrm{~V}$ & $20.061 \mathrm{~V}$ & $2.0075 \mathrm{~A}$ & $3.4575 \mathrm{~A}$ \\
\hline Min. & $4.9289 \mathrm{~A}$ & $2.95 \mathrm{~A}$ & $-14.075 \mathrm{~V}$ & $19.945 \mathrm{~V}$ & $-2.2343 \mathrm{~A}$ & $-3.7343 \mathrm{~A}$ \\
\hline Peak-Peak & $0.0286 \mathrm{~A}$ & $4.2209 \mathrm{~A}$ & $0.0993 \mathrm{~V}$ & $0.1162 \mathrm{~V}$ & $4.2418 \mathrm{~A}$ & $7.1918 \mathrm{~A}$ \\
\hline \%Ripple & $0.5778 \%$ & $83.77 \%$ & $0.7078 \%$ & $0.5807 \%$ & N/A & N/A \\
\hline
\end{tabular}




\section{LTSpice}

Table B-3 lists the complete LTSpice standard boost design simulation measurement set.

Table B-3. LTSpice Standard Boost Design Measurements

\begin{tabular}{|c|c|c|}
\hline & Inductor Current (A) & Capacitor Voltage (V) \\
\hline Average & 4.9627 & 19.839 \\
\hline RMS & 4.999 & 19.839 \\
\hline Max. & 6.004 & 19.892 \\
\hline Min. & 3.921 & 19.787 \\
\hline Peak-Peak & 2.0827 & 0.1042 \\
\hline \%Ripple & $41.967 \%$ & $0.5252 \%$ \\
\hline
\end{tabular}

Table B-4 lists the complete LTSpice modified boost design simulation measurement set.

Table B-4. LTSpice Modified Boost Design Measurements

\begin{tabular}{|c|c|c|c|c|c|c|}
\hline & $\begin{array}{c}\mathbf{L}_{1} \\
\text { Current }\end{array}$ & $\begin{array}{c}\mathbf{L}_{2} \\
\text { Current }\end{array}$ & $\begin{array}{c}\mathbf{C}_{1} \\
\text { Voltage }\end{array}$ & $\begin{array}{c}\mathbf{C}_{2} \\
\text { Voltage }\end{array}$ & $\begin{array}{c}\mathbf{C}_{1} \\
\text { Current }\end{array}$ & $\begin{array}{c}\mathbf{C}_{2} \\
\text { Current }\end{array}$ \\
\hline Average & $5.0188 \mathrm{~A}$ & $5.0183 \mathrm{~A}$ & $-13.999 \mathrm{~V}$ & $19.993 \mathrm{~V}$ & $523 \mu \mathrm{A}$ & $50 \mu \mathrm{A}$ \\
\hline RMS & $5.0188 \mathrm{~A}$ & $5.1638 \mathrm{~A}$ & $13.999 \mathrm{~V}$ & $19.993 \mathrm{~V}$ & $1.2242 \mathrm{~A}$ & $2.5308 \mathrm{~A}$ \\
\hline Max. & $5.0425 \mathrm{~A}$ & $7.1121 \mathrm{~A}$ & $-13.913 \mathrm{~V}$ & $20.032 \mathrm{~V}$ & $2.1349 \mathrm{~A}$ & $3.5427 \mathrm{~A}$ \\
\hline Min. & $4.9982 \mathrm{~A}$ & $2.9023 \mathrm{~A}$ & $-14.127 \mathrm{~V}$ & $19.234 \mathrm{~V}$ & $-2.0914 \mathrm{~A}$ & $-3.5861 \mathrm{~A}$ \\
\hline Peak-Peak & $0.0444 \mathrm{~A}$ & $4.2098 \mathrm{~A}$ & $0.2134 \mathrm{~V}$ & $0.1084 \mathrm{~V}$ & $4.2263 \mathrm{~A}$ & $7.1288 \mathrm{~A}$ \\
\hline \%Ripple & $0.8847 \%$ & $83.889 \%$ & $1.5244 \%$ & $0.5422 \%$ & N/A & N/A \\
\hline
\end{tabular}




\section{Control Loop Compensation}

Recommended loop compensation places the crossover frequency (C-1) approximately a decade below the boost converter's right-half-plane (RHP) zero [38].

$$
f_{c} \approx \frac{f_{z-R H P}}{10}
$$

A RHP zero (C-2) results from the separation of the inductor and load during the boost converter's switch-on state [38]. The standard boost design's control transfer function contains a RHP zero at approximately $19.1 \mathrm{kHz}$. The compensator places the crossover frequency around $2 \mathrm{kHz}$.

$$
\begin{gathered}
f_{z-R H P}=\frac{R\left(\frac{V_{I N}}{V_{\text {OUT }}}\right)^{2}}{2 \pi \cdot L} \\
f_{z-R H P}=\frac{(13.333 \Omega)\left(\frac{6 \mathrm{~V}}{20 \mathrm{~V}}\right)^{2}}{2 \pi \cdot(10 \mu \mathrm{H})} \approx 19.1 \mathrm{kHz} \\
f_{c} \approx \frac{19.1 \mathrm{kHz}}{10} \approx 2 \mathrm{kHz}
\end{gathered}
$$

The type-I compensator design adds a pole and a zero to the control-to-output transfer function. The compensation capacitor and the error amplifier's output resistance, given as $50 \mathrm{k} \Omega$, place the compensator pole (C-3) approximately two decades below the crossover frequency [38]. The compensation capacitor and resistor place the compensator zero (C-4) near the crossover frequency [38].

$$
\begin{array}{ll}
f_{p-\text { comp }}=\frac{1}{2 \pi \cdot C_{\text {comp }} R_{\text {out }}} \approx \frac{f_{c}}{100} & (C-3) \\
f_{\text {z-comp }}=\frac{1}{2 \pi \cdot C_{\text {comp }} R_{\text {comp }}} \approx f_{c} & (C-4)
\end{array}
$$


The standard component values $150 \mathrm{nF}$ and $536 \Omega$ provide appropriate compensator pole and zero locations.

$$
\begin{aligned}
& f_{p-\text { comp }}=\frac{1}{2 \pi \cdot(150 \mathrm{nF})(50 \mathrm{k} \Omega)}=21.22 \mathrm{~Hz} \\
& f_{z-\text { comp }}=\frac{1}{2 \pi \cdot(150 \mathrm{nF})(536 \Omega)}=1.979 \mathrm{kHz}
\end{aligned}
$$




\section{Hardware Documentation}

\section{Eagle CAD Schematics}

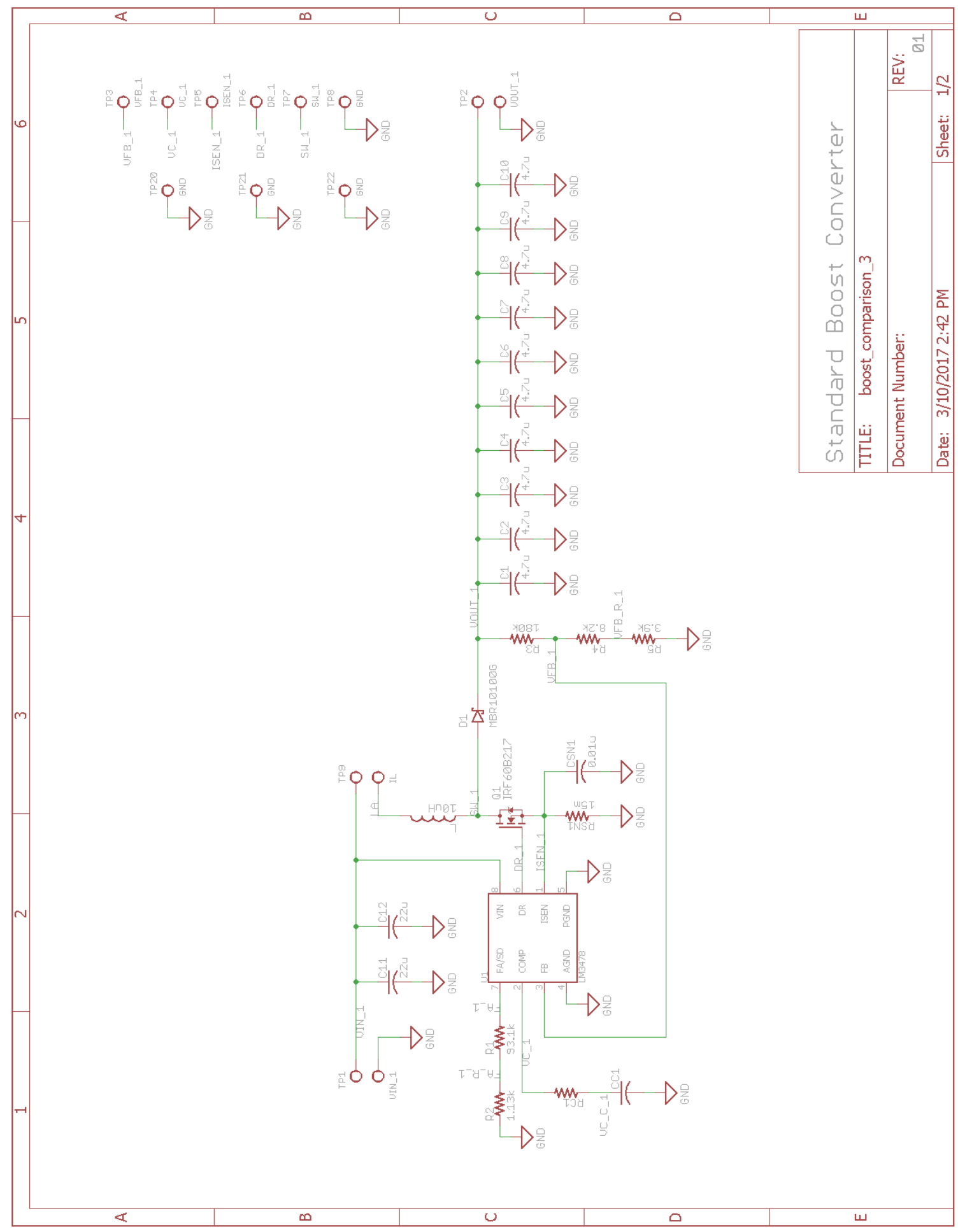

Figure D-1. Standard Boost Converter Eagle CAD Schematic 


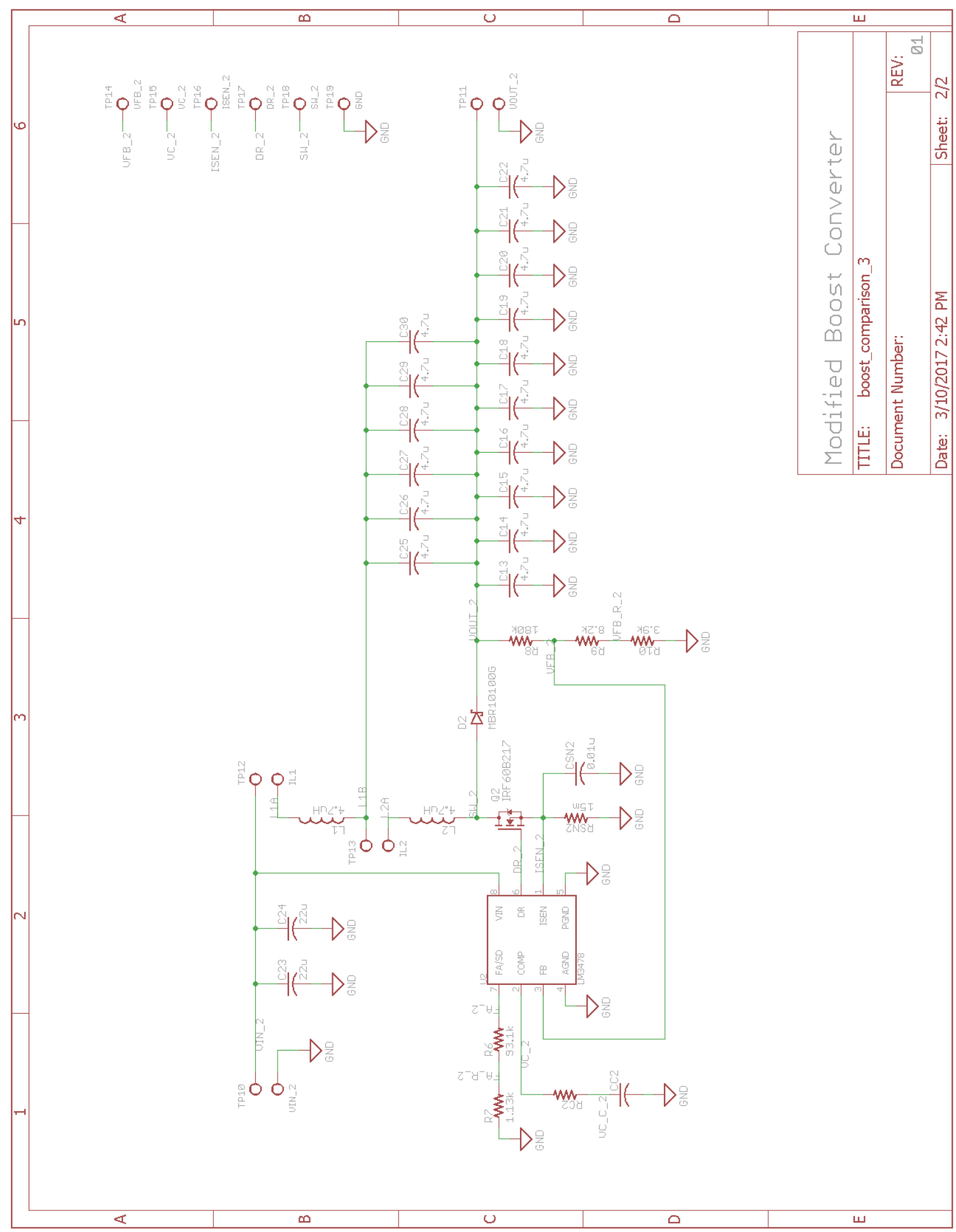

Figure D-2. Modified Boost Converter Eagle CAD Schematic 


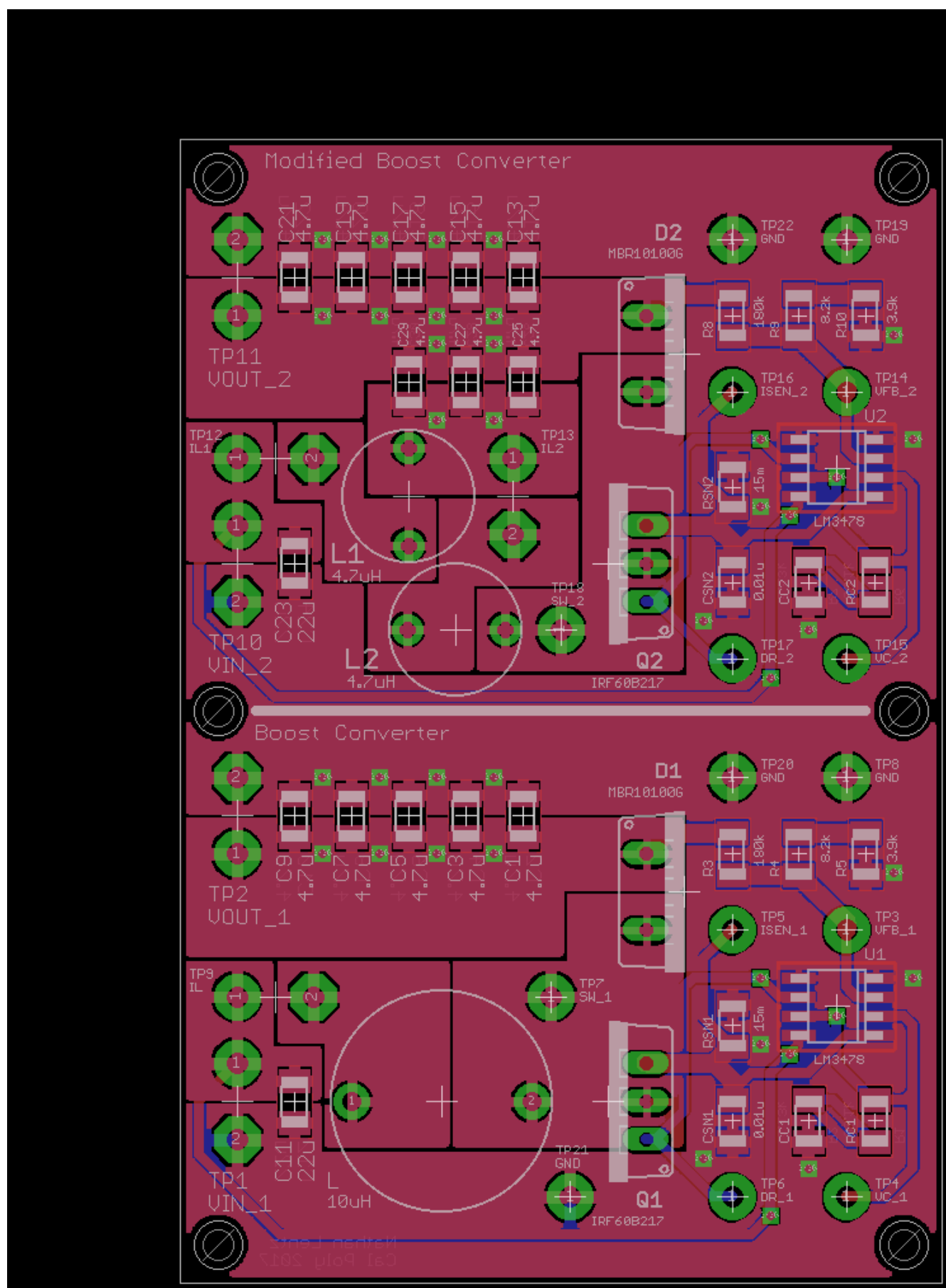

Figure D-3. Eagle CAD PCB Layout 


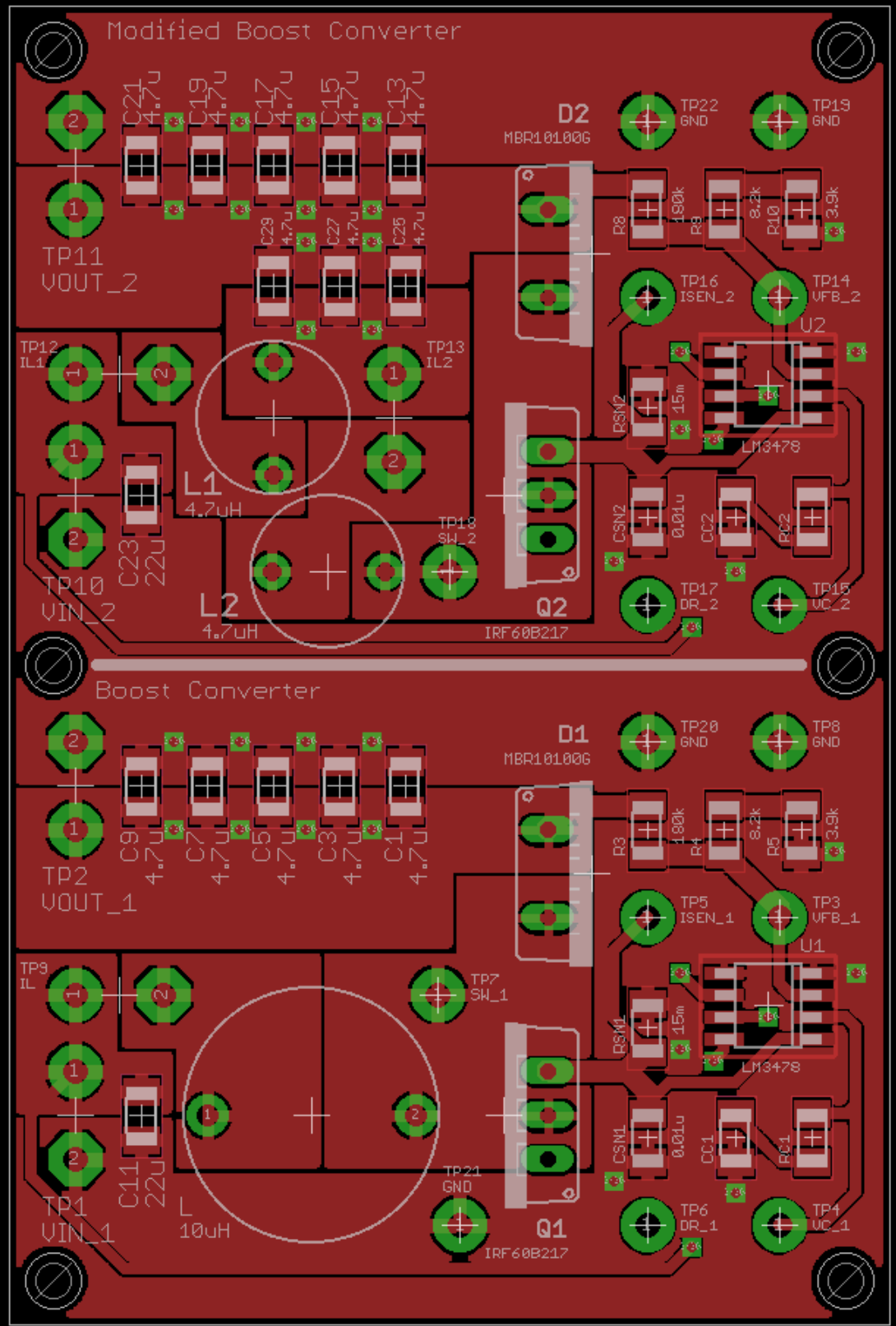

Figure D-4. Top PCB Layer 


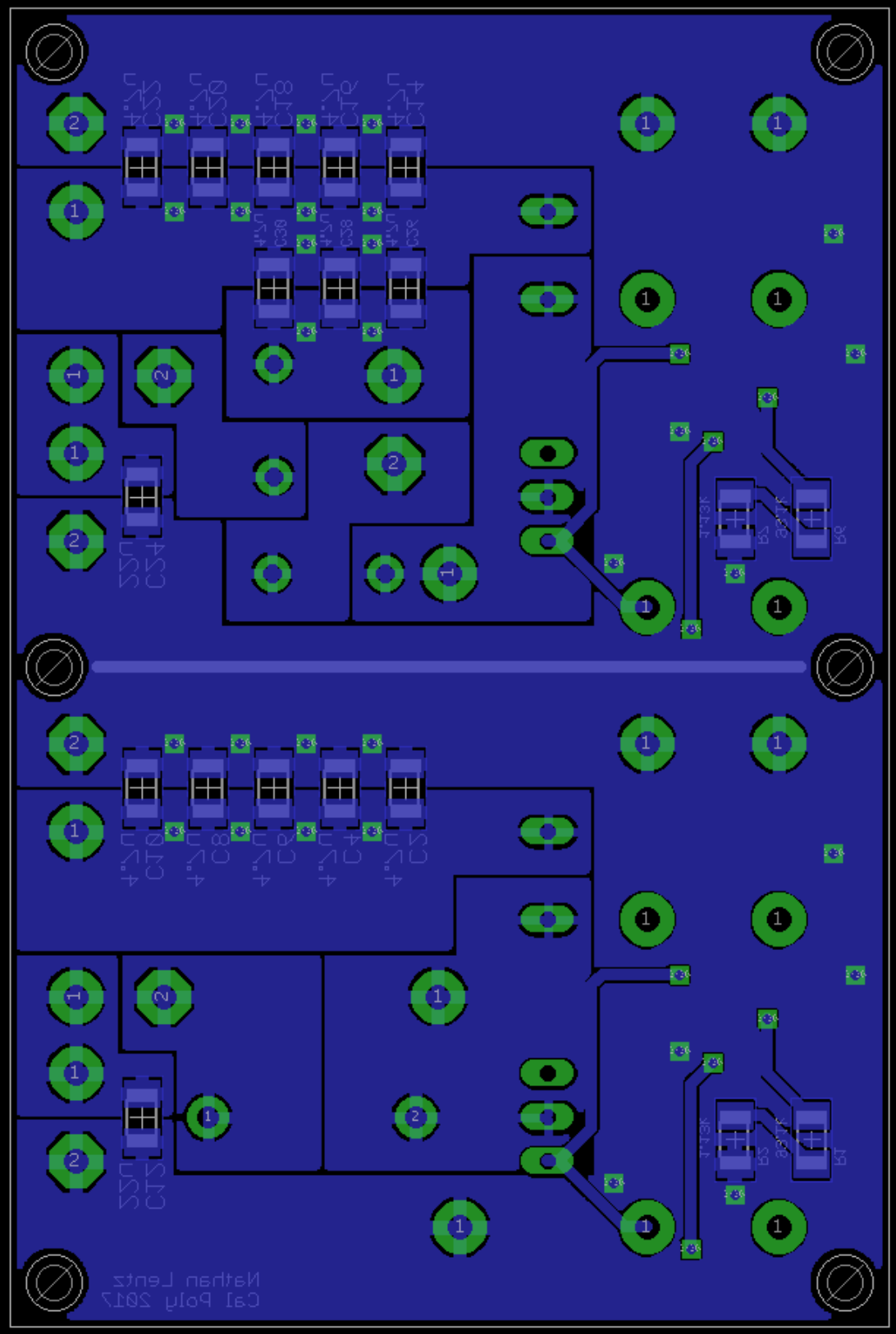

Figure D-5. Bottom PCB Layer 


\section{Bill of Materials}

Table D-5. Electrical Bill of Materials

\begin{tabular}{|c|c|c|c|c|}
\hline Eagle Ref. Des. & Description & Qty. & Mfg. & Part No. \\
\hline RSN1-2 & $15 \mathrm{~m} \Omega$ SMD $12061 \% 250 \mathrm{~mW}$ & 2 & Vishay & WSL1206R0150FEA \\
\hline R1, R6 & $93.1 \mathrm{k} \Omega$ SMD $12061 \% 250 \mathrm{~mW}$ & 2 & Panasonic & ERJ-8ENF9312V \\
\hline $\mathrm{R} 2, \mathrm{R} 7$ & $1.13 \mathrm{k} \Omega$ SMD $12061 \% 250 \mathrm{~mW}$ & 2 & Panasonic & ERJ-8ENF1131V \\
\hline R3, R8 & $180 \mathrm{k} \Omega \mathrm{SMD} 12061 \% 250 \mathrm{~mW}$ & 2 & Panasonic & ERJ-8ENF1803V \\
\hline R4, R9 & 8.2k $\Omega$ SMD $12061 \% 250 \mathrm{~mW}$ & 2 & Panasonic & ERJ-8ENF8201V \\
\hline R5, R10 & $3.9 \mathrm{k} \Omega \mathrm{SMD} 12061 \% 250 \mathrm{~mW}$ & 2 & Panasonic & ERJ-8ENF3901V \\
\hline $\mathrm{RC} 1-2$ & $536 \Omega$ SMD $12061 \% 250 \mathrm{~mW}$ & 2 & Panasonic & ERJ-8ENF5360V \\
\hline $\mathrm{CC} 1-2$ & 0.15uF SMD 1206 100VDC 10\% X7R & 2 & Murata & GRM31MR72A154KA1L \\
\hline $\mathrm{C} 11-12, \mathrm{C} 23-24$ & 22uF SMD 1206 10VDC 20\% X7R & 4 & Murata & GRM31CR71A226ME5L \\
\hline CSN1-2 & 0.01uF SMD 1206 25VDC 5\% X7R & 2 & Kemet & C1206C103J3RAUTO \\
\hline $\mathrm{C} 1-10, \mathrm{C} 13-24, \mathrm{C} 25-30$ & 4.7uF SMD 1206 25VDC 10\% X7R & 26 & Murata & GRM31CR71E475KA88 \\
\hline $\mathrm{L}$ & 10uH 8.9A 12.4Asat 8mOhm $20 \%$ & 1 & Wuerth & 744750530100 \\
\hline L1-2 & 4.7uH 6.5A 9.6Asat $4.1 \mathrm{mOhm} 20 \%$ & 2 & Wuerth & 744750230047 \\
\hline Q1-2 & NMOS TO220 60V 60A 7.3mOhm & 2 & Infineon & IRF60B217 \\
\hline D1-2 & Schottky TO220-2 10A 100V & 2 & ON Semi & MBR10100G \\
\hline $\mathrm{U} 1-2$ & Low Side N-Channel Controller & 2 & TI & LM3478MM/NOPB \\
\hline TP1-2, TP10-11 & Red Test Point & 4 & Keystone & 5000 \\
\hline ТP1-2, TP8, ТP10-11, ТP19-22 & Black Test Point & 9 & Keystone & 5001 \\
\hline TP3-7, TP14-18 & White Test Point & 10 & Keystone & 5002 \\
\hline
\end{tabular}

